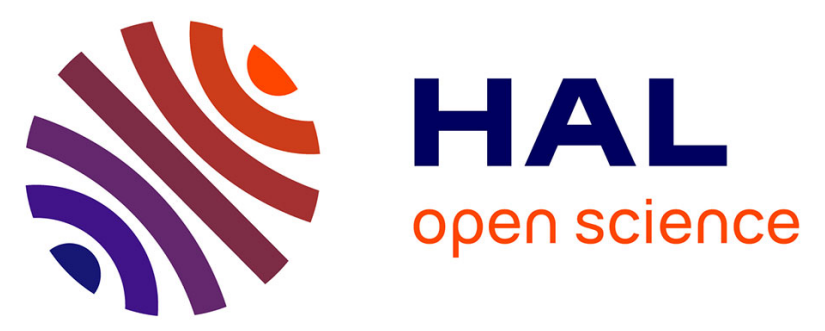

\title{
Review and Thermodynamic Modeling with NRTL Model of Vapor-Liquid Equilibria (VLE) of Aroma Compounds Highly Diluted in Ethanol-Water Mixtures at $101.3 \mathrm{kPa}$
}

Cristian Puentes, Xavier Joulia, Violaine Athès, Martine Esteban-Decloux

\section{To cite this version:}

Cristian Puentes, Xavier Joulia, Violaine Athès, Martine Esteban-Decloux. Review and Thermodynamic Modeling with NRTL Model of Vapor-Liquid Equilibria (VLE) of Aroma Compounds Highly Diluted in Ethanol-Water Mixtures at $101.3 \mathrm{kPa}$. Industrial and engineering chemistry research, 2018, 57 (10), pp.3443-3470. 10.1021/acs.iecr.7b03857 . hal-02063567

\section{HAL Id: hal-02063567 https://hal.science/hal-02063567}

Submitted on 11 Mar 2019

HAL is a multi-disciplinary open access archive for the deposit and dissemination of scientific research documents, whether they are published or not. The documents may come from teaching and research institutions in France or abroad, or from public or private research centers.
L'archive ouverte pluridisciplinaire HAL, est destinée au dépôt et à la diffusion de documents scientifiques de niveau recherche, publiés ou non, émanant des établissements d'enseignement et de recherche français ou étrangers, des laboratoires publics ou privés. 


\section{OATAO}

Open Archive Toulouse Archive Ouverte

\section{Open Archive Toulouse Archive Ouverte}

OATAO is an open access repository that collects the work of Toulouse researchers and makes it freely available over the web where possible

This is an author's version published in: http://oatao.univ-toulouse.fr/23314

Official URL : https://doi.org/10.1021/acs.iecr.7b03857

\section{To cite this version:}

Puentes, Cristian and Joulia, Xavier" and Athès, Violaine and Esteban-Decloux, Martine Review and Thermodynamic Modeling with NRTL Model of Vapor-Liquid Equilibria (VLE) of Aroma Compounds Highly Diluted in Ethanol-Water Mixtures at 101.3 kPa. (2018) Industrial \& Engineering Chemistry Research, 57 (10). 3443-3470. ISSN 0888-5885

Any correspondence concerning this service should be sent to the repository administrator: tech-oatao@listes-diff.inp-toulouse.fr 


\title{
Review and Thermodynamic Modeling with NRTL Model of Vapor- Liquid Equilibria (VLE) of Aroma Compounds Highly Diluted in Ethanol-Water Mixtures at $101.3 \mathrm{kPa}$
}

\author{
Cristian Puentes, $^{\dagger \odot}$ Xavier Joulia, ${ }^{\ddagger}$ Violaine Athès, ${ }^{\S}$ and Martine Esteban-Decloux ${ }^{*}, \dagger \odot$ \\ †Unité Mixte de Recherche Ingénierie Procédés Aliments, AgroParisTech, INRA, Université Paris Saclay, F 91300 Massy, France \\ ${ }^{\ddagger}$ Laboratoire de Génie Chimique, Université de Toulouse INPT ENSIACET, CNRS, F 31030 Toulouse, France \\ ${ }^{\S}$ Unité Mixte de Recherche Génie et Microbiologie des Procédés Alimentaires, AgroParisTech, INRA, Université Paris Saclay, \\ F 78850 Thiverval Grignon, France
}

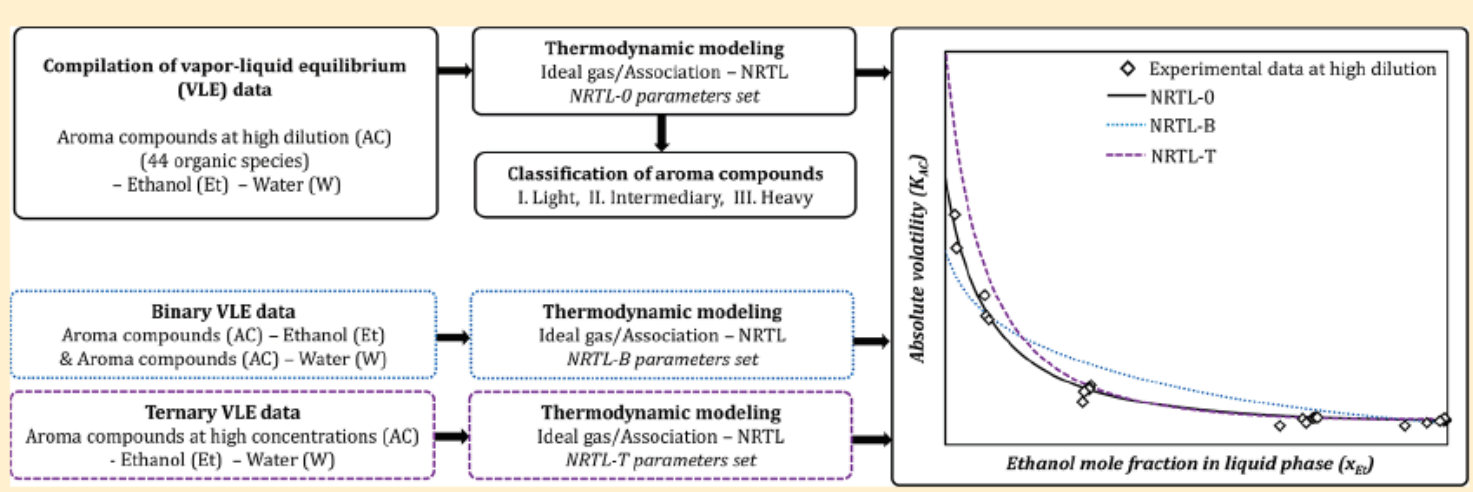

ABSTRACT: A review of the vapor-liquid equilibrium data of aroma compounds highly diluted in hydroalcoholic mixtures at $101.3 \mathrm{kPa}$ is presented. The study includes 44 aroma compounds present in distilled beverages from seven chemical families: acetals, alcohols, carbonyl compounds, carboxylic acids, esters, furans, and terpenes. The equilibrium data are modeled using the ideal gas hypothesis (with a correction term for dimerization in the case of carboxylic acids) and the NRTL model. A set of binary interaction parameters is generated, and the quality of the representation is evaluated. A classification of the aroma compounds in terms of their relative volatility with respect to ethanol and water is proposed over the whole ethanol composition range in the liquid phase. Finally, a comparison with the representation obtained when using interaction parameters calculated from binary and ternary mixture data at high concentrations is performed in order to evaluate the extrapolation capability of the NRTL model.

\section{INTRODUCTION}

The knowledge of vapor-liquid equilibria is the starting point for the simulation and optimization of distillation processes, including the production of alcoholic beverages. ${ }^{1-3}$ In this last field, an accurate description of the compounds is relatively complex because the wine and the final products are highly nonideal mixtures containing many chemical species. These solutions can be considered as a mixed solvent system, composed of ethanol and water (main components, represent ing over $96 \%$ of the total mass), with hundreds of volatile organic compounds, also called congeners. They belong to a wide variety of chemical families (acetals, alcohols, carbonyl compounds, carboxylic acids, esters, furans, and terpenes) and come either from the raw material or are produced during the fermentation and distillation steps. ${ }^{4-7}$

The congeners are present at low concentrations, ranging from a few $\mathrm{ng} \cdot \mathrm{L}^{-1}$ to several $\mathrm{mg} \cdot \mathrm{L}^{-1}$ (maximum mass fraction of the order of $10^{-3}$ ), and their influence on the thermal properties (such as enthalpy and specific heat) of the system is negligible. However, from a sensory point of view, these compounds determine the quality of wine and distillate, whence their designation as aroma compounds and the use of their concentration levels as enological parameters. ${ }^{8-13}$

The relationship between the concentration of the aroma compounds and the organoleptic quality of a distilled beverage is so intricate that trace compounds can have a greater impact than the compounds at higher concentrations. Furthermore, while some compounds have a positive effect at low levels, their behavior may become radically opposite when their concen trations exceed certain levels, adding unpleasant aromatic notes. ${ }^{14}$ These phenomena evince that vapor-liquid equilibria 

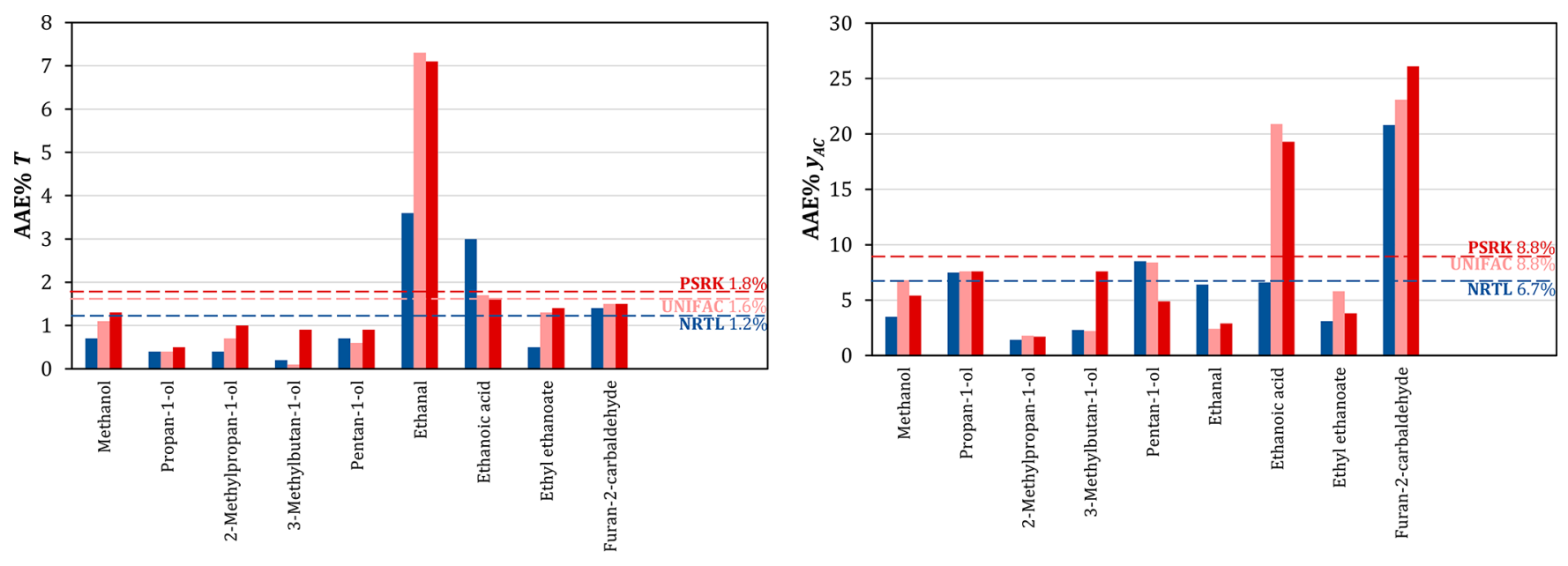

Aroma compound (AC)

Aroma compound (AC)

Figure 1. AAE\% values of two variables $\left(T\right.$ and $\left.y_{\mathrm{AC}}\right)$ obtained from the representation of the vapor-liquid equilibria of binary systems volatile aroma compound-ethanol at $101.3 \mathrm{kPa}$ with different thermodynamic models. (blue bars) NRTL, (pink bars) UNIFAC, and (red bars) PSRK. The horizontal dashed lines represent the average AAE\% value for each model. Comparison results from Faúndez and Valderrama. ${ }^{19}$

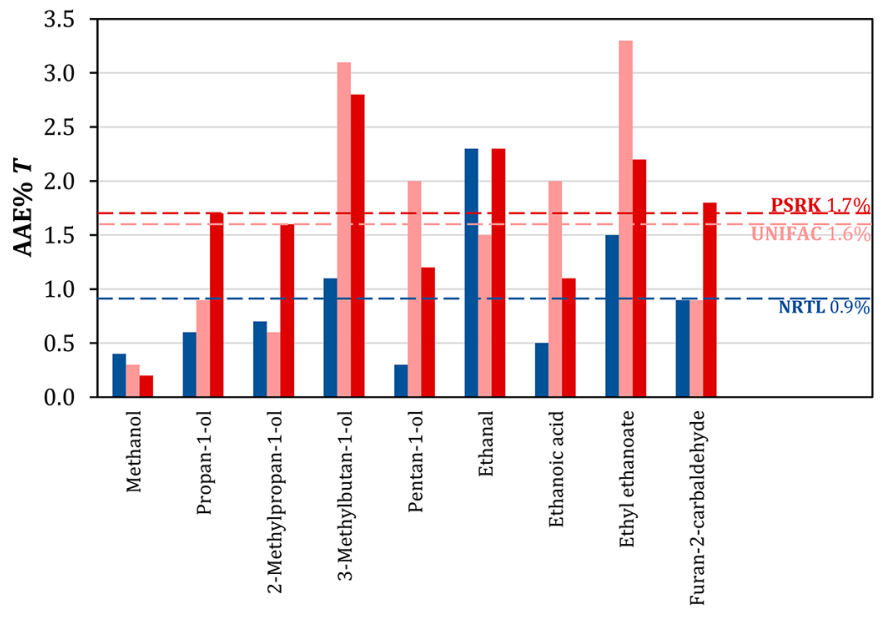

Aroma compound (AC)

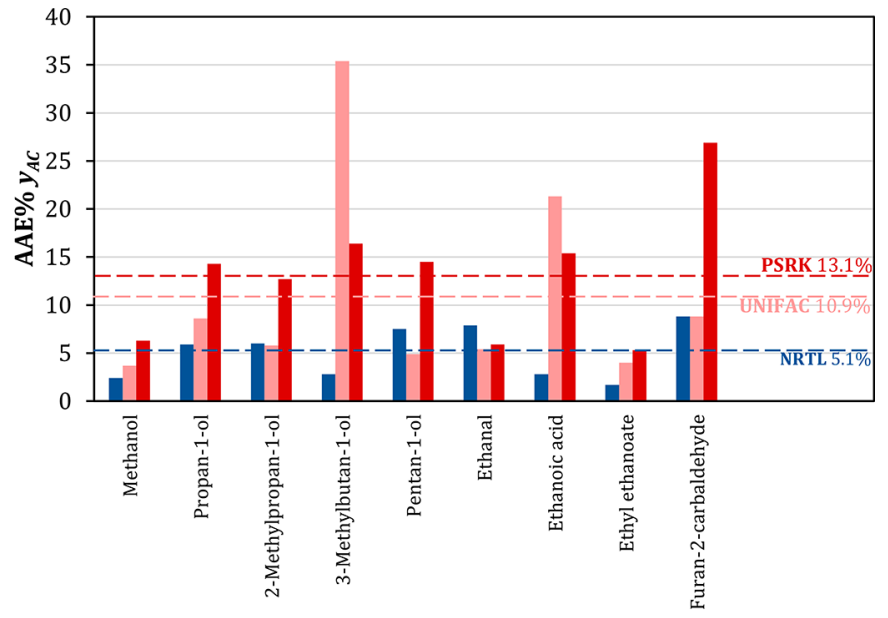

Aroma compound (AC)

Figure 2. AAE\% values of two variables ( $T$ and $y_{\mathrm{AC}}$ ) obtained from the representation of the vapor-liquid equilibria of binary systems volatile aroma compound-water at $101.3 \mathrm{kPa}$ with different thermodynamic models. (blue bars) NRTL, (pink bars) UNIFAC, and (red bars) PSRK. The horizontal dashed lines represent the average AAE\% value for each model. Comparison results from Faúndez and Valderrama. ${ }^{19}$

information is fundamental to understand the behavior of aroma compounds during distillation, and therefore to master their concentration to the desired levels, through thermody namic modeling and simulation.

The equilibrium behavior of an aroma compound (AC) in hydro alcoholic medium (solvent), which depends on the physical conditions $(T, P)$ and on the solvent composition, can be characterized by means of three parameters:

- The partition coefficient, equilibrium constant, or absolute volatility $\left(K_{\mathrm{AC}}\right)$, which quantifies the distribu tion between the vapor $\left(y_{\mathrm{AC}}\right)$ and liquid phases $\left(x_{\mathrm{AC}}\right)$.

- The relative volatilities with respect to ethanol (Et) $\left(\alpha_{\mathrm{AC} / \mathrm{Et}}\right)$ and water $(\mathrm{W})\left(\alpha_{\mathrm{AC} / \mathrm{W}}\right)$, indicator of the repartition of the aroma compounds between the top and bottoms product in distillation. ${ }^{15}$

- The activity coefficient at infinite dilution $\left(\gamma_{\mathrm{AC}}^{\infty}\right)$, a thermodynamic parameter that characterizes the aroma compound (solute)-mixed solvent interactions in the absence of solute-solute interactions, providing accurate information about the deviation from ideality. ${ }^{16,17}$

Regarding the thermodynamic modeling, a classical hetero geneous approach can be applied to the systems aroma compounds-ethanol-water because all the chemical species are polar and can develop complex intermolecular interactions (such as van der Waals interactions, hydrogen bonds, and chemical association), and second because the distillation units operate at atmospheric pressure. In this case, the vapor phase is often represented as an ideal gas, whereas the main deviations from ideal behavior are associated with the liquid phase and are described with an excess Gibbs free energy $\left(G^{\mathrm{E}}\right)$ model. $^{18}$

The choice of a suitable thermodynamic model is based on the research work published by Faúndez and Valderrama concerning the thermodynamic modeling of mixtures found in wine distillation. ${ }^{7,18-21}$ Their research was focused on three types of mixtures at atmospheric pressure: binary systems volatile aroma compound-ethanol and volatile aroma com pound-water, as well as ternary systems volatile aroma 

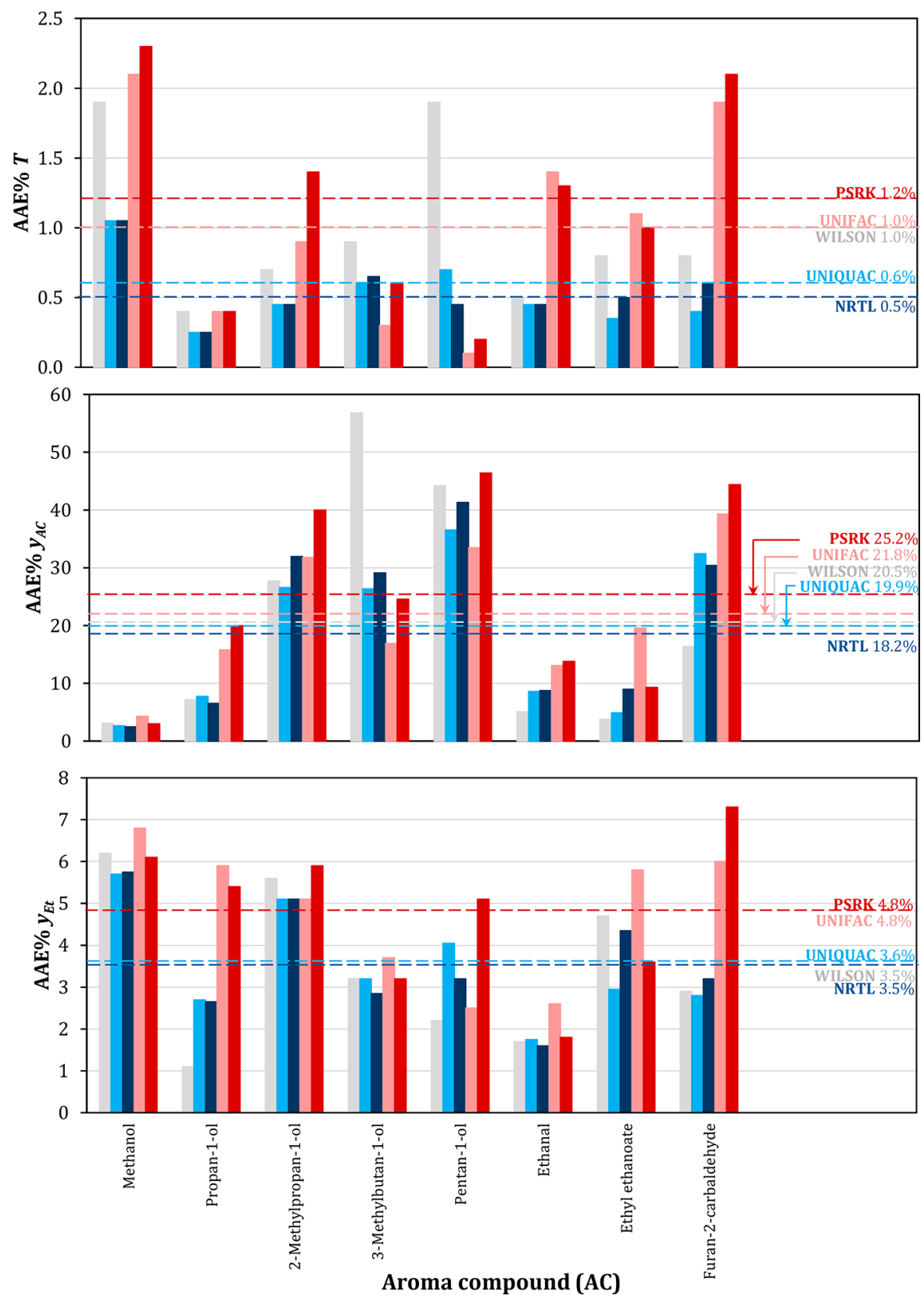

Figure 3. AAE\% values of three variables $\left(T, y_{\mathrm{AC}}\right.$, and $\left.y_{\mathrm{Et}}\right)$ obtained from the representation of the vapor-liquid equilibria of ternary systems volatile aroma compound-ethanol-water at $101.3 \mathrm{kPa}$ with different thermodynamic models. (gray bars) Wilson, (blue bars) NRTL, (cyan bars) UNIQUAC, (pink bars) UNIFAC, and (red bars) PSRK. The horizontal dashed lines represented the average AAE\% value for each model. Comparison results from Faúndez et al. ${ }^{18}$ and Faúndez and Valderrama. ${ }^{20}$

compound-ethanol-water. Equilibrium data for these systems are relatively scarce in the literature. The authors used data from specialized monographs and databases, including nine aroma compounds from five chemical families: alcohols (methanol, propan 1 ol, 2 methylpropan $1 \mathrm{ol}, 3$ methylbutan $1 \mathrm{ol}$, and pentan $1 \mathrm{ol}$ ), carbonyl compounds (ethanal), carboxylic acids (ethanoic acid), esters (ethyl ethanoate), and furans (furan 2 carbaldhyde).

The vapor-liquid equilibrium data were represented with two types of models: (i) semiempirical models, in which the experimental data are correlated by adjusting binary interaction parameters, and (ii) predictive models, which include universal parameters (nonspecific to a particular mixture) to represent phase equilibria. The semiempirical models compared in their work belong to the so called local composition approach for the calculation of activity coefficients and include Wilson, ${ }^{22}$ NRTL, ${ }^{23}$ and UNIQUAC. ${ }^{24}$ Regarding the predictive approach, two models were compared: UNIFAC ${ }^{25}$ and PSRK. ${ }^{26}$ UNIFAC is a local composition model based on the group contribution concept, while PSRK is an adaptation of the Soave-RedlichKwong equation of state ${ }^{27}$ that introduces a mixing rule based on an activity coefficient model (UNIFAC in this case) to compute the attractive parameter.

The results of their comparison are depicted in Figures 1 and 2 for binary systems and in Figure 3 for ternary systems. In these figures, the average absolute deviation (AAE\%) of the calculated values with respect to the experimental data are presented for two equilibrium variables: temperature $(T)$ and 
mole fraction in the vapor phase (only for aroma compound $\left(y_{\mathrm{AC}}\right)$ in the case of binary systems, and for both aroma compound $\left(y_{\mathrm{AC}}\right)$ and ethanol $\left(y_{\mathrm{Et}}\right)$ in the case of ternary systems). According to this criteria, the NRTL model provides the best representation of the experimental data, as the overall $\mathrm{AAE} \%$ values for $T, y_{\mathrm{AC}}$, and $y_{\mathrm{Et}}$ are the lowest among the compared models. In the case of the binary systems aroma compound-ethanol (Figure 1), the overall AAE\% for $T$ is $1.2 \%$ (in comparison to $1.6 \%$ with UNIFAC and $1.8 \%$ with PSRK) and for $y_{\mathrm{AC}}$ is $6.7 \%$ (in comparison to $8.8 \%$ with UNIFAC and PSRK). Concerning the binary systems aroma compoundwater (Figure 2), the overall AAE\% values are slightly lower, $0.9 \%$ for $T$ (in comparison to $1.6 \%$ with UNIFAC and $1.7 \%$ with PSRK), and $5.1 \%$ for $y_{\mathrm{AC}}$ (in comparison to $10.9 \%$ with UNIFAC and $13.1 \%$ with PSRK).

Finally, in the case of ternary systems, the global balance for the 8 mixtures is also more favorable with the NRTL model (Figure 3). The overall AAE\% value obtained with this model is $0.5 \%$ for $T$ (in comparison to $1.0 \%$ with Wilson, $0.6 \%$ with UNIQUAC, $1.0 \%$ with UNIFAC, and $1.2 \%$ with PSRK), $18.2 \%$ for $y_{\mathrm{AC}}$ (in comparison to $20.5 \%$ with Wilson, $19.9 \%$ with UNIQUAC, $21.8 \%$ with UNIFAC, and $25.2 \%$ with PSRK), and $3.5 \%$ for $y_{\mathrm{Et}}$, equivalent to the value obtained with the Wilson model and lower in comparison to the other models (3.6\% with UNIQUAC, $4.8 \%$ with UNIFAC, and $4.8 \%$ with PSRK).

In the light of these results, the NRTL model is used in this work for modeling purposes. From a theoretical point of view, this choice is consistent regarding two aspects: (i) the nature of the investigated systems and (ii) the operating conditions in alcoholic beverages distillation. In the first case, because this model was developed to represent the phase behavior of moderately and strongly nonideal liquid mixtures by taking into account the effects of both differing molecular size and intermolecular forces. ${ }^{23}$ Regarding the second aspect, NRTL is well adapted to systems at pressures lower than $1000 \mathrm{kPa}$ and temperatures below $150{ }^{\circ} \mathrm{C}$, conditions in which the non ideality can be supposed to be located in the liquid phase. Furthermore, NRTL is appreciated as a performing model in process simulation, not only for its coherence with respect to the Gibbs-Duhem equation but also for a good computing efficiency due to a relatively small set of adjustable parameters. This model has been used to correlate both vapor-liquid and liquid-liquid equilibria with satisfactory results (including ethanol-water ${ }^{28,29}$ as well as some binary ${ }^{30,31}$ and multi component aroma systems at high dilution ${ }^{13-32}$ ), as well as mixing heat data and infinite dilution activity coefficients for a great number of polar and nonpolar binary and multicompound systems.

Although the results of research from Faúndez and Valderrama's research group are useful for general under standing and thermodynamic modeling, they suffer from some drawbacks for simulation purposes: (i) they deal with a limited number of aroma compounds (between 8 and 12) and (ii) the experimental data used for modeling correspond to binary or ternary mixtures in which the ranges of concentration of the aroma compounds are generally much higher than those actually found in alcoholic beverages distillation. For ternary mixtures aroma compound-ethanol-water, the molar fractions in the liquid phase vary between $8 \times 10^{-4}$ and $8 \times 10^{-1}$, while for binary mixtures aroma compound-ethanol and aroma compound-water the whole concentration interval in the liquid phase is included $\left(0<x_{\mathrm{AC}}<1\right)$. In both cases, the concentration interval is very different from the case of alcoholic beverages in which the aroma compounds are present at high or infinite dilution.

In this context, the objectives of the current study are to generate a database containing all the information available in the open literature on the vapor-liquid equilibria of aroma compounds highly diluted in ethanol-water mixtures at atmospheric pressure and to generate new binary interaction parameters of the NRTL model for simulation purposes. 44 representative aroma compounds present in distilled beverages such as Armagnac, Calvados, and Cognac are considered. With the purpose of evaluating the extrapolation capability of NRTL model, the study is concluded by a comparison of the equilibrium representation obtained when using the new set of parameters and the one derived from parameters estimated from binary or ternary mixture data at high concentrations.

The paper is organized as follows: a general description of the equilibrium information available in the literature is presented, followed by some elements on the thermodynamic modeling approach. Using the literature data, a set of binary interaction parameters is estimated, followed by a classification of the aroma compounds, and finally by a comparison of the representation obtained with different sets of interaction parameters.

\section{COMPILATION AND THERMODYNAMIC MODELING OF VAPOR-LIQUID EQUILIBRIUM DATA}

2.1. Compilation of Vapor-Liquid Equilibrium Data of Aroma Compounds. The experimental research work on vapor-liquid equilibria of aroma compounds highly diluted in hydro alcoholic mixtures is a relatively unexplored field. This is probably due to the high variety of chemical species and their presence at low concentrations, which implies a high complexity in the chemical analysis of the vapor and liquid phases, sometimes disturbed by the presence of variable amounts of ethanol. ${ }^{33}$

Despite this limitation, some relevant studies have been reported in the literature. The earliest one dates back to the 1960s, with the compilation made by Williams, ${ }^{9}$ including 29 compounds from six chemical families, followed by a series of publications by Ikari et al., ${ }^{34-38}$ which concern 11 aroma compounds from four families. Other studies that consider several aroma compounds have been published by Athès et al. ${ }^{13}$ (13 brandy aroma compounds, including five alcohols, two carbonyl compounds, and six esters), Martin et al. ${ }^{39}$ (10 compounds, including one acetal, five alcohols, and sour esters), and Deterre et al., ${ }^{32}$ who studied five bitter orange aroma compounds, including two monoterpene hydrocarbons and three oxygenated terpenes.

Specific measurements for ternary systems have also been reported. The aroma compounds considered are ethanal ${ }^{8}$ and ethyl lactate. ${ }^{40}$ This latter study was carried out by the same authors of this paper.

In general, the data are of very variable nature, but in all cases (ternary and multicomponent systems), they are related, directly or indirectly, to the absolute and relative volatilities at $101.3 \mathrm{kPa}$. No studies presenting experimental data of activity coefficients at infinite dilution and equilibrium conditions were found in the open literature.

One important point in common between the different studies is that the measurements were performed via a dynamic method with recirculating stills. In this method, known for providing rapid and accurate vapor-liquid equilibria data, the 
Table 1. Research Works Published in the Open Literature on Vapor-Liquid Equilibrium Data of Aroma Compounds Highly Diluted in Ethanol Mixtures at $101.3 \mathrm{kPa}$

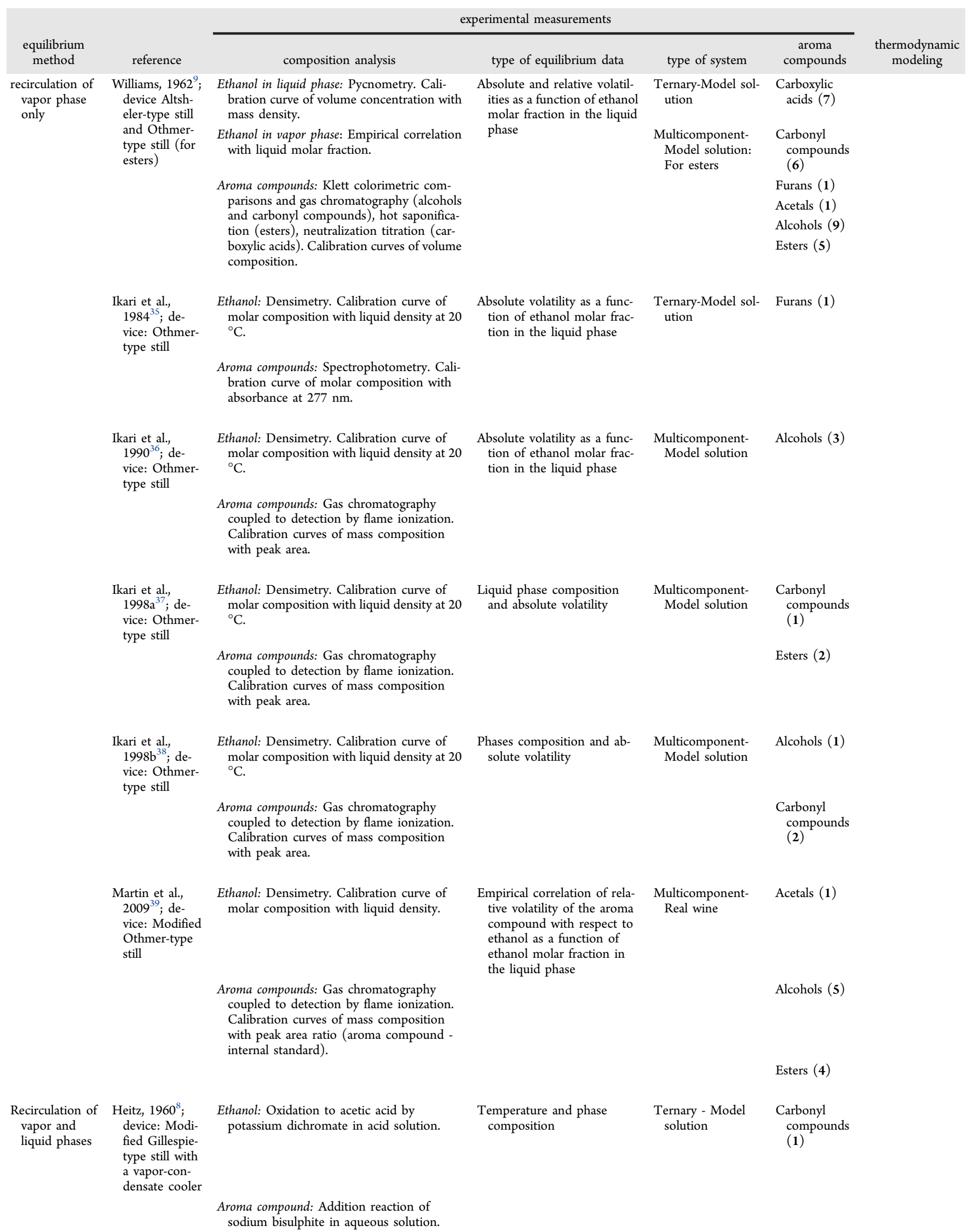


Table 1. continued

\begin{tabular}{|c|c|c|c|c|c|c|}
\hline \multirow[b]{2}{*}{$\begin{array}{l}\text { equilibrium } \\
\text { method }\end{array}$} & \multirow[b]{2}{*}{ reference } & \multicolumn{4}{|c|}{ experimental measurements } & \multirow[b]{2}{*}{$\begin{array}{l}\text { thermodynamic } \\
\text { modeling }\end{array}$} \\
\hline & & composition analysis & type of equilibrium data & type of system & $\begin{array}{l}\text { aroma } \\
\text { compounds }\end{array}$ & \\
\hline & \multirow[t]{5}{*}{$\begin{array}{l}\text { Athès et al., } \\
2008^{13} \text {; de- } \\
\text { vice: Gillespie- } \\
\text { type still } \\
\text { (Labodest } \\
\text { VLE 602) }\end{array}$} & $\begin{array}{l}\text { Ethanol: High-performance liquid chroma- } \\
\text { tography coupled to detection by refrac- } \\
\text { tometry. Calibration curve of volume } \\
\text { concentration with change in refractive } \\
\text { index of the chromatographic effluent. }\end{array}$ & \multirow[t]{5}{*}{$\begin{array}{l}\text { Temperature and phase } \\
\text { composition }\end{array}$} & \multirow[t]{5}{*}{$\begin{array}{l}\text { Multicomponent- } \\
\text { Model solution }\end{array}$} & Alcohols (4) & \multirow[t]{2}{*}{$\begin{array}{l}\text { Semiempirical: } \\
\text { NRTL }\end{array}$} \\
\hline & & & & & $\begin{array}{l}\text { Carbonyl } \\
\text { compounds } \\
\text { (1) }\end{array}$ & \\
\hline & & \multirow[t]{3}{*}{$\begin{array}{l}\text { Aroma compounds: Gas chromatography } \\
\text { coupled to detection by flame ionization. } \\
\text { Calibration curves of mass composition } \\
\text { with peak area ratio (aroma compound- } \\
\text { internal standard). }\end{array}$} & & & Esters (6) & \multirow[t]{3}{*}{$\begin{array}{l}\text { Predictive: } \\
\text { COSMO-SAC }\end{array}$} \\
\hline & & & & & Furans (1) & \\
\hline & & & & & Terpenes (1) & \\
\hline & $\begin{array}{l}\text { Deterre et al., } \\
2012^{32} \text {; de- } \\
\text { vice: Gillespie- } \\
\text { type still } \\
\text { (Labodest } \\
\text { VLE 602) }\end{array}$ & $\begin{array}{l}\text { Ethanol and Aroma compounds: Gas chroma- } \\
\text { tography coupled to detection by flame } \\
\text { ionization. Calibration curves of mass } \\
\text { composition with peak area ratio (aroma } \\
\text { compound-internal standard). }\end{array}$ & $\begin{array}{l}\text { Temperature and phase } \\
\text { composition }\end{array}$ & $\begin{array}{l}\text { Multicomponent - } \\
\text { Model solution }\end{array}$ & Terpenes (2) & $\begin{array}{l}\text { Semiempirical: } \\
\text { NRTL, Henry's } \\
\text { Law }\end{array}$ \\
\hline & \multirow[t]{2}{*}{$\begin{array}{l}\text { Puentes et al., } \\
2018^{40} \text {; de- } \\
\text { vice: Gillespie- } \\
\text { type still } \\
\text { (Labodest } \\
\text { VLE 602) }\end{array}$} & $\begin{array}{l}\text { Ethanol: From temperature measurements. } \\
\text { Correlation with molar composition } \\
\text { through thermodynamic modeling of } \\
\text { vapor liquid equilibrium for Ethanol } \\
\text { Water system }\end{array}$ & \multirow[t]{2}{*}{$\begin{array}{l}\text { Temperature and phase } \\
\text { composition }\end{array}$} & \multirow[t]{2}{*}{$\begin{array}{l}\text { Ternary-Model sol- } \\
\text { ution }\end{array}$} & \multirow[t]{2}{*}{ Esters (1) } & \multirow[t]{2}{*}{$\begin{array}{l}\text { Semiempirical: } \\
\text { NRTL, UNI- } \\
\text { QUAC }\end{array}$} \\
\hline & & $\begin{array}{l}\text { Aroma compounds: Gas chromatography } \\
\text { coupled to detection by flame ionization. } \\
\text { Calibration curves of mass composition } \\
\text { with peak area ratio (aroma compound- } \\
\text { internal standard). }\end{array}$ & & & & \\
\hline
\end{tabular}

vapor, evolved from a liquid phase, is continuously separated under steady state conditions and directed to the condenser, configured to prevent, or at least minimize, any risk of reflux. ${ }^{8,41}$ The recirculation is maintained until the composition variation of the vapor or liquid phases is no longer appreciable. ${ }^{42}$

The recirculating devices can be classified in two categories:

- In the first one, only the vapor phase circulates within the apparatus, while the liquid remains in the boiling chamber. For measurements involving aroma com pounds, all the devices are based on the design of Altsheler and Othmer stills. ${ }^{42,43}$

- In the second category, the vapor and liquid phased are recirculated and maintained in intimate contact before they are disengaged. This case covers the Gillespie type stills ${ }^{44}$ and more particularly the Labodest still, developed by i Fischer Engineering GmbH. A detailed description of this latter has been already presented in several experimental works. ${ }^{13,40,45,46}$

The second category of recirculating stills has been recommended for equilibrium measurements of diluted mixtures at temperatures higher than $298.15 \mathrm{~K}$ when coupled to an accurate analysis technique of the liquid and condensed vapor composition. ${ }^{47,48}$ However, given the highlighted scarcity of vapor-liquid data of aroma compounds-ethanol-water systems, all the information found in the open literature, concerning both the categories of recirculating devices, will be retained in the current work.

In Table 1, the different studies are summarized and classified according to the recirculating method. This synthesis includes information about the experimental measurements (composition analysis, type of equilibrium data, and aroma compounds studied) as well as main features of the thermodynamic modeling when performed.

As a result of this compilation, vapor-liquid equilibrium data at $101.3 \mathrm{kPa}$ for 44 aroma compounds were extracted. The references and some specifications for each chemical species are presented in Table 2, including the number of data points and, if available, the composition ranges of ethanol and of aroma compounds in the vapor and liquid phases.

For most of the chemical species studied in this work, including ethanol and water, the physical properties were available in the Simulis Thermodynamics database, software developed by ProSim and used for the equilibrium calculations presented in the current work. Regarding five missing species, the properties were extracted from literature and subsequently added to the database. These compounds are $(Z)$ hex 3 en 1 ol, ethyl hexanoate, 2 phenylethyl ethanoate, ethyl octanoate, and ethyl decanoate. For equilibrium calculations, the whole set of information provided to characterize each chemical species was: CAS no., molecular formula, molecular mass (MM), boiling temperature at $101.3 \mathrm{kPa}\left(T_{\mathrm{b}}\right)$, and vapor pressure $\left(P^{\mathrm{O}}\right)$. Most of these values were taken from NIST Chemistry Webbook. ${ }^{49}$ Further information about the calculation of vapor pressures for these compounds are presented in section 2.2.

2.2. Thermodynamic Modeling. The principle for vaporliquid equilibrium modeling is the equality of chemical potentials of every species in both phases in conditions of thermal and mechanical equilibrium. For engineering applica 


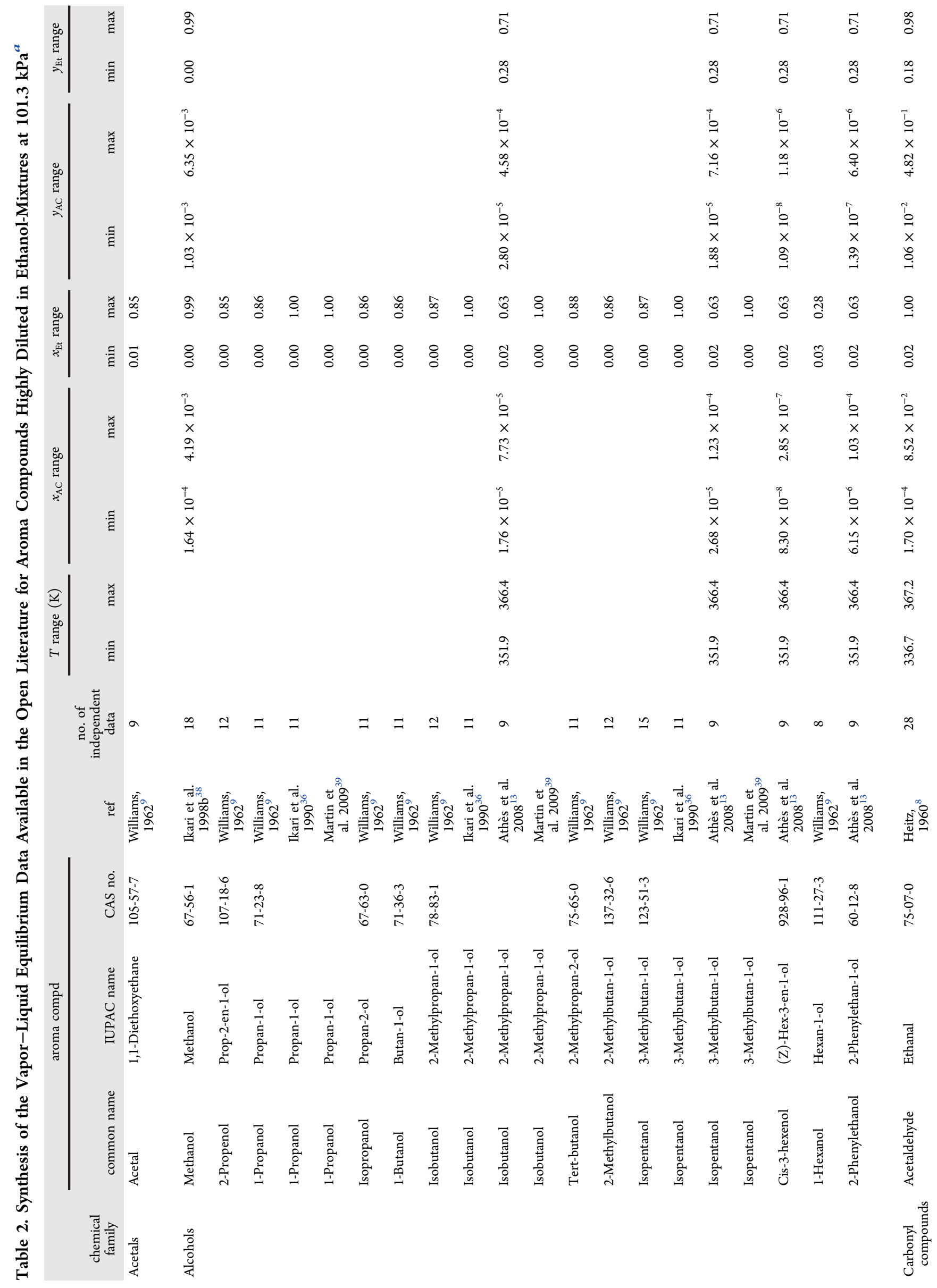




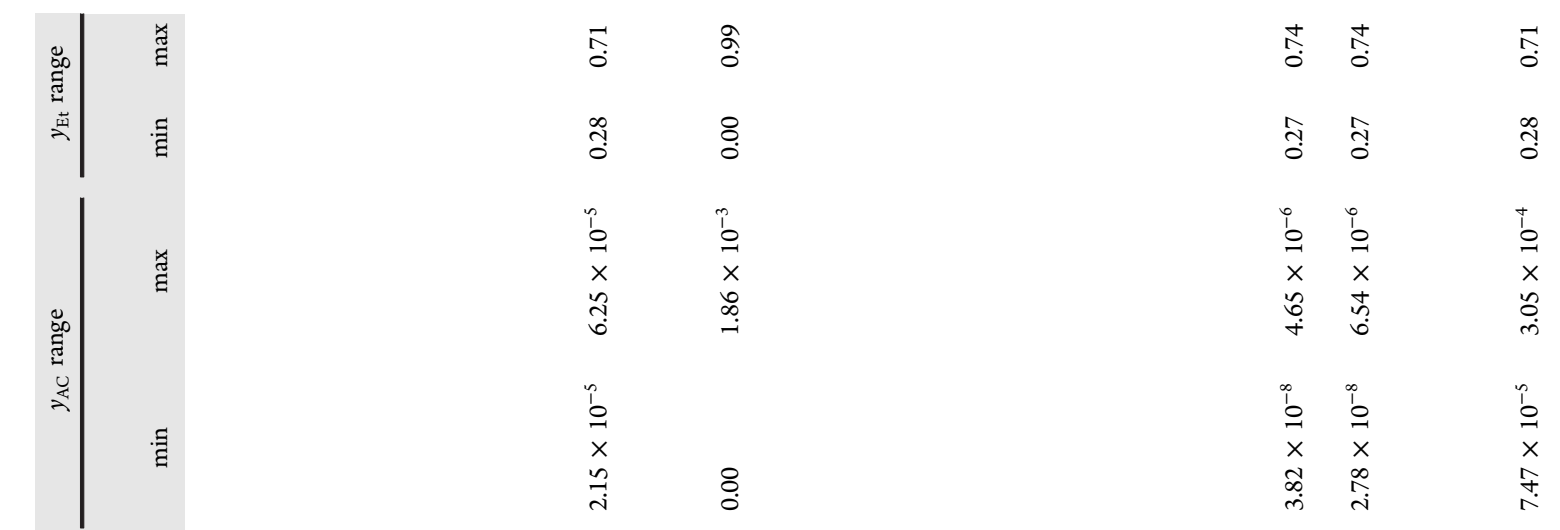

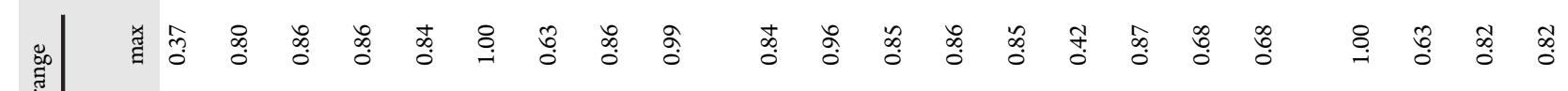

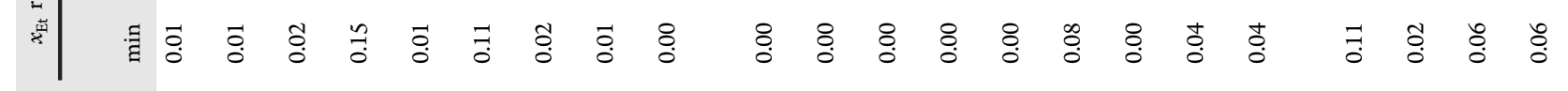

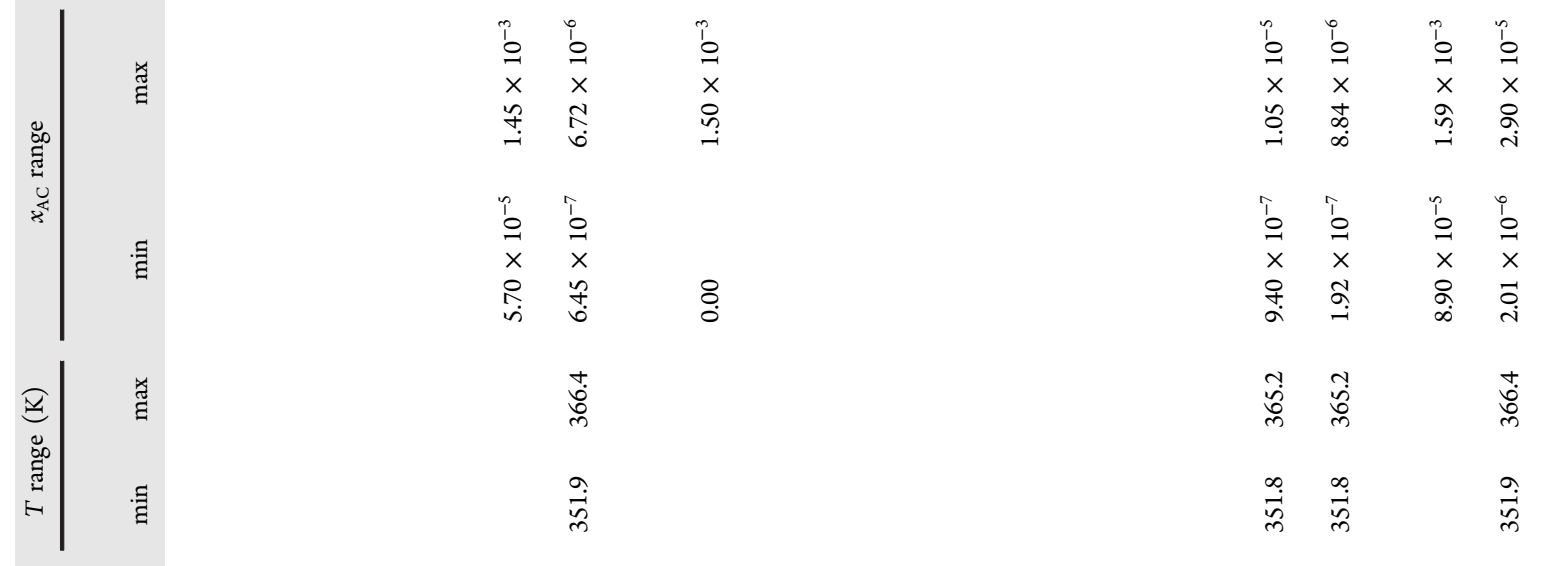

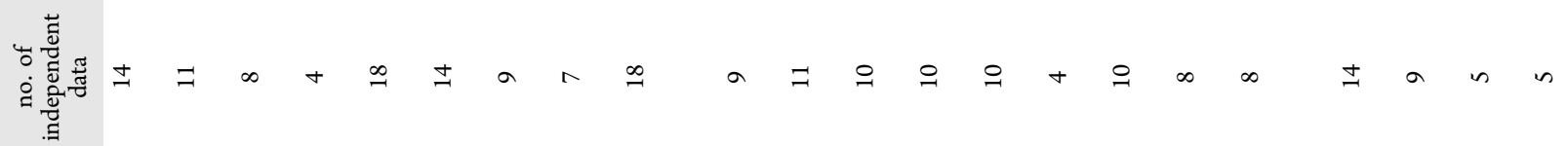

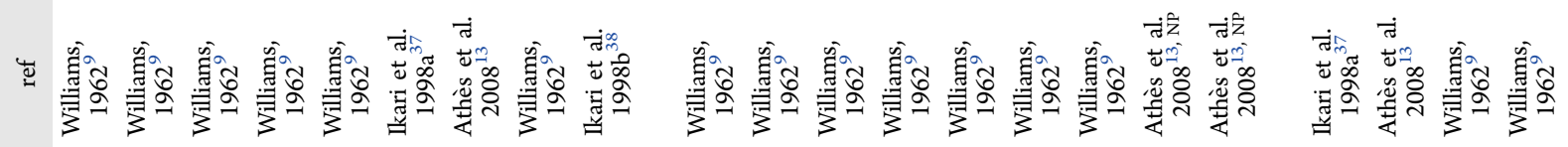

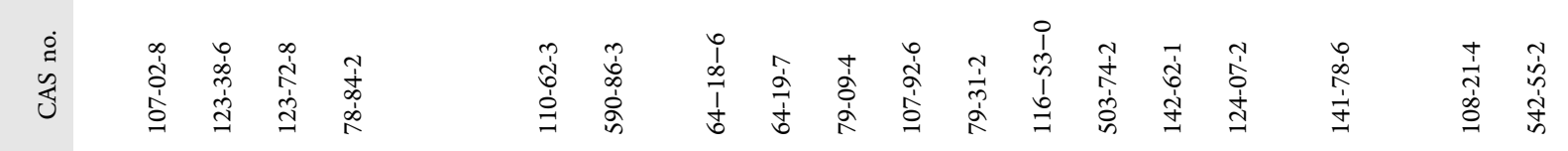

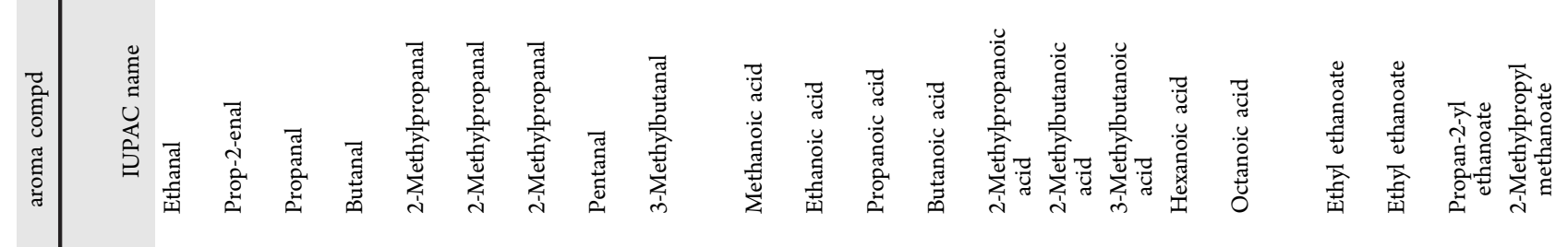

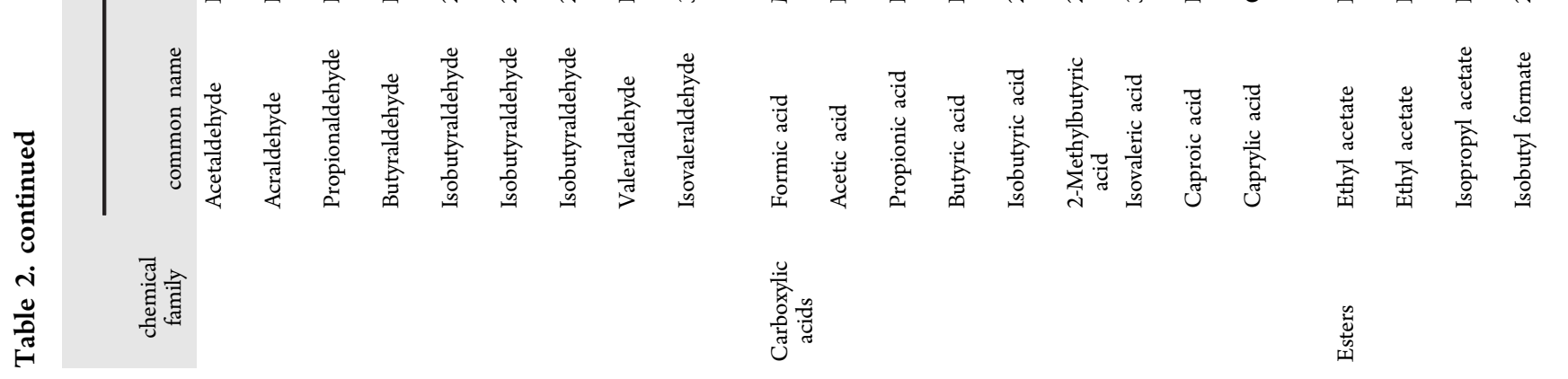




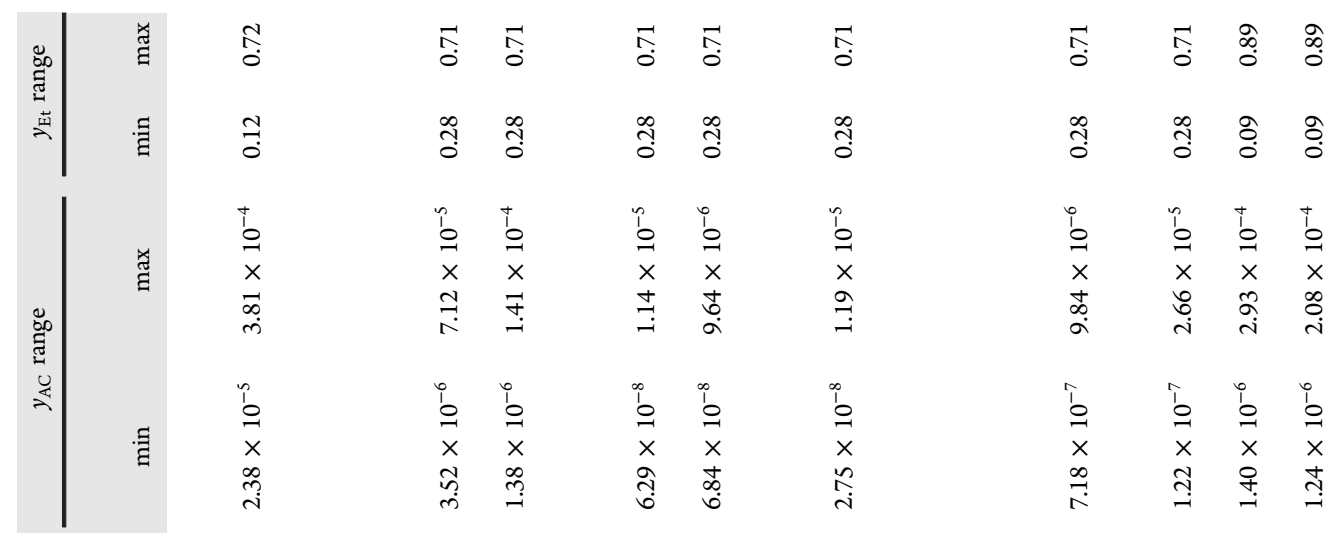

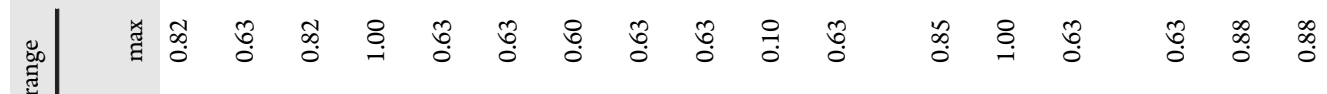

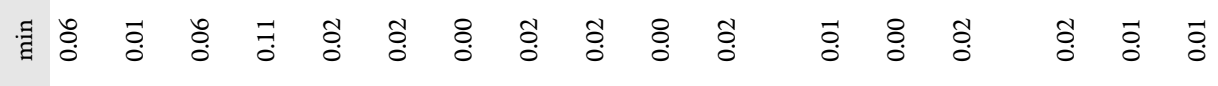

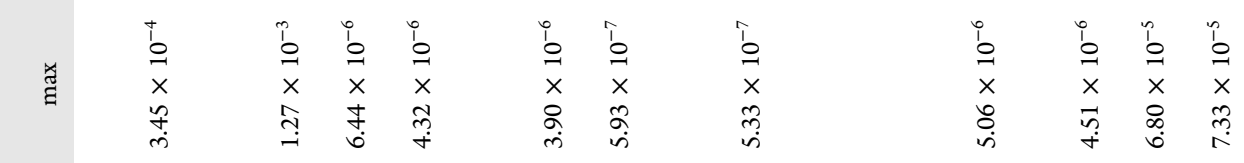

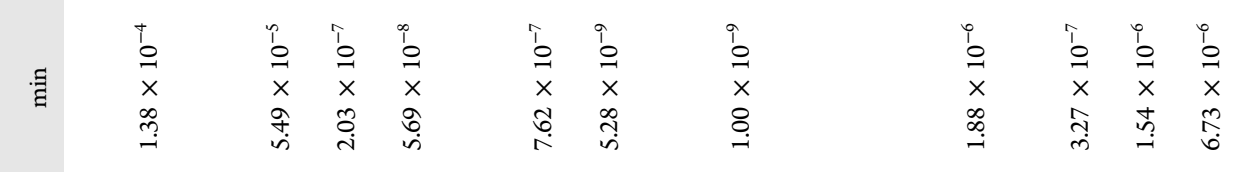

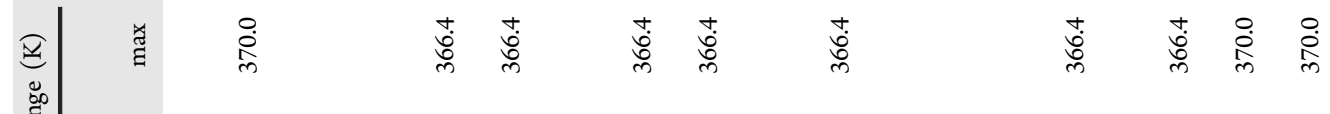

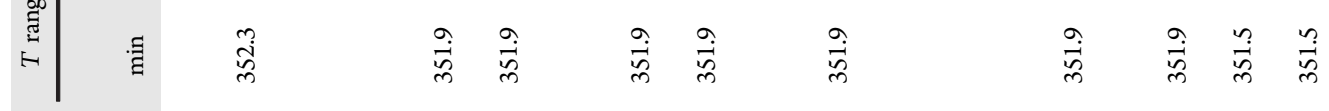

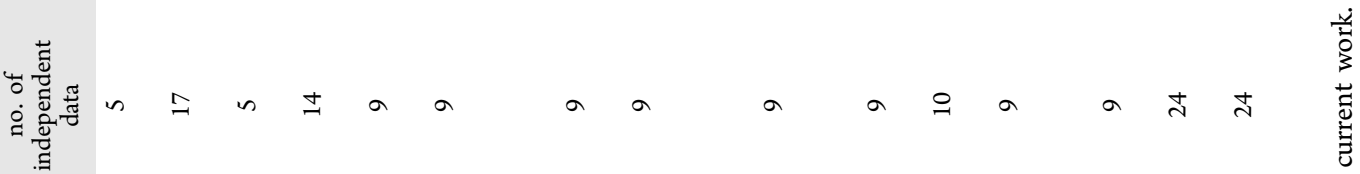

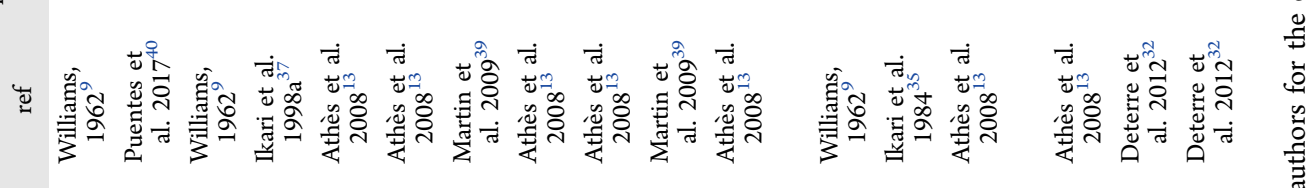

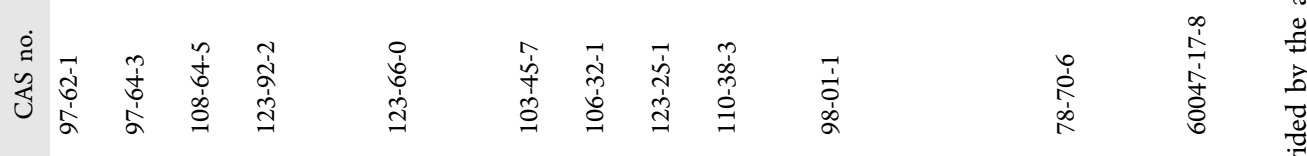

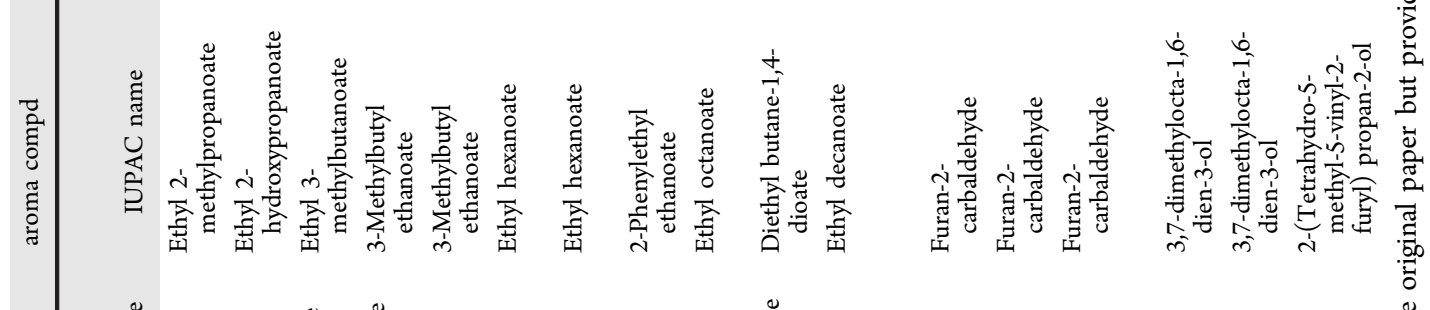

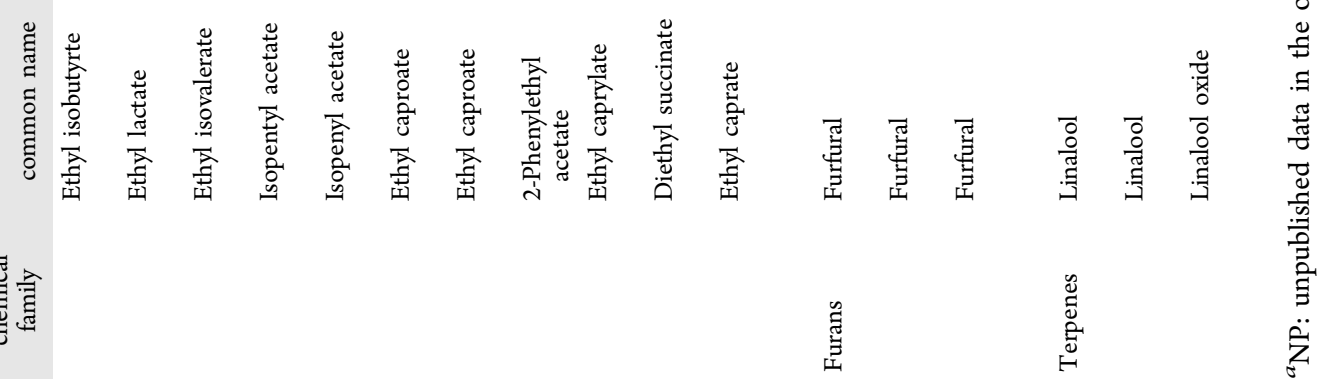


tions, the equilibrium condition is written in terms of fugacity, a variable that corresponds to a generalized partial pressure and that depends on the temperature $(T)$, pressure $(P)$, and composition. $^{50,51}$

By following a classical heterogeneous approach, also known as the gamma-phi $(\gamma-\phi)$ method, the vapor phase fugacity of the component $i, f_{i}^{V}(T, P, y)$, can be expressed as a function of the fugacity coefficient, $\phi_{i}^{V}(T, P, y)$, and the liquid phase fugacity, $f_{i}^{L}(T, P, \boldsymbol{x})$, as a function of the activity coefficient, $\gamma_{i}(T, \boldsymbol{x})$, and the standard state liquid fugacity, $f_{i}^{O L}(T, P)$. The resulting expressions are

$$
\begin{aligned}
& f_{i}^{V}(T, P, \boldsymbol{y})=f_{i}^{L}(T, P, \boldsymbol{x}) \\
& \phi_{i}^{V}(T, P, \boldsymbol{y}) y_{i} P=\gamma_{i}(T, \boldsymbol{x}) x_{i} f_{i}^{O L}(T, P)
\end{aligned}
$$

At atmospheric pressure, the standard state liquid fugacity can be approximated to the vapor pressure of the pure component at the temperature of the system, $P_{i}^{O}(T)$, and the vapor phase can be considered as an ideal gas mixture, which means that fugacity coefficient is equal to 1 . In this way, eq 2 becomes

$$
y_{i} P=\gamma_{i}(T, \boldsymbol{x}) x_{i} P_{i}^{O}(T)
$$

which can in turn be rewritten to obtain an expression for the absolute volatility, as follows:

$$
K_{i}(T, P, \boldsymbol{x})=\frac{y_{i}}{x_{i}}=\frac{\gamma_{i}(T, \boldsymbol{x}) P_{i}^{O}(T)}{P}
$$

The relative volatility with respect to ethanol and water are defined as the ratio of absolute volatilities, that is

$$
\begin{aligned}
& \alpha_{i / \mathrm{Et}}(T, \boldsymbol{x})=\frac{K_{i}}{K_{\mathrm{Et}}}=\frac{y_{i} / x_{i}}{y_{\mathrm{Et}} / x_{\mathrm{Et}}}=\frac{\gamma_{i}(T, \boldsymbol{x}) P_{i}^{O}(T)}{\gamma_{\mathrm{Et}}(T, \boldsymbol{x}) P_{\mathrm{Et}}^{O}(T)} \\
& \alpha_{i / \mathrm{W}}(T, \boldsymbol{x})=\frac{K_{i}}{K_{\mathrm{W}}}=\frac{y_{i} / x_{i}}{y_{\mathrm{W}} / x_{\mathrm{W}}}=\frac{\gamma_{i}(T, \boldsymbol{x}) P_{i}^{O}(T)}{\gamma_{\mathrm{W}}(T, \boldsymbol{x}) P_{\mathrm{W}}^{O}(T)}
\end{aligned}
$$

In the case of carboxylic acids, it is necessary to use a supplementary term that account for the chemical equili brium. ${ }^{52}$ Indeed, theoretical and experimental studies ${ }^{53,54}$ have demonstrated that this kind of compounds can exist either as monomer (single molecules) or dimers due to strong hydrogen bonds. This phenomenon is referred to as chemical association or dimerization and essentially takes place in the vapor phase. Higher polymerization and heterodimerization (formation of dimers from monomers of different chemical species) have also been discussed in the literature, ${ }^{55,56}$ but they will not be considered in this work for the sake of simplicity.

For a carboxylic acid $\left(\mathrm{CA}_{x}\right)$, the reaction and corresponding chemical equilibrium constant $\left(\mathrm{KD}_{\mathrm{CAx}}\right)$ can be expressed as follows:

$$
2 \mathrm{CA} x \rightleftharpoons \mathrm{CA} x_{2} \quad \mathrm{KD}_{\mathrm{CAx}}(T)=v\left(10^{L_{\mathrm{CAx}}+M_{\mathrm{CAx}} / T}\right)
$$

$T$ is given in $\mathrm{K}$ and the parameter $v$ is a correction factor to express $\mathrm{KD}_{\mathrm{CAx}}$ in $\mathrm{kPa}^{-1}$, equal to 7.5. $L_{\mathrm{CAx}}$ and $M_{\mathrm{CAx}}$ are empirical coefficients to quantify the dependency of the dimerization constant with temperature. On the basis of this representation, Detcheberry et al. $^{52}$ have proposed the following correction for eq 3 :

$$
\frac{y_{i} P}{\phi_{i}^{O V}\left(T, P_{i}^{O}(T)\right)}=\gamma_{i}(T, \boldsymbol{x}) x_{i} P_{i}^{O}(T) \quad \text { For } i=\mathrm{CA} x
$$

where the term $\phi_{i}^{O V}\left(T, P_{i}^{O}(T)\right)$ can be calculated with the following relation:

$$
\begin{aligned}
& \phi_{i}^{O V}\left(T, P_{i}^{O}(T)\right)=\frac{-1+\left[4 \mathrm{KD}_{i}(T) P_{i}^{O}(T)\right]^{1 / 2}}{2 \mathrm{KD}_{i}(T) P_{i}^{O}(T)} \\
& \text { For } i=\mathrm{CA} x
\end{aligned}
$$

Therefore, the alternative equations for calculating $K_{i}, \alpha_{i / \mathrm{E} t}$ and $\alpha_{i / \mathrm{w}}$ are

$$
\begin{aligned}
& K_{i}(T, P, \boldsymbol{x})=\frac{y_{i}}{x_{i}}=\frac{\gamma_{i}(T, \boldsymbol{x}) P_{i}^{O}(T) \phi_{i}^{O V}\left(T, P_{i}^{O}(T)\right)}{P} \\
& \text { For } i=\mathrm{CA} x \\
& \alpha_{i / \mathrm{Et}}(T, x)=\frac{K_{i}}{K_{\mathrm{Et}}}=\frac{y_{i} / x_{i}}{y_{\mathrm{Et}} / x_{\mathrm{Et}}} \\
& =\frac{\gamma_{i}(T, \boldsymbol{x}) P_{i}^{O}(T) \phi_{i}^{O V}\left(T, P_{i}^{O}(T)\right)}{\gamma_{\mathrm{Et}}(T, \boldsymbol{x}) P_{\mathrm{Et}}^{O}(T)} \quad \text { For } i=\mathrm{CA} x \\
& \alpha_{i / \mathrm{W}}(T, x)=\frac{K_{i}}{K_{\mathrm{W}}}=\frac{y_{i} / x_{i}}{y_{\mathrm{W}} / x_{\mathrm{W}}} \\
& =\frac{\gamma_{i}(T, \boldsymbol{x}) P_{i}^{O}(T) \phi_{i}^{O V}\left(T, P_{i}^{O}(T)\right)}{\gamma_{\mathrm{W}}(T, \boldsymbol{x}) P_{\mathrm{W}}^{O}(T)}
\end{aligned}
$$

For the first five carboxylic acids studied in this work (from methanoic to 2 methylpropanoic acid), the values of coefficients $L_{\mathrm{CAx}}$ and $M_{\mathrm{CAx}}$ were taken from the DECHEMA database, available through the Simulis Thermodynamics software. $^{57}$ The missing coefficients were estimated by linear interpolation or extrapolation, by using the values available for heptanoic acid (not studied in this work) as supplementary data. The approximation criterion chosen was the number of carbon atoms in the molecule $\left(n_{\mathrm{C}}\right)$, for two reasons: (i) the group of compounds corresponds to the homologous series of carboxylic acids from methanoic to octanoic acid, and (ii) the values of $L_{\mathrm{CAx}}$ and $M_{\mathrm{CAx}}$ for butanoic acid and 2 methylpropanoic acid, both with four carbon atoms, are the same. The estimation equations were established by taking as unique reference points the values of $L_{\mathrm{CAx}}$ and $M_{\mathrm{CAx}}$ for butanoic acid and heptanoic acid, obtaining:

$$
\begin{aligned}
& L_{\mathrm{CAx}}=0.100 n_{\mathrm{C}}-10.501 \quad n_{\mathrm{C}} \geq 4 \\
& M_{\mathrm{CAx}}=-47.341 n_{\mathrm{C}}+3229.2 \quad n_{\mathrm{C}} \geq 4
\end{aligned}
$$

The final set of parameters is summarized in Table 3. No bias of interpolation or extrapolation is associated with this calculation as only two reference points were considered. The values of $L_{\mathrm{CAx}}$ and $M_{\mathrm{CAx}}$ for the first three carboxylic acids (from methanoic to propanoic acid) were not included because they do not follow a linear trend. This can be explained by the fact that they are small molecules for which chemical association is stronger, hence the dimerized fraction in the vapor phase is more important than for acids with higher molar masses. As a result, one could expect that in such case there is no a simple, direct relation between the dimerization parameters and the number of carbon atoms. Nonetheless, a linear approximation in the interval $4 \leq n_{\mathrm{C}} \leq 8$ remains valid because the known values of $L_{\mathrm{CAx}}$ and $M_{\mathrm{CAx}}$ are relatively close to each other. Moreover, this estimation is actually not critical as the vaporliquid equilibrium data are represented with a semiempirical 
Table 3. Values of the Parameters $L_{\mathrm{CAx}}$ and $M_{\mathrm{CAx}}$ for the Group of Carboxylic Acids Studied in This Work

\begin{tabular}{|c|c|c|c|c|}
\hline source & aroma compound & $\begin{array}{c}\mathrm{C} \\
\text { atoms }\end{array}$ & $L_{\mathrm{CAx}}$ & $M_{\mathrm{CAx}}$ \\
\hline \multirow{5}{*}{$\begin{array}{c}\text { DECHEMA } \\
\text { database }^{57}\end{array}$} & Methanoic acid & 1 & 10.743 & 3083.0 \\
\hline & Ethanoic acid & 2 & 10.421 & 3166.0 \\
\hline & Propanoic acid & 3 & 10.843 & 3316.0 \\
\hline & Butanoic acid & 4 & 10.100 & 3040.0 \\
\hline & $\begin{array}{l}\text { 2-Methylpropanoic } \\
\text { acid }\end{array}$ & 4 & 10.100 & 3040.0 \\
\hline \multirow[t]{3}{*}{$\begin{array}{l}\text { Estimation by } \\
\text { interpolation }\end{array}$} & $\begin{array}{l}\text { 2-Methylbutanoic } \\
\text { acid }\end{array}$ & 5 & 10.005 & 2993.0 \\
\hline & $\begin{array}{l}\text { 3-Methylbutanoic } \\
\text { acid }\end{array}$ & 5 & 10.005 & 2993.0 \\
\hline & Hexanoic acid & 6 & 9.891 & 2943.0 \\
\hline $\begin{array}{l}\text { DECHEMA } \\
\text { database }^{57} \text { (included } \\
\text { for estimation } \\
\text { purposes) }\end{array}$ & Heptanoic acid & 7 & 9.807 & 2900.0 \\
\hline $\begin{array}{l}\text { Estimation by } \\
\text { extrapolation }\end{array}$ & Octanoic acid & 8 & 9.703 & 2851.3 \\
\hline
\end{tabular}

model, a case in which the interaction parameters associated with the liquid phase are adjusted by minimizing the deviation between the experimental and calculated values. In the case of carboxylic acids, this fitting procedure implies that the activity coefficients condenses information not only about the energetic interactions in the liquid phase, but also, indirectly, about the association phenomena in the vapor phase.

Returning to phase equilibria modeling, in the region of very low concentration, it is customary to define the activity of the component $i$ with respect to its fugacity at infinite dilution at the temperature and pressure of the mixture. The liquid fugacity is then expressed in an alternative way, the so called Henry law: ${ }^{58}$

$$
f_{i}^{L}(T, P, \boldsymbol{x})=x_{i} \mathcal{H}_{i}\left(T, P, x_{\mathrm{s}}\right)
$$

$\mathcal{H}_{i}$, or Henry constant, corresponds to the reference liquid fugacity and is defined by the following relation:

$$
\mathcal{H}_{i}\left(T, P, x_{\mathrm{s}}\right)=\lim _{x_{i} \rightarrow 0} \frac{f_{i}^{L}(T, P, \boldsymbol{x})}{x_{i}}
$$

$\mathcal{H}_{i}$ depends not only on temperature and pressure but also on the solvent nature (here ethanol-water) and its composition, $x_{s}$. By comparison with eq $3, \mathcal{H}_{i}$ can also be expressed as the product $P_{i}^{O}(T)$ and $\gamma_{i}(T, \boldsymbol{x})$ at infinite dilution or $\gamma_{i}^{\infty}\left(T, x_{\mathrm{s}}\right)$ :

$$
H_{i}\left(T, x_{\mathrm{s}}\right)=\gamma_{i}^{\infty}\left(T, x_{\mathrm{s}}\right) P_{i}^{O}(T)
$$

Or, by comparison with eq 4 , as a function of the absolute volatility and total pressure:

$$
H_{i}\left(T, x_{\mathrm{s}}\right)=K_{i} P
$$

In the current study, the vapor pressure of ethanol, water, and the aroma compounds have been calculated with the Riedel equation, $^{59}$ an extended version of the Antoine equation:

$$
P_{i}^{O}(T)=\frac{1}{1000} \exp \left(A_{i}+\frac{B}{T}+C_{i} \ln (T)+D_{i} T^{E_{i}}\right)
$$

With $P_{i}^{O}(T)$ given in $\mathrm{kPa}$ and $T$ in $\mathrm{K} . A_{i}, B_{i}, C_{i}, D_{i}$, and $E_{i}$ are coefficients specific for each chemical species. Two sources were used to obtain them:

- For the compounds already included in the Simulis Thermodynamics database, the coefficients were taken from the DIPPR database. ${ }^{60}$

- For the five compounds added to the Simulis Thermodynamics database, the coefficients were esti mated by regression of experimental data available in the literature. ${ }^{49,61-68}$ The minimized objective function (OF) is as follows:

$$
\mathrm{OF}\left(P^{O}\right)=\sum_{k=1}^{N}\left(\frac{P_{k-\exp }^{O}-P_{k-\text { calc }}^{O}}{P_{k-\exp }^{0}}\right)^{2}
$$

and the absolute average relative error (AAE\%) between experimental and calculated pressure was obtained with eq 21 :

$$
\operatorname{AAE} \%\left(P^{O}\right)=\sum_{k=1}^{N}\left|\frac{P_{k-\exp }^{O}-P_{k-\text { calc }}^{O}}{P_{k-\exp }^{O}}\right| 100 \%
$$

Because of the relatively limited number of experimental values, the coefficients $D_{i}$ and $E_{i}$ were fixed to 0 . The values of AAE\% vary between $1 \%$ for 2 phenylethyl ethanoate and $6 \%$ for ethyl decanoate.

For the set of 44 aroma compounds, the coefficients are valid in the temperature range of vapor-liquid equilibrium for hydro alcoholic mixtures at $101.3 \mathrm{kPa}$, from 351.4 to $373.15 \mathrm{~K}$.

With regard to the activity coefficient, the non random two liquid (NRTL) model was used in this work. ${ }^{22}$ It is a pressure independent model of liquid solution based on the concept of local composition introduced by Wilson, ${ }^{23}$ valid at low pressures (less than $1000 \mathrm{kPa}$ ) and widely recommended for the description of hydro alcoholic solutions. ${ }^{7}$ According to the hypothesis introduced by Wilson, the local concentration around a molecule can be different from the bulk concentration. This phenomenon is due to a difference between the interaction energy of the central molecule with molecules of its own nature and the interaction energy with molecules of other nature. The energy difference also introduces a nonrandomness effect at the local molecular level.

In the NRTL model, the activity coefficient of a component $i$ in a mixture of $n$ components as a function of composition and temperature is given by

$$
\begin{aligned}
\ln \gamma_{i}(T, \boldsymbol{x})= & \frac{\sum_{j=1}^{n} \tau_{j i} G_{j i} x_{j}}{\sum_{k=1}^{n} G_{k i} x_{k}}+\sum_{j=1}^{n} \frac{G_{i j} x_{j}}{\sum_{k=1}^{n} G_{k j} x_{k}} \\
& \left(\tau_{i j}-\frac{\sum_{k=1}^{n} \tau_{k j} G_{k j} x_{k}}{\sum_{k=1}^{n} G_{k j} x_{k}}\right)
\end{aligned}
$$

with

$$
G_{i j}=\exp \left(-c_{i j} \tau_{i j}\right)
$$

Here, $G_{i j}, c_{i j}$, and $\tau_{i j}$ are binary interaction parameters. Their temperature dependence is evaluated according to the following formalism, included in the Simulis Thermodynamics package:

$$
c_{i j}=c_{i j}^{0}+c_{i j}^{T}(T-273.15)
$$


Table 4. Interaction Parameters of the of the NRTL Model for the Binary Ethanol (2)-Water (3) and Fitting Quality Statistics with Respect to Four Experimental Data Sets Obtained from Literature

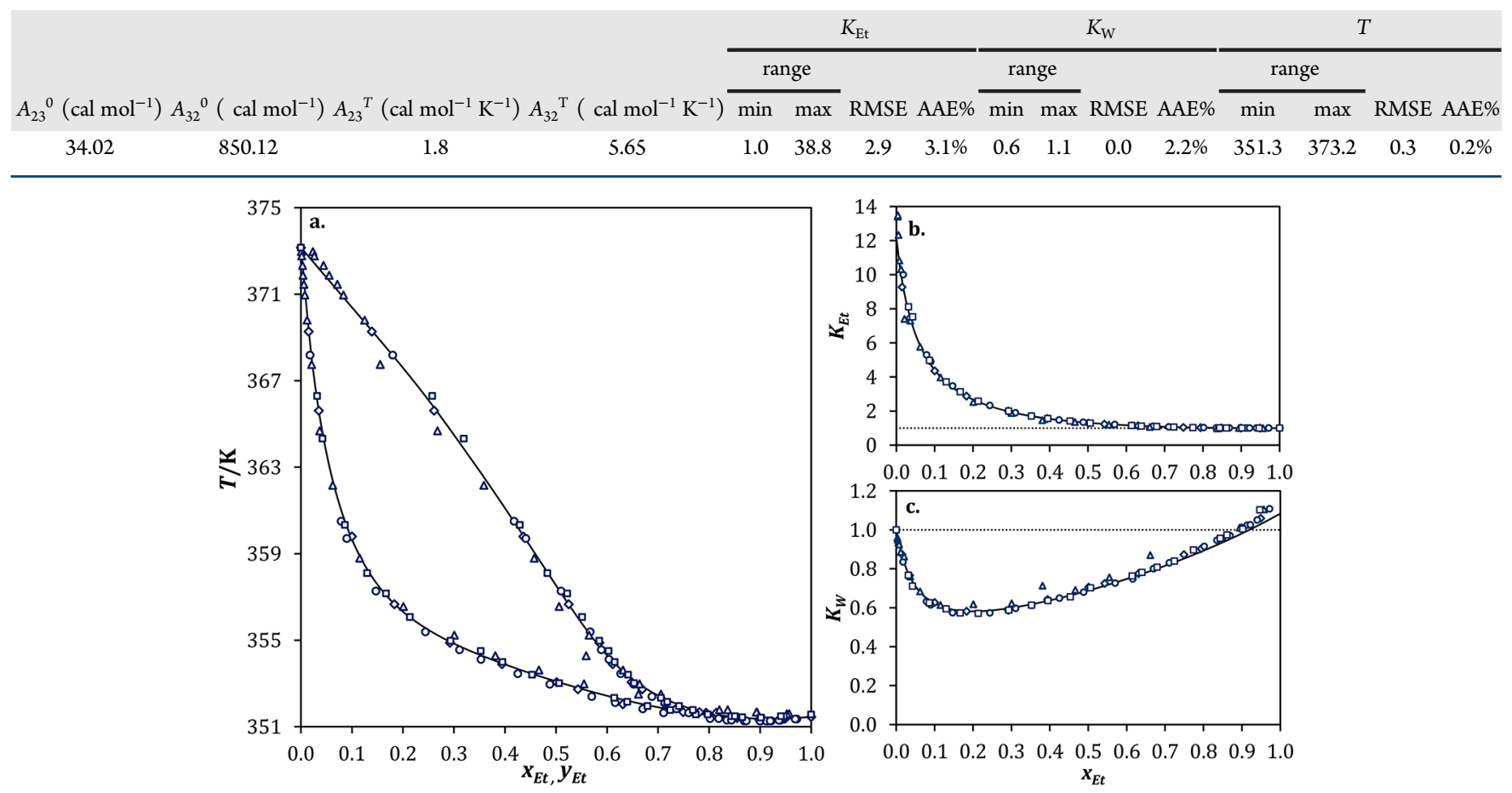

Figure 4. (a) Vapor-liquid equilibrium diagram of the binary system ethanol-water at $101.3 \mathrm{kPa}$ ( $T$ is the temperature, $y_{\mathrm{Et}}$ the ethanol mole fraction in the vapor phase, and $x_{\mathrm{Et}}$ the ethanol mole fraction in the liquid phase). (b) Evolution of the absolute volatility of ethanol ( $\left.K_{\mathrm{Et}}\right)$ with liquid composition $\left(x_{\mathrm{Et}}\right)$. (c) Evolution of the absolute volatility of water $\left(K_{\mathrm{W}}\right)$ with liquid composition $\left(x_{\mathrm{Et}}\right)$. Experimental data from $(\diamond),{ }^{29}(\square),{ }^{71}(\triangle),{ }^{72}$ $(O) .{ }^{73}(-)$ NRTL model using the interaction parameters calculated by Kadir. ${ }^{70}$

$$
\tau_{i j}=\frac{g_{i j}-g_{j j}}{R T}=\frac{A_{i j}^{0}+A_{i j}^{T}(T-273.15)}{R T}
$$

In eq $25, R$ is the ideal gas constant. The variables $A_{i j}^{0}, A_{i j}^{T}$ (nonsymmetric, $A_{i j}^{0} \neq A_{j i}^{0}$ and $A_{i j}^{T} \neq A_{j i}^{T}$ ) are energy parameters describing the $i-j$ interaction, whereas $c_{i j}^{0}$ and $c_{i j}^{T}$ (symmetric, $c_{i j}^{0}$ $=c_{j i}^{0}$ and $c_{i j}^{T}=c_{j i}^{T}$ ) account for the non-randomness of the mixture. These variables are specific to each pair of chemical species and must be identified from experimental data of vapor-liquid equilibria and/or other thermophysical properties of the liquid phase. The estimation of these parameters for the different aroma compounds, the object of this paper, is presented in the next section.

\section{RESULTS AND DISCUSSION}

A database including all the experimental vapor-liquid equilibria data previously presented was created and used for the generation of a set of binary interaction parameters of the NRTL model. This set, named NRTL 0 , will be used to simulate distillation units involved in the production of alcoholic beverages. In this section, the estimation methodology and the parameters obtained are presented (section 3.1.), followed by a classification of the aroma compounds according to their relative volatilities (section 3.2.) using the model representation over the whole ethanol concentration range in the liquid phase $\left(0<x_{\mathrm{Et}}<1\right)$. The discussion is concluded with a comparison of the equilibrium representation for some aroma compounds using several sets of parameters (section 3.3.): (i) the main set (NRTL 0), (ii) a set estimated from binary data for mixtures aroma compound-ethanol and aroma com pound-water (named NRTL B), and (iii) a set from ternary data for mixtures aroma compound at finite concentrationethanol-water (named NRTL T). Given that data at high dilution are scarce and more difficult to measure, the objective of this comparison is to evaluate if the representation from equilibrium data at finite concentration would be accurate enough for simulation purposes of other aroma compounds, similar in nature to those studied in this work, in the alcoholic beverages field.

3.1. Generation of a Set of Binary Interaction Parameters. The objective of modeling with the NRTL model is to determine a set of interaction parameters for the group of 44 aroma compounds in ethanol-water mixtures, using directly the source of experimental information found in the literature. A critical point before this calculation was the selection of coherent data. Further details on the methodology applied for this purpose are presented as Supporting Information.

In consideration of the big number of chemical species, the following assumptions are considered to simplify the model identification problem:

- The main one is that the interactions between aroma compounds are neglected, as their molar fractions in the liquid phase are equal or lower than $x_{\mathrm{AC}}<10^{-4}$, the limit of infinite dilution defined by Alessi et al. ${ }^{69}$ This means that $\tau_{i j}=0$, when $i$ and $j$ are both aroma compounds. In this way, the only interaction parameters considered are those associated with the solvent binary ethanol (2)water (3) and to the pairs aroma compound (1)-ethanol (2) and aroma compound (1)-water (3).

- The nonrandomness parameters, $c_{i j}^{0}$ and $c_{i j}^{T}$, are respectively set to 0.3 and 0 for all binaries. This 


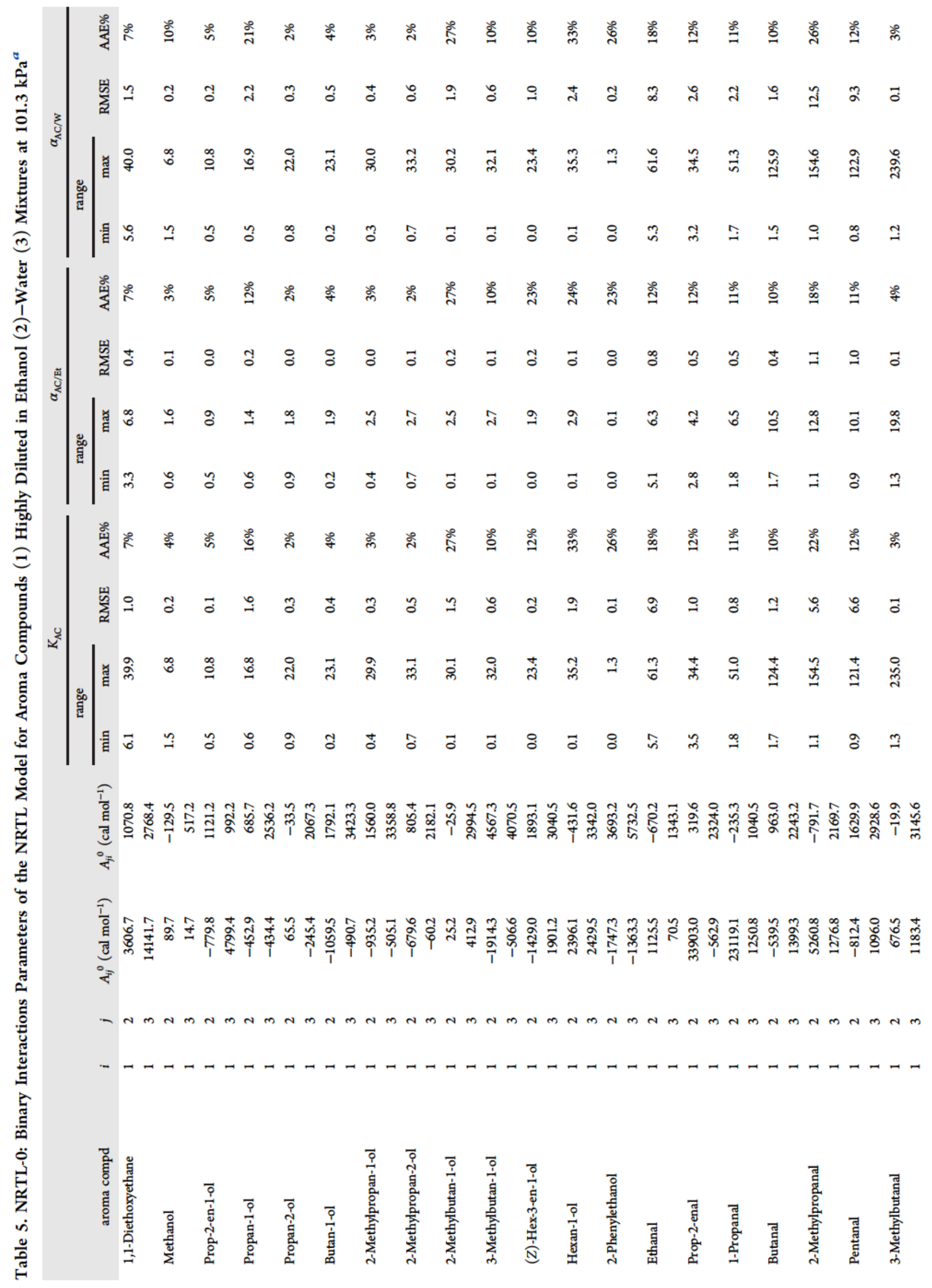




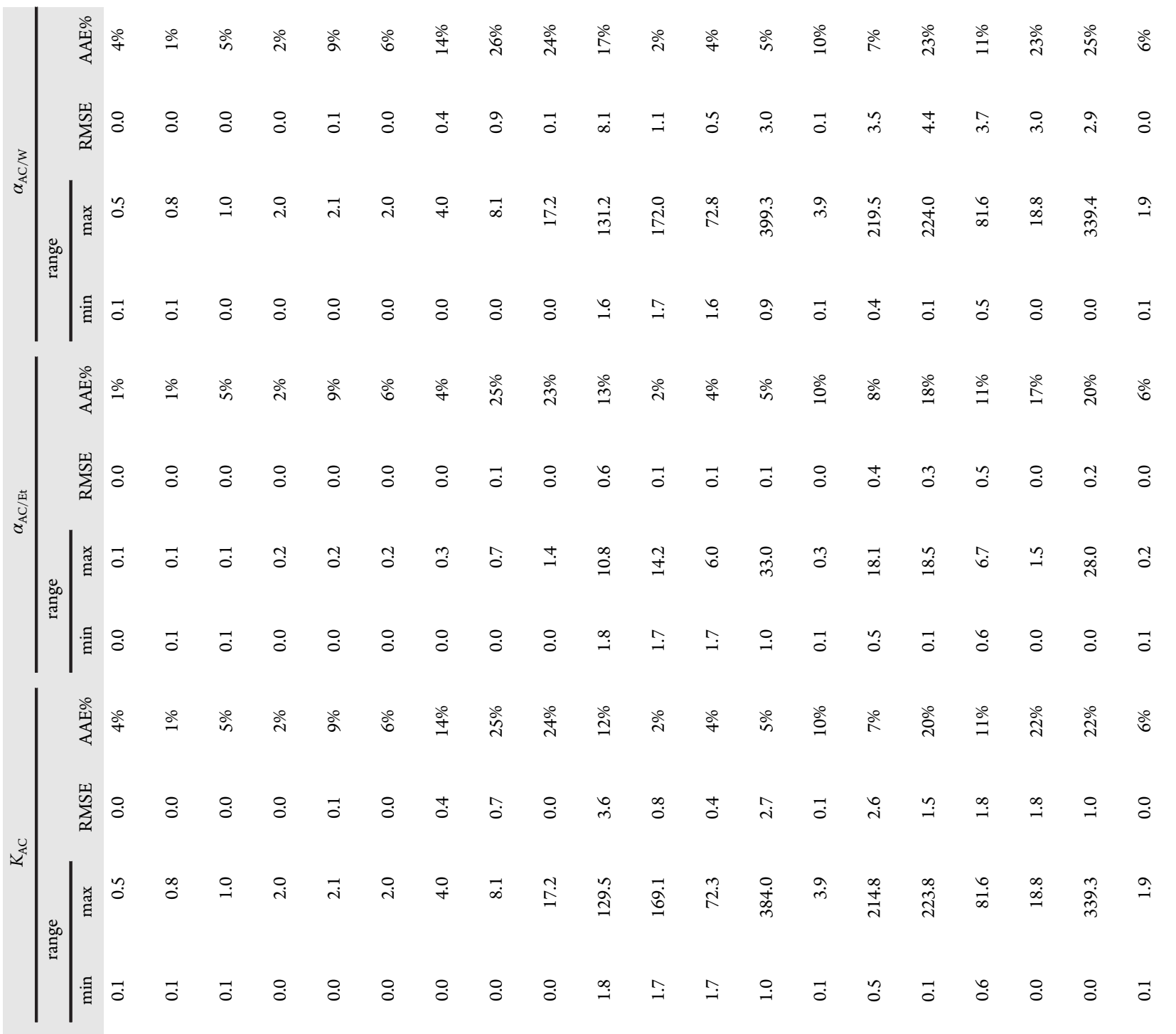

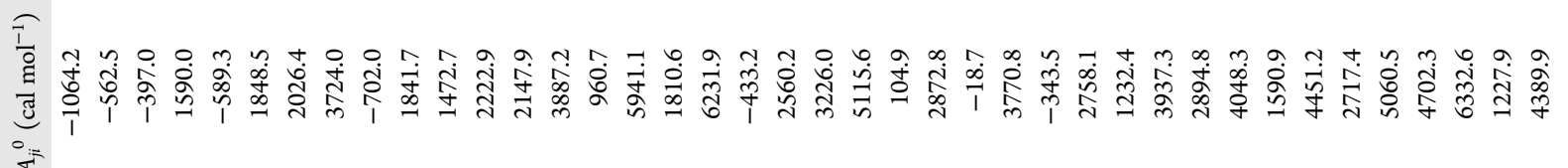

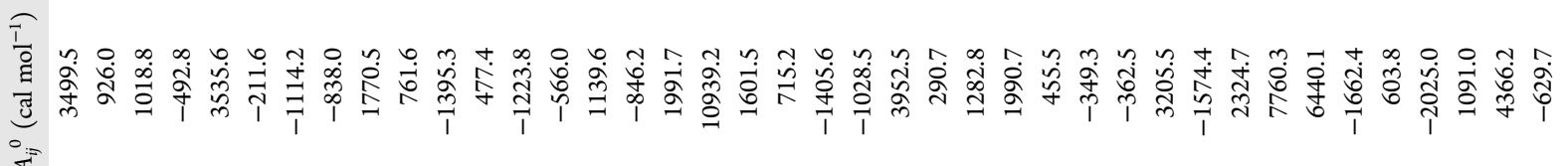

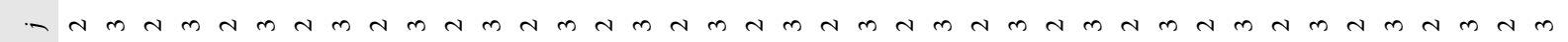

焉
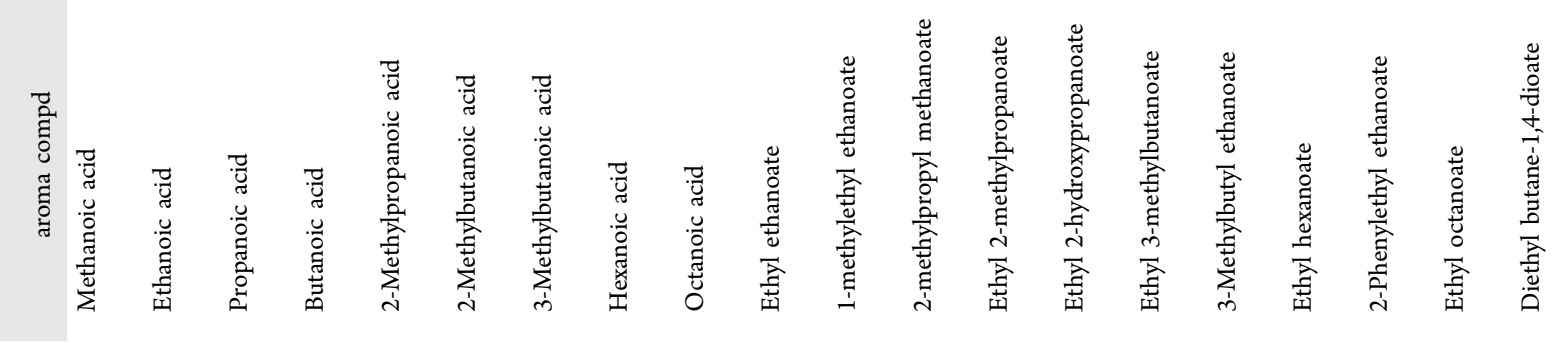


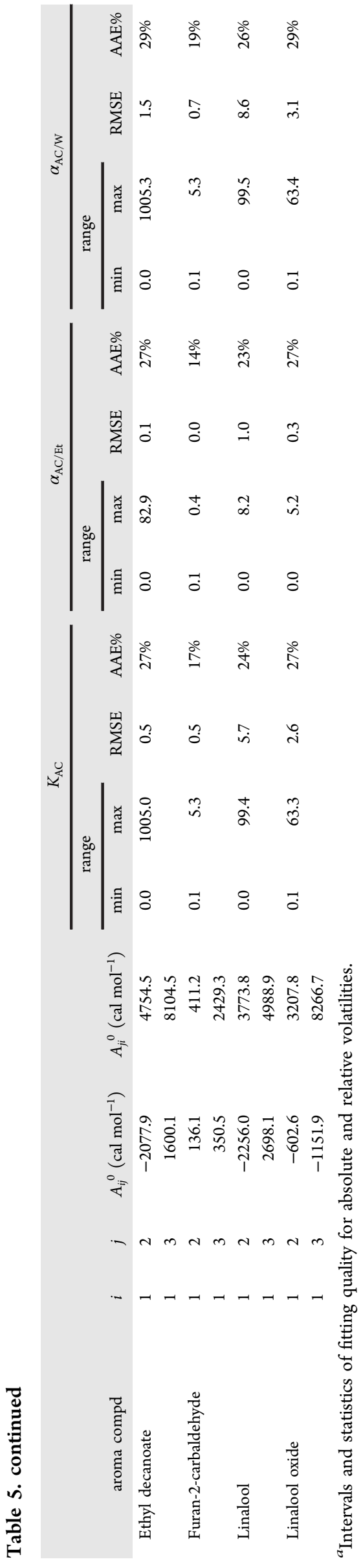

assumption is suitable for polar systems in vapor-liquid equilibrium. $^{23}$

- For the binaries aroma compound (1)-ethanol (2) and aroma compound (1)-water (3), $A_{i j}^{T}$, the temperature dependent parameter of $\tau_{i j}$ is neglected. Two factors justify this approximation: (1) the number of exper imental data is limited and (2) the equilibrium temperature interval is reduced (from 351.44 to 373.15 K).

- The interaction parameters of the binary ethanol (2)water (3) are obtained from the literature. ${ }^{70}$ The values are presented in Table 4 . The reliability of these parameters was verified by fitting the experimental data (79 independent points) measured by different au thors. ${ }^{29,71-73}$ The average relative deviation between the experimental and the calculated temperatures was $0.2 \%$ and that of the absolute volatilities of ethanol and water, $3.1 \%$ and $2.2 \%$, respectively. The equilibrium diagram including the experimental data and the NRTL representation is presented in Figure 4.

In this way, the problem was reduced to the estimation of a set of four parameters for each aroma compound, that is, 176 parameters:

- 88 associated with each binary aroma compound (1)ethanol (2): $A_{12}^{0}, A_{21}^{0}$.

- 88 associated with each binary aroma compound (1)water (3): $A_{13}^{0}, A_{31}^{0}$.

The parameters were estimated by minimizing an objective function through the Excel Solver for nonlinear problems. ${ }^{74}$ The equilibrium property considered was the relative volatility of the aroma compound with respect to ethanol, $\alpha_{\mathrm{AC} / \mathrm{Et}}$. This selection is due to the fact that the interaction parameters will be used for the simulation of distillation units, whose separation performance is directly based upon the difference of volatilities between the chemical species. The relative volatility condenses all the information about the equilibrium distribution of an aroma compound and its behavior with respect to ethanol, main component of the distillate, the product of interest.

The objective function is written in terms of an absolute deviation, formulation that gives more weight to high values of $\alpha_{\mathrm{AC} / \mathrm{Et}}$ :

$$
\mathrm{OF}(\alpha)=\sum_{k=1}^{N}\left(\alpha_{\mathrm{AC} / \mathrm{Etexp}_{k}}-\alpha_{\mathrm{AC} / \mathrm{EtCalc}_{k}}\right)^{2}
$$

where $N$ is the number of independent data, $\alpha_{\mathrm{AC} / \mathrm{Et} \text { Expk }}$ is the experimental value of $\alpha_{\mathrm{AC} / \mathrm{Et}}$ and $\alpha_{\mathrm{AC} / \mathrm{Et} \text { Calck }}$ the valued calculated with the NRTL model. For the majority of aroma compounds, the relative volatility is higher when the ethanol concentration in the liquid phase is low, and this corresponds to the region in which distillation of alcoholic beverages takes place.

The calculation of $\alpha_{\mathrm{AC} / \mathrm{Et}}$ was carried out using the Bubble Temperature algorithm of the Simulis Thermodynamics package. The values of two variables were fixed to the experimental data, namely, pressure $(P)$ and composition in the liquid phase $(x)$. The algorithms allows computation of the temperature $(T)$ and the compositions of the vapor phase $(y)$ in equilibrium. $\alpha_{\mathrm{AC} / \mathrm{Et}}$ is obtained with eq 5 or eq 11 , for carboxylic acids.

The fitting quality is evaluated with respect to three variables (U): $K_{\mathrm{AC}}, \alpha_{\mathrm{AC} / \mathrm{Et}}$ and $\alpha_{\mathrm{AC} / \mathrm{w}}$. Two statistics were calculated: 


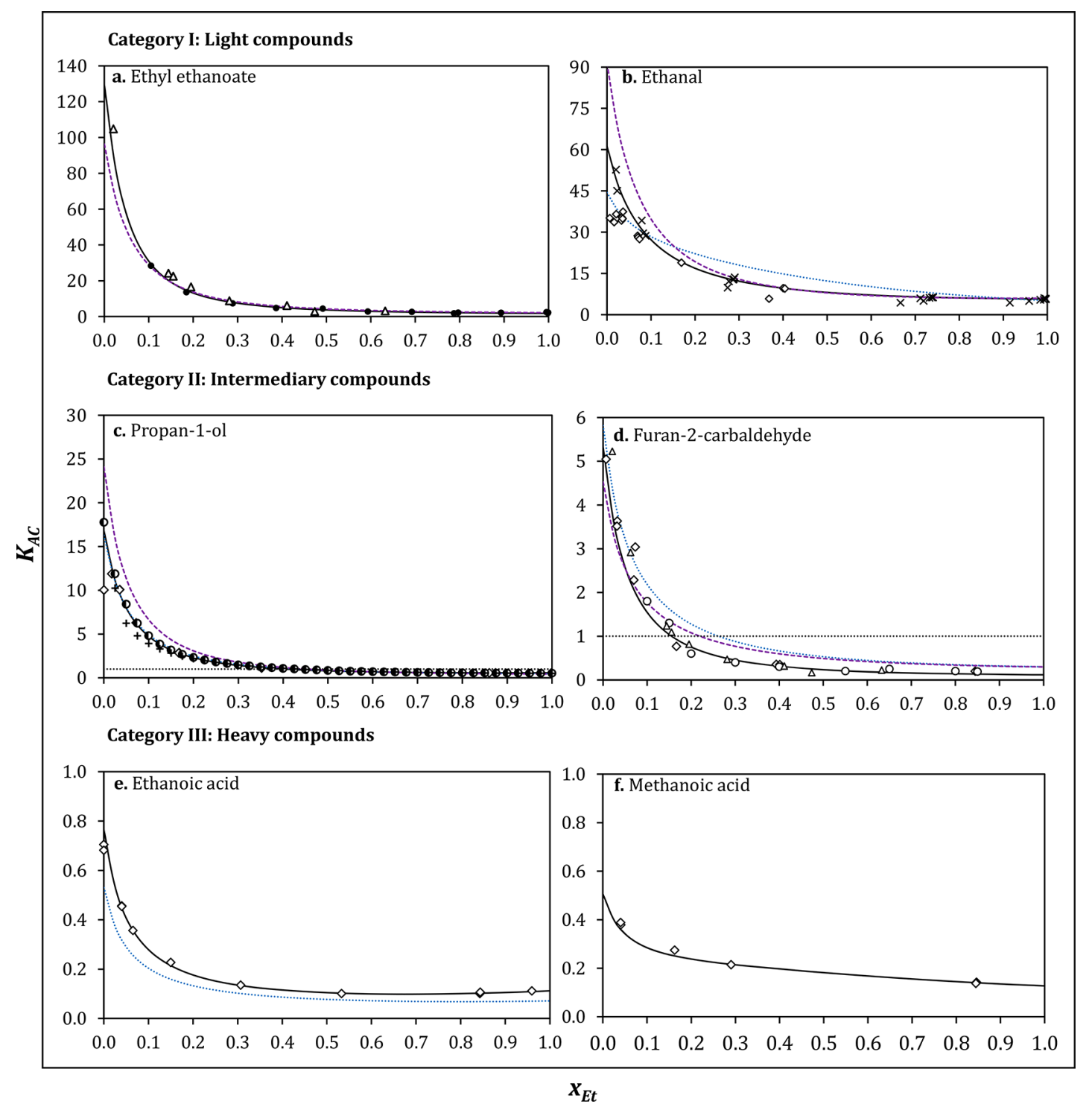

Figure 5. Evolution of the absolute volatility of aroma compounds $\left(K_{\mathrm{AC}}\right)$ with the ethanol composition in the liquid phase $\left(x_{\mathrm{Et}}\right)$ at $101.3 \mathrm{kPa}$ for: Category I, light compounds: (a) ethyl ethanoate, (b) ethanal. Category II, intermediary compounds: (c) propan 1 ol, (d) furan 2 carbaldehyde. Category III, heavy compounds: (e) ethanoic acid, (f) methanoic acid. Experimental data at high dilution from $(\times),{ }^{8}(\diamond),{ }^{9}(\triangle),{ }^{13}(O),{ }^{35}(\mathbf{D}){ }^{36}$ $(\bullet),{ }^{37}(+) .{ }^{38}$ Calculation with NRTL model using $(-)$ NRTL 0 parameters set (estimated from data at high dilution, Table 5). (blue dotted lines) NRTL B parameters set (estimated from binary data, Table 9). NRTL T parameters set (violet dashed lines) (estimated from ternary data, Table $10)$.

- Absolute average relative error (AAE\%):

$$
\mathrm{AAE} \%=\frac{1}{N} \sum_{k=1}^{N}\left|\frac{U_{k \exp }-U_{k \text { Calc }}}{U_{k \exp }}\right| 100 \%
$$

- Root mean square error (RMSE):

$$
\text { RMSE }=\left[\frac{1}{N} \sum_{k=1}^{N}\left(U_{\text {exp } i}-U_{i \text { Calc }}\right)^{2}\right]^{1 / 2}
$$

With reference to the interaction parameters already published in the literature, only those proposed for ethyl lactate by the authors ${ }^{40}$ are directly used in this work. For uniformity reasons, those presented by Athès et al. ${ }^{13}$ and Deterre et al. $^{32}$ were recalculated from the corresponding equilibrium data, as in both cases $A_{i j}^{T} \neq 0$. In relation to the parameters from Athès et al., ${ }^{13}$ it is important to indicate that an alternative formalism was used by the authors to evaluate the temperature dependence of the interaction parameter $\tau_{i j}$. The expression is

$$
\tau_{i j}=a_{i j}+\frac{b_{i j}}{T}
$$

By comparison with eq 25, the following equivalence with the formalism of the current work is deduced:

$$
\begin{aligned}
& \frac{A_{i j}^{0}}{R T}+\frac{A_{i j}^{T}(T-273.15)}{R T}=a_{i j}+\frac{b_{i j}}{T} \\
& \frac{A_{i j}^{T}}{R}+\frac{A_{i j}^{0}-273.15 A_{i j}^{T}}{R T}=a_{i j}+\frac{b_{i j}}{T}
\end{aligned}
$$

where 


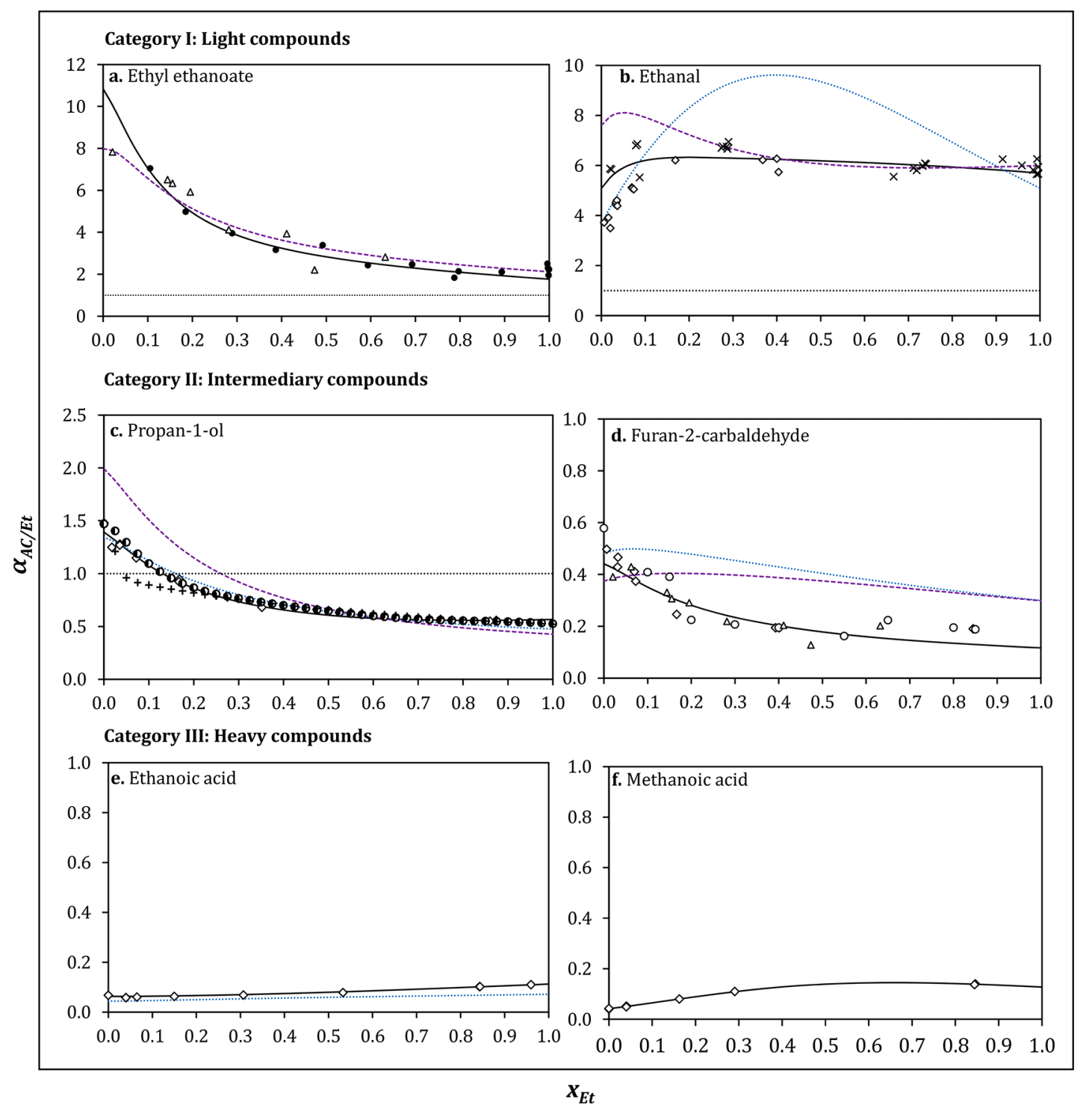

Figure 6. Evolution of the relative volatility of aroma compounds with respect to ethanol $\left(\alpha_{\mathrm{AC} / \mathrm{Et}}\right)$ with the ethanol composition in the liquid phase $\left(x_{\mathrm{Et}}\right)$ at $101.3 \mathrm{kPa}$. Category I, light compounds: (a) ethyl ethanoate, (b) ethanal. Category II, intermediary compounds: (c) propan 1 ol, (d) furan 2 carbaldehyde. Category III, heavy compounds: (e) ethanoic acid, (f) methanoic acid. Experimental data at high dilution from $(\times),{ }^{8}(\diamond),{ }^{9}(\triangle),{ }^{13}$ $(\bigcirc),{ }^{35}(\bigcirc),{ }^{36}(\bullet),{ }^{37}(+) .{ }^{38}$ Calculation with NRTL model using $(-)$ NRTL 0 parameters set (estimated from data at high dilution, Table 5). (blue dotted lines) NRTL B parameters set (estimated from binary data, Table 9). NRTL T parameters set (violet dashed lines) (estimated from ternary data, Table 10).

$$
\begin{aligned}
& A_{i j}^{T}=a_{i j} R \\
& A_{i j}^{0}=b_{i j} R+273.15 A_{i j}^{T}=R\left(b_{i j}+273.15 a_{i j}\right)
\end{aligned}
$$

and consequently, because $a_{i j} \neq 0$, necessarily $A_{i j}^{T} \neq 0$, as stated above.

The new set of interaction parameters for the 44 aroma compounds as well as the statistics of fitting are summarized in Table 5. According to these information, the RMSE of $K_{\mathrm{AC}}$ varies between 0.0 and 6.9 with an overall average of 1.3 , error that remains small regarding the order of magnitude of this property, between $10^{\circ}$ and $10^{2}$. For $\alpha_{\mathrm{AC} / \mathrm{Et}}$ (order of magnitude between $10^{0}$ and $10^{1}$ ), the RMSE is in the range from 0.0 to 1.1 with an overall average of 0.2 , and for $\alpha_{\mathrm{AC} / \mathrm{Et}}$ (order of magnitude between $10^{0}$ and $10^{2}$ ) the overall average is 2.1 . Regarding AAE\%, the overall average is about $12 \%$ for the three equilibrium variables with a variation range between $1 \%$ and

$33 \%$. The analysis by chemical family indicates that the lowest deviations are associated with acetals, overall AAE\% around 7\%, while the highest deviation concern the terpenes, with an overall AAE\% of the order of $25 \%$.

The evolution of absolute and relative volatilities with the ethanol composition in the liquid phase is presented in Figures 5 , 6, and 7 for six representative aroma compounds: ethyl ethanoate, ethanal, propan 1 ol, furan 2 carbaldehyde, ethanoic acid, and methanoic acid. These compounds were classified according to the criterion presented in section 3.2: ethyl ethanoate and ethanal as light compounds, propan $1 \mathrm{ol}$ and furan 2 carbaldehyde as intermediary compounds, and ethanoic and methanoic acid as heavy compounds. In some of these figures, the representation with different sets of interaction parameters is also depicted. A comparative interpretation of theses curves is developed later, in section 3.3. 


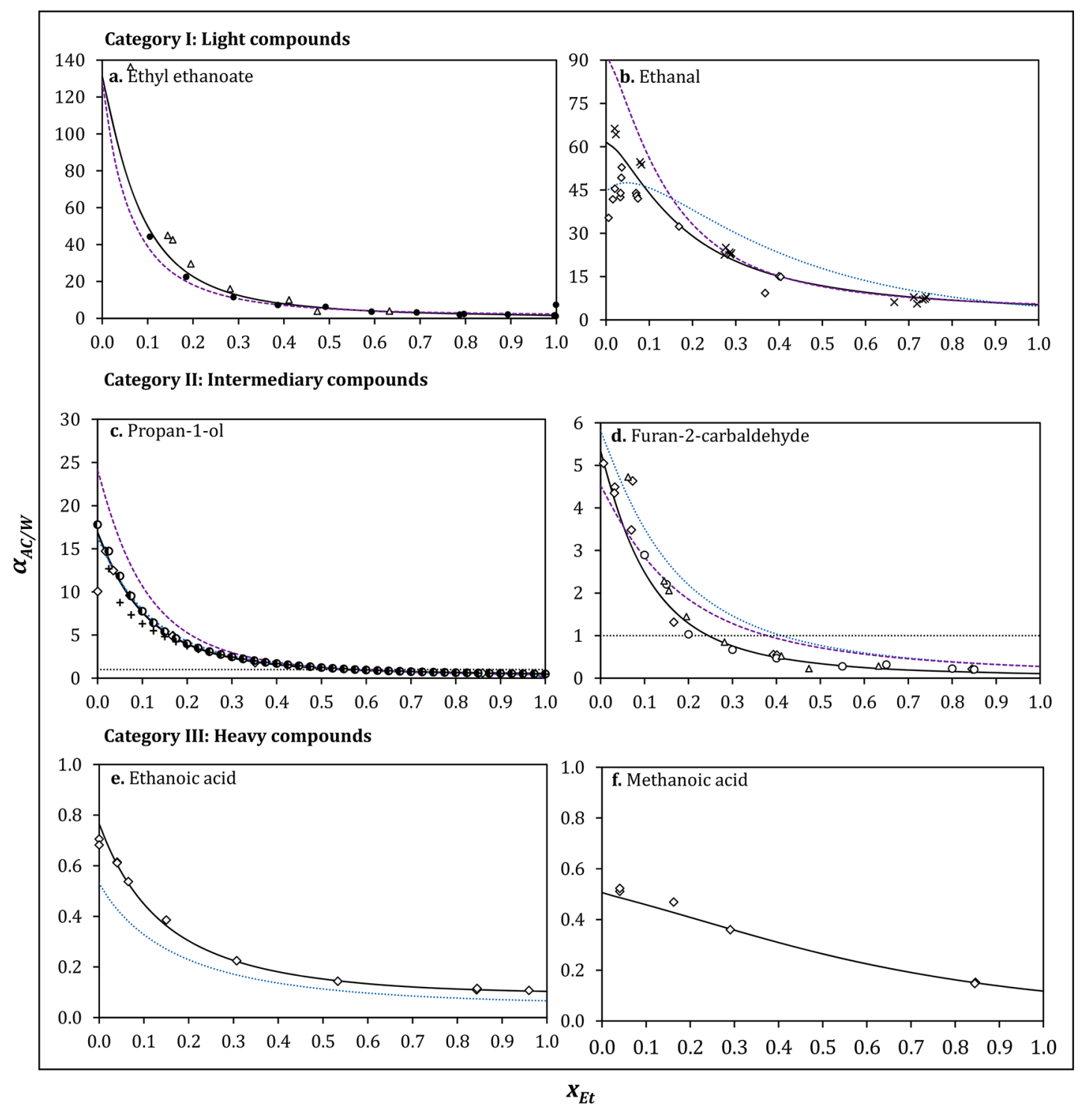

Figure 7. Evolution of the relative volatility of aroma compounds with respect to water $\left(\alpha_{\mathrm{AC} / \mathrm{w}}\right)$ with the ethanol composition in the liquid phase $\left(x_{\mathrm{Et}}\right)$ at $101.3 \mathrm{kPa}$. Category I. light compounds: (a) ethyl ethanoate, (b) ethanal. Category II, intermediary compounds: (c) propan 1 ol, (d) furan 2 carbaldehyde. Category III, heavy compounds: (e) ethanoic acid, (f) methanoic acid. Experimental data at high dilution from $(\times),{ }^{8}(\diamond),{ }^{9}(\triangle),{ }^{13}$ $(\bigcirc),{ }^{35}(\bigcirc),{ }^{36}(\bullet),{ }^{37}(+) .{ }^{38}$ Calculation with NRTL model using $(-)$ NRTL 0 parameters set (estimated from data at high dilution, Table 5). (blue dotted lines) NRTL B parameters set (estimated from binary data, Table 9). NRTL T parameters set (violet dashed lines) (estimated from ternary data, Table 10).

Regarding the experimental data, one can observe that they are globally well represented by the NRTL model, using the interaction parameters calculated in this work (NRTL 0 set). For all compounds, both $K_{\mathrm{AC}}$ and $\alpha_{\mathrm{AC} / \mathrm{w}}$ decrease when the liquid phase is enriched in ethanol, behavior that has already been identified for other aroma compounds. ${ }^{13,40}$ Concerning $\alpha_{\mathrm{AC} / \mathrm{E} \text {, }}$ the evolution with composition are more variable, independently of its order of magnitude. Three trends can be identified: (i) decreasing (for ethyl ethanoate, propan $1 \mathrm{ol}$, furfural, and most of the aroma compounds studied in this work), (ii) slightly linear increasing (for ethanoic acid), and (iii) nearly constant, in the case of ethanal, after a slight increase of $\alpha_{\mathrm{AC} / \mathrm{Et}}$ in the region of low ethanol concentration $\left(x_{\mathrm{Et}}<1\right)$.

As for the Henry constant of aroma compounds, this parameter can be calculated at boiling conditions by using directly the absolute volatility data, according to eq 18 . The values of $\ln \mathcal{H}_{\mathrm{AC}}$ as a function of $T^{-1}$ are depicted in Figure 8 for the same aroma compounds. As in the previous figures, model curves obtained with different parameters sets are plotted (see section 3.3).

In general terms, the activity model represents correctly the experimental data. Regarding ethanal (Figure 8b), even if an important dispersion of the experimental data is observed, the model follows the global trend in most of the temperature interval. In all cases, the continuous representation with the NRTL model shows that the evolution of $\ln \mathcal{H}_{\mathrm{AC}}$ is decreasing and concave for all compounds, and not linear, as observed in a pure solvent. This is due to the fact that the temperature and the composition of the liquid phase are not independent at boiling conditions: each bubble temperature $T$ corresponds to a different mole fraction of ethanol.

In this way, considering the great diversity of chemical species and data resources, the whole of results are acceptable 


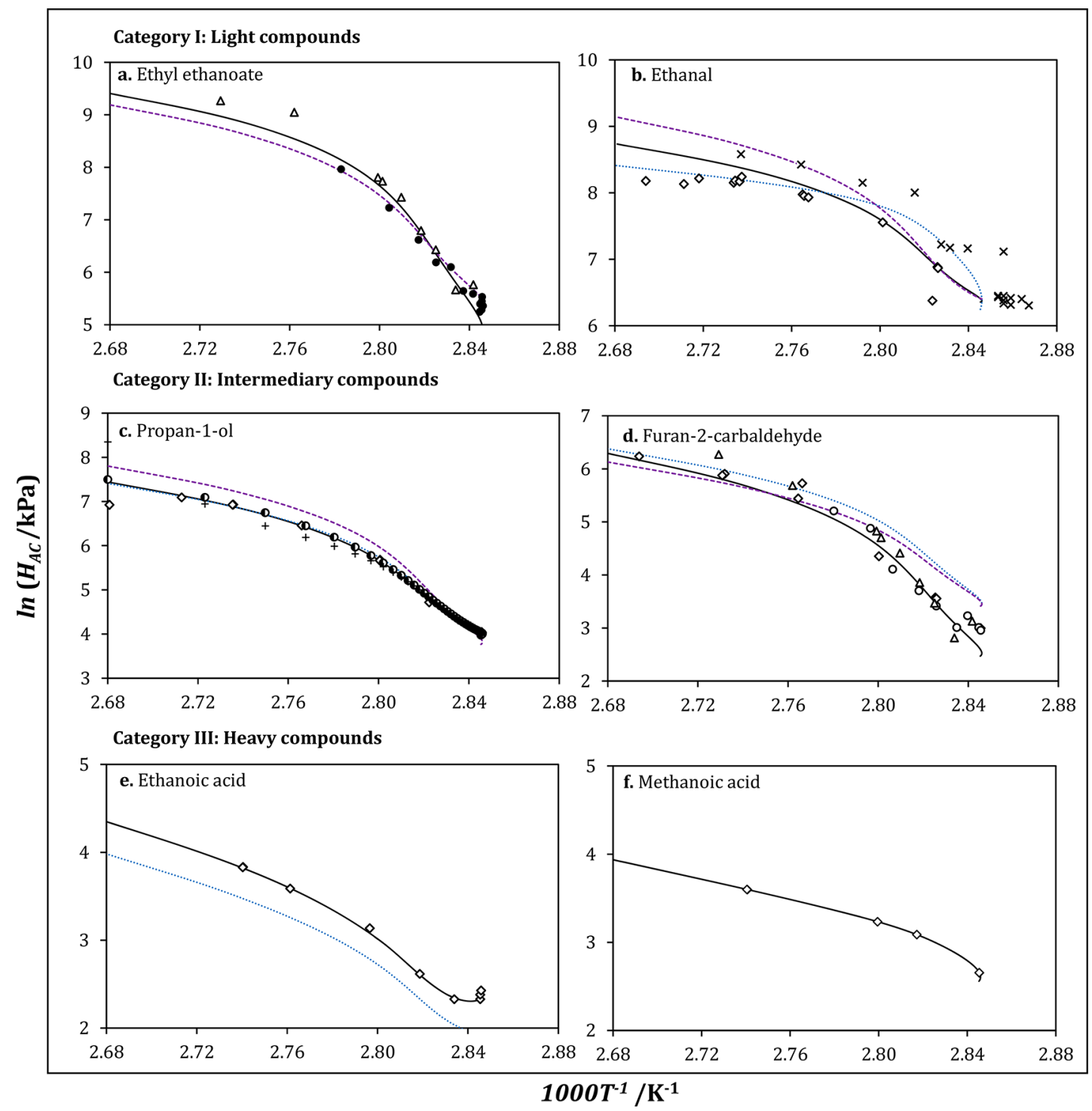

Figure 8. Evolution of $\ln H$ with $T^{-1}$ at $101.3 \mathrm{kPa}$. Category I, light compounds: (a) ethyl ethanoate, (b) ethanal. Category II, intermediary compounds: (c) propan $1 \mathrm{ol}$, (d) furan 2 carbaldehyde. Category III, heavy compounds: (e) ethanoic acid, (f) methanoic acid. Experimental data at high dilution from $(\times),{ }^{8}(\diamond),{ }^{9}(\triangle),{ }^{13}(O),{ }^{35}(\boldsymbol{D}),{ }^{36}(\bullet),{ }^{37}(+),{ }^{38}$ Calculation with NRTL model using $(-)$ NRTL 0 parameters set (estimated from data at high dilution, Table 5). (blue dotted line) NRTL B parameters set (estimated from binary data, Table 9). NRTL T parameters set (violet dashed line) (estimated from ternary data, Table 10).

and confirm that the NRTL model can correctly represent the vapor-liquid equilibria of aroma compounds in hydroalcoholic mixtures, a conclusion already established in other synthesis works.

3.2. Classification of Aroma Compounds. The set of interaction parameters estimated will be used for simulation purposes at a later stage, with the aim of understanding the behavior of aroma compounds in alcoholic beverages distillation. Given the considerable number of studied species, a systematic classification turns out be useful for identifying general trends.

By following a classic approach of multicomponent distillation, two key components governing the separation are first selected: ethanol as light key and water as heavy key. The first will be recovered to a significant extent in the top product, whereas the second, less volatile, will mainly be recovered in the bottom product. Then, by taking as criterion the relative volatility with respect to both key components over the entire ethanol composition range, three categories of aroma compounds can be defined:

- Category I, light compounds: The minimal value of $\alpha_{\mathrm{AC} / \mathrm{Et}}$ is higher than the unity $\left(\alpha_{\mathrm{AC} / \mathrm{Et}-\mathrm{MIN}}>1\right)$. They are lighter than light key and will be therefore mainly present in the top product or distillate.

- Category II, intermediary or distributed compounds: The minimal value of $\alpha_{\mathrm{AC} / \mathrm{Et}}$ is lower than the unity $\left(\alpha_{\mathrm{AC} / \mathrm{Et}-\mathrm{MIN}}<1\right)$, and the maximal value of $\alpha_{\mathrm{AC} / \mathrm{W}}$ is higher than the unity $\left(\alpha_{\mathrm{AC} / \mathrm{W}-\mathrm{MAX}}>1\right)$. Their volatility are intermediate between that of light and heavy key. They will be distributed in top and bottom products.

- Category III, heavy compounds: the maximal value of $\alpha_{\mathrm{AC} / \mathrm{W}}$ is lower than the unity $\left(\alpha_{\mathrm{AC} / \mathrm{W}-\mathrm{MAX}}<1\right)$. They are heavier than heavy key and will be therefore mainly recovered in the bottom product.

For simulation purposes, an accurate representation of phase equilibrium for intermediary compounds is fundamental to 
Table 6. Classification of Aroma Compounds According to Their Relative Volatilities with Respect to Ethanol and Water, Over the Whole Ethanol Composition Range in the Liquid Phase

\begin{tabular}{|c|c|c|c|c|c|}
\hline \multirow[b]{2}{*}{ category } & \multirow[b]{2}{*}{ aroma compd } & \multicolumn{2}{|c|}{$\alpha_{\mathrm{AC} / \mathrm{Et}}$} & \multicolumn{2}{|c|}{$\alpha_{\mathrm{AC} / \mathrm{W}}$} \\
\hline & & $\min$ & $\max$ & $\min$ & $\max$ \\
\hline \multirow[t]{10}{*}{ (I) Light } & 3-Methylbutanal & 1.3 & 19.8 & 1.2 & 239.6 \\
\hline & Propan-2-yl ethanoate & 1.7 & 14.2 & 1.7 & 172.0 \\
\hline & 2-Methylpropanal & 1.1 & 12.8 & 1.0 & 154.6 \\
\hline & Ethyl ethanoate & 1.8 & 10.8 & 1.6 & 131.2 \\
\hline & Butanal & 1.7 & 10.5 & 1.5 & 125.9 \\
\hline & Ethanal & 5.1 & 6.3 & 5.3 & 61.6 \\
\hline & 1,1-Diethoxyethane & 3.3 & 6.8 & 5.6 & 40.0 \\
\hline & Propanal & 1.8 & 6.5 & 1.7 & 51.3 \\
\hline & 2-Methylpropyl methanoate & 1.7 & 6.0 & 1.6 & 72.8 \\
\hline & Prop-2-enal & 2.4 & 4.5 & 2.4 & 30.1 \\
\hline \multirow[t]{32}{*}{ (II) Intermediary } & Ethyl decanoate & 0.0 & 82.9 & 0.0 & 1005.3 \\
\hline & Ethyl 2-methylpropanoate & 1.0 & 33.0 & 0.9 & 399.3 \\
\hline & Ethyl octanoate & 0.0 & 28.0 & 0.0 & 339.4 \\
\hline & 3-Methylbutyl ethanoate & 0.1 & 18.5 & 0.1 & 224.0 \\
\hline & Ethyl 3-methylbutanoate & 0.5 & 18.1 & 0.4 & 219.5 \\
\hline & Pentanal & 0.9 & 10.1 & 0.8 & 122.9 \\
\hline & Linalool & 0.0 & 8.2 & 0.0 & 99.5 \\
\hline & Ethyl hexanoate & 0.6 & 6.7 & 0.5 & 81.6 \\
\hline & Linalool oxide & 0.0 & 5.2 & 0.1 & 63.4 \\
\hline & 2-Methylpropan-2-ol & 0.7 & 2.7 & 0.7 & 33.2 \\
\hline & Hexan-1-ol & 0.1 & 2.9 & 0.1 & 35.3 \\
\hline & Propan-2-ol & 0.9 & 1.8 & 0.8 & 22.0 \\
\hline & 3-Methylbutan-1-ol & 0.1 & 2.7 & 0.1 & 32.1 \\
\hline & 2-Methylpropan-1-ol & 0.4 & 2.5 & 0.3 & 30.0 \\
\hline & 2-Methylbutan-1-ol & 0.1 & 2.5 & 0.1 & 30.2 \\
\hline & Butan-1-ol & 0.2 & 1.9 & 0.2 & 23.1 \\
\hline & (Z)-Hex-3-en-1-ol & 0.0 & 1.9 & 0.0 & 23.4 \\
\hline & Propan-1-ol & 0.6 & 1.4 & 0.5 & 16.9 \\
\hline & Methanol & 0.6 & 1.5 & 1.4 & 6.8 \\
\hline & 2-Phenylethyl ethanoate & 0.0 & 1.5 & 0.0 & 18.8 \\
\hline & Octanoic acid & 0.0 & 1.4 & 0.0 & 17.2 \\
\hline & Prop-2-en-1-ol & 0.5 & 0.9 & 0.5 & 10.8 \\
\hline & Hexanoic acid & 0.0 & 0.7 & 0.0 & 8.1 \\
\hline & Furan-2-carbaldehyde & 0.1 & 0.4 & 0.1 & 5.3 \\
\hline & Ethyl 2-hydroxypropanoate & 0.1 & 0.3 & 0.1 & 3.9 \\
\hline & 3-Methylbutanoic acid & 0.0 & 0.3 & 0.0 & 4.0 \\
\hline & 2-Methylpropanoic acid & 0.0 & 0.2 & 0.0 & 2.1 \\
\hline & Butanoic acid & 0.0 & 0.2 & 0.0 & 2.0 \\
\hline & Diethyl butane-1,4-dioate & 0.1 & 0.2 & 0.1 & 1.9 \\
\hline & 2-Methylbutanoic acid & 0.0 & 0.2 & 0.0 & 2.0 \\
\hline & 2-Phenylethan-1-ol & 0.0 & 0.1 & 0.0 & 1.3 \\
\hline & Propanoic acid & 0.1 & 0.1 & 0.0 & 1.0 \\
\hline \multirow[t]{2}{*}{ (III) Heavy } & Ethanoic acid & 0.1 & 0.1 & 0.1 & 0.8 \\
\hline & Methanoic acid & 0.0 & 0.1 & 0.1 & 0.5 \\
\hline
\end{tabular}

correctly estimate the ratio of distribution between the top and bottom product. The classification of the aroma compounds studied in this work is presented in Table 6. According to this approach, most of the compounds, 32, are intermediary compounds. Ten compounds, mainly carbonyl compounds, are light compounds, and only two carboxylic acids, methanoic and ethanoic, are heavier than water. The aroma compounds presented in Figures 5-7 are classified on the basis of this criterion, from the more (ethyl ethanoate) to the less volatile (methanoic acid).
It should be noted that the classification is proposed over the whole ethanol composition range in the liquid phase $\left(0<x_{\mathrm{Et}}<\right.$ $1)$. Given that the relative volatilities vary with composition, the classification could be different when considering a more restricted composition interval.

3.3. Comparison of the Representation Obtained from Data at High Dilution and That Obtained from Binary and Ternary Data at Higher Concentrations of Aroma Compounds. The discussion concludes with a comparison between: (1) the representation of the equilibrium data using the set of parameters calculated in this work, from 
Table 7. Synthesis of Vapor-Liquid Data for Binary Systems Aroma Compound (1)-Ethanol (2) and Aroma Compound (1)Water (3) at $101.3 \mathrm{kPa}$

\begin{tabular}{|c|c|c|c|c|c|c|c|c|c|}
\hline \multirow[b]{2}{*}{ aroma compd } & \multirow[b]{2}{*}{ solvent } & \multirow[b]{2}{*}{ data ref } & \multirow[b]{2}{*}{$\begin{array}{l}\text { no. of } \\
\text { independent data }\end{array}$} & \multicolumn{2}{|c|}{$T$ range $(\mathrm{K})$} & \multicolumn{2}{|c|}{$x_{\mathrm{AC}}$ range } & \multicolumn{2}{|c|}{$y_{\mathrm{AC}}$ range } \\
\hline & & & & $\min$ & $\max$ & $\min$ & $\max$ & $\min$ & $\max$ \\
\hline \multirow[t]{2}{*}{ Methanol } & Ethanol & $\begin{array}{l}\text { Amer et al. } 1956 ;^{77} \text { Delzenne, } 1958 ;^{78} \text { Slobodyanyk et al. } \\
1966^{79}\end{array}$ & 58 & 337.9 & 351.6 & 0.00 & 1.00 & 0.00 & 1.00 \\
\hline & Water & $\begin{array}{l}\text { Dunlop, } 1948 ;^{80} \text { Ocon and Rebolleda, } 1958 ;^{81} \text { Kohoutova et } \\
\text { al. } 1970^{82}\end{array}$ & 66 & 337.7 & 373.2 & 0.00 & 1.00 & 0.00 & 1.00 \\
\hline \multirow[t]{2}{*}{ Propan-1-ol } & Ethanol & Gay, $1927 ;^{83}$ Ochi and Kojima, $1979^{84}$ & 32 & 351.5 & 370.8 & 0.00 & 1.00 & 0.00 & 1.00 \\
\hline & Water & $\begin{array}{l}\text { Chu et al. } 1950 ;{ }^{85} \text { Smirnova, } 1959 ;^{86} \text { Droboserdov and Ilina, } \\
1961^{87}\end{array}$ & 51 & 360.7 & 373.2 & 0.00 & 1.00 & 0.00 & 1.00 \\
\hline \multirow[t]{2}{*}{ 3-Methylbutan-1-ol } & Ethanol & Gay, $1927^{83}$ & 17 & 351.5 & 404.2 & 0.00 & 1.00 & 0.00 & 1.00 \\
\hline & Water & Andiappan and McLean, $1972^{88}$ & 11 & 368.3 & 381.2 & 0.00 & 0.88 & 0.11 & 0.43 \\
\hline \multirow[t]{2}{*}{ Ethanal } & Ethanol & Suska, $1979^{89}$ & 21 & 293.6 & 351.5 & 0.00 & 1.00 & 0.00 & 1.00 \\
\hline & Water & Perry, $1950 ;^{90}$ Suska, $1979^{89}$ & 27 & 293.3 & 373.2 & 0.00 & 1.00 & 0.00 & 1.00 \\
\hline \multirow[t]{2}{*}{ Ethanoic acid } & Ethanol & Rius et al., $1959^{91}$ & 18 & 350.0 & 389.0 & 0.00 & 1.00 & 0.00 & 1.00 \\
\hline & Water & $\begin{array}{l}\text { Brown and Ewald, } 1950 ;{ }^{92} \text { Conti et al., } 1960 ;{ }^{93} \text { Sebastiani } \\
\text { and Lacquaniti, } 1967^{94}\end{array}$ & 59 & 373.2 & 391.3 & 0.00 & 1.00 & 0.00 & 1.00 \\
\hline \multirow[t]{2}{*}{ Furan-2-carbaldehyde } & Ethanol & Kharin et al. $1970 a^{95}$ & 8 & 351.6 & 407.2 & 0.02 & 0.98 & 0.00 & 0.40 \\
\hline & Water & Mains, $1922^{96}$ & 9 & 371.1 & 434.9 & 0.00 & 1.00 & 0.00 & 1.00 \\
\hline
\end{tabular}

Table 8. Synthesis of Vapor-Liquid Data for Ternary Systems Aroma Compound (1)-Ethanol (2 -Water (3) at 101.3 kPa

\begin{tabular}{|c|c|c|c|c|c|c|c|c|c|c|c|c|c|c|c|c|}
\hline \multirow[b]{2}{*}{ aroma compd } & \multirow[b]{2}{*}{ data ref } & \multirow{2}{*}{$\begin{array}{c}\text { no. of } \\
\text { independent } \\
\text { data }\end{array}$} & \multicolumn{2}{|c|}{$T$ range $(\mathrm{K})$} & \multicolumn{2}{|c|}{$x_{\mathrm{AC}}$ range } & \multicolumn{2}{|c|}{$x_{\mathrm{Et}}$ range } & \multicolumn{2}{|c|}{$x_{\mathrm{W}}$ range } & \multicolumn{2}{|c|}{$y_{\mathrm{AC}}$ range } & \multicolumn{2}{|c|}{$y_{\mathrm{Et}}$ range } & \multicolumn{2}{|c|}{$y_{\mathrm{W}}$ range } \\
\hline & & & $\min$ & $\max$ & $\min$ & $\max$ & $\min$ & $\max$ & $\min$ & $\max$ & $\min$ & $\max$ & $\min$ & $\max$ & $\min$ & $\max$ \\
\hline Methanol & $\begin{array}{l}\text { Griswold and Dim- } \\
\text { viddie, } 1942 ;{ }^{97} \\
\text { Huges and Malo- } \\
\text { ney, } 1952 ;{ }^{98} \\
\text { Delzenne, } 1958^{78}\end{array}$ & 80 & 340.0 & 360.7 & 0.0 & 0.9 & 0.0 & 0.8 & 0.0 & 0.9 & 0.1 & 0.9 & 0.0 & 0.8 & 0.0 & 0.5 \\
\hline Propan-1-ol & $\begin{array}{l}\text { Ochi and Kojima, } \\
1969 ;{ }^{84} \text { Kharin et } \\
\text { al. } 1970 \mathrm{~b} ;{ }^{99} \text { Tan } \\
\text { et al. } 2005^{76}\end{array}$ & 70 & 351.2 & 368.8 & 0.0 & 1.0 & 0.0 & 0.9 & 0.0 & 1.0 & 0.0 & 0.9 & 0.0 & 0.9 & 0.0 & 0.9 \\
\hline Propan-2-ol & $\begin{array}{l}\text { Kojima et al. } \\
1969 ;{ }^{100} \text { Kharin }^{101} \\
\text { et al. } 1971 \mathrm{a} ;{ }^{100} \\
\text { Tan et al. } 2004^{72}\end{array}$ & 80 & 351.2 & 361.9 & 0.0 & 0.9 & 0.0 & 0.9 & 0.0 & 0.9 & 0.0 & 0.9 & 0.0 & 0.9 & 0.0 & 0.7 \\
\hline 2-Methylpropan-1-ol & $\begin{array}{l}\text { Suska et al. } \\
1970 ;{ }^{102} \text { Kharin } \\
\text { et al. } 1971 b^{103}\end{array}$ & 37 & 351.9 & 362.2 & 0.0 & 0.5 & 0.1 & 1.0 & 0.0 & 0.9 & 0.0 & 0.3 & 0.1 & 1.0 & 0.0 & 0.6 \\
\hline 3-Methylbutan-1-ol & $\begin{array}{l}\text { Kharin et al. } \\
1972^{104}\end{array}$ & 31 & 351.7 & 366.1 & 0.0 & 0.5 & 0.1 & 0.8 & 0.1 & 0.9 & 0.0 & 0.1 & 0.4 & 0.8 & 0.2 & 0.6 \\
\hline Ethanal & Heitz, $1960^{8}$ & 40 & 316.9 & 372.2 & 0.0 & 0.4 & 0.0 & 1.0 & 0.0 & 1.0 & 0.0 & 0.8 & 0.0 & 1.0 & 0.0 & 1.0 \\
\hline Ethyl ethanoate & $\begin{array}{l}\text { Griswold et al. } \\
1949 ;^{105} \text { Vans } \\
\text { Zandijcke and } \\
\text { Verhoeye, } \\
1974^{106}\end{array}$ & 147 & 343.8 & 358.6 & 0.0 & 0.9 & 0.1 & 1.0 & 0.0 & 0.9 & 0.0 & 0.9 & 0.1 & 1.0 & 0.0 & 0.6 \\
\hline Furan-2-carbaldehyde & $\begin{array}{c}\text { Kharin et al. } \\
1971 c^{107}\end{array}$ & 25 & 353.2 & & 0.0 & 0.5 & 0.1 & 0.9 & 0.1 & 0.9 & 0.0 & 0.1 & 0.4 & 0.9 & 0.1 & 0.6 \\
\hline
\end{tabular}

data at high dilution regarding the aroma compounds (Table 2 and Table 5), and (2) the one obtained with parameters fitted to data for binary and ternary systems, in which the aroma compounds are present at high concentrations. These parameters are available in the literature for some aroma compounds. ${ }^{7,18-21,75,76}$ However, according to the writing of eqs 22 and 23, they cannot be used directly for two reasons: (i) the formalisms to evaluate the temperature dependence of the interaction parameters $c_{i j}$ and $\tau_{i j}$ are not the same of this work, and (ii) the nonrandomness parameters $c_{i j}^{0}$ is different from the value set in this work (0.3), which does not make possible the conversion of the parameters $G_{i j}$ and $\tau_{i j}$ in the different formalisms.

Consequently, new interaction parameters are estimated from experimental data by following an analogous procedure to that described in section 3.1 Information on the aroma compounds considered, the data references ${ }^{8,75-107}$ as well as the temperature and composition intervals are summarized in Table 7 for binary systems (aroma compound-ethanol and aroma compound-water) and in Table 8 for ternary systems 


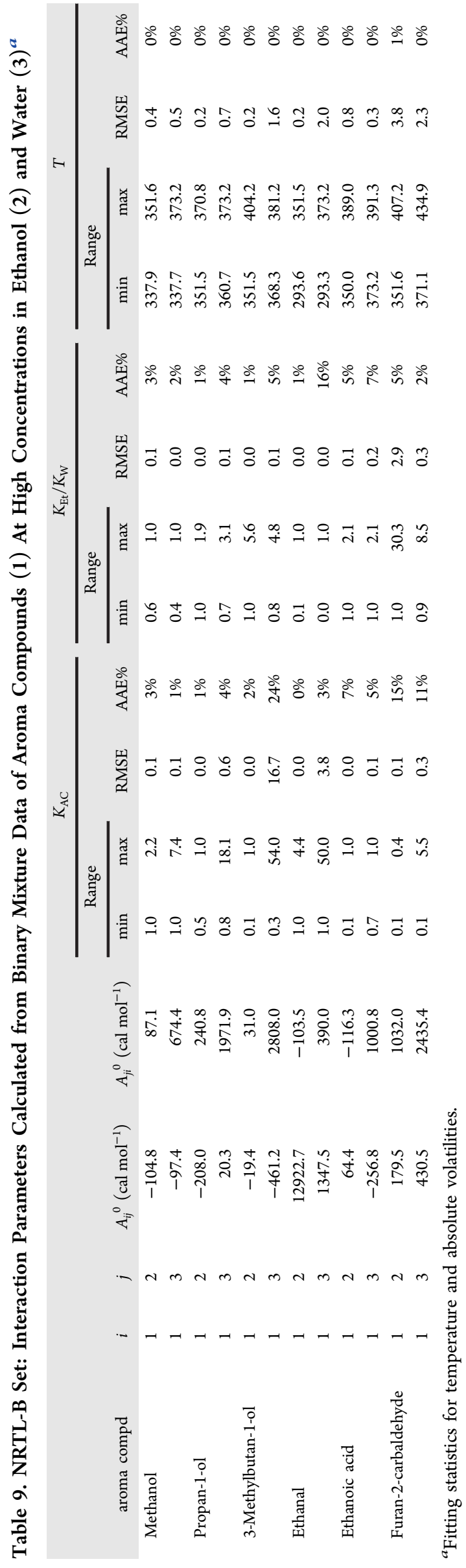

(aroma compound-ethanol-water). Nine aroma compounds from five chemical families are considered.

The objective function is expressed in terms of the relative deviation of temperature and absolute volatility data:

$$
\begin{aligned}
\mathrm{OF}\left(T, K_{i}\right)= & \sum_{k=1}^{N}\left(\frac{T_{\operatorname{Exp}_{k}}-T_{\text {calc }_{k}}}{T_{\operatorname{Exp}_{k}}}\right)^{2} \\
& +\sum_{k=1}^{N} \sum_{i=1}^{n}\left(\frac{K_{i \operatorname{Exp}_{k}}-K_{i \text { Calc }_{k}}}{K_{i \operatorname{Exp}_{k}}}\right)^{2}
\end{aligned}
$$

$T_{\text {Calc }_{k}}$ and $K_{i}$ Calc $_{k}$ are computed with the Bubble Temperature algorithm of the Simulis Thermodynamics package by fixing the pressure $(P)$ and composition in the liquid phase $(x)$ to the experimental data. In all cases, the interaction parameters of the binary ethanol-water used for the equilibrium calculations were those used previously in this work (Table 4). ${ }^{66}$ The fitting quality is evaluated with respect to $T$ and $K_{i}$, by considering the parameters AAE\% (eq 27) and RMSE (eq 28).

In comparison to eq 26, used for the parameter estimation from data at high dilution (NRTL 0 set), the formulation of eq 34 was chosen for three reasons: (i) relative deviations were preferred to absolute ones because the function includes two variables with different magnitude orders; (ii) temperature was added because in binary and ternary systems the corresponding intervals are variable, whereas that of high dilution systems is always the same at $101.3 \mathrm{kPa}$ (from 351.4 to $373.2 \mathrm{~K}$ ), as it is fixed by the ethanol-water binary; (iii) absolute volatilities were used because they do not give more weight to a component with respect to another, which is more appropriate for this estimation because all the species concerned are present at wide concentration intervals (from 0 to 1 ). The formulation of eq 26 is more adapted to systems with aroma compounds highly diluted, as it privileges this species in relation to ethanol and water.

Thereby, the set of interaction parameters derived from binary data (identified as NRTL B) is given in Table 9 and that from ternary data (identified as NRTL T) in Table 10. In both tables, the fitting statistics, with the temperature and absolute volatilities ranges, are presented. According to these values, all the concerned systems are globally well represented with the NRTL model, with an overall relative error of $1 \%$ for temperature (variation between $0 \%$ and $3 \%$ ) and of $7 \%$ for absolute volatilities (variation between $1 \%$ and $24 \%$ ).

The comparison with data at high dilution is performed in relation to the fitting quality of the equilibrium data. The values of $\mathrm{RMSE}$ and $\mathrm{AAE} \%$ for the nine aroma compounds are presented in Table 11, using the three sets of interaction parameters: NRTL 0 (from ternary or multicomponent data at low concentration of the aroma compound), NRTL B, and NRTL T.

The evolution of $K_{\mathrm{AC}}, \alpha_{\mathrm{AC} / \mathrm{Et}}$ and $\alpha_{\mathrm{AC} / \mathrm{W}}$ is also represented with the different sets of interaction parameters in Figures 5-7. The number of curves for each compound varies according to the binary and ternary data available, reported in Tables 7 and 8 (three curves for ethanal, propan $1 \mathrm{ol}$, and furan 2 carbalde hyde; 2 curves for ethyl ethanoate and ethanoic acid; 1 curve for methanoic acid, for which no binary or ternary data were found in the open literature). These figures show that the experimental data of $K_{\mathrm{AC}}$ and $\alpha_{\mathrm{AC} / \mathrm{W}}$ at high dilution can be represented with reasonable precision using any of the sets. The decreasing tendency obtained is correct. However, as for $\alpha_{\mathrm{AC} / \mathrm{Et}}$ 


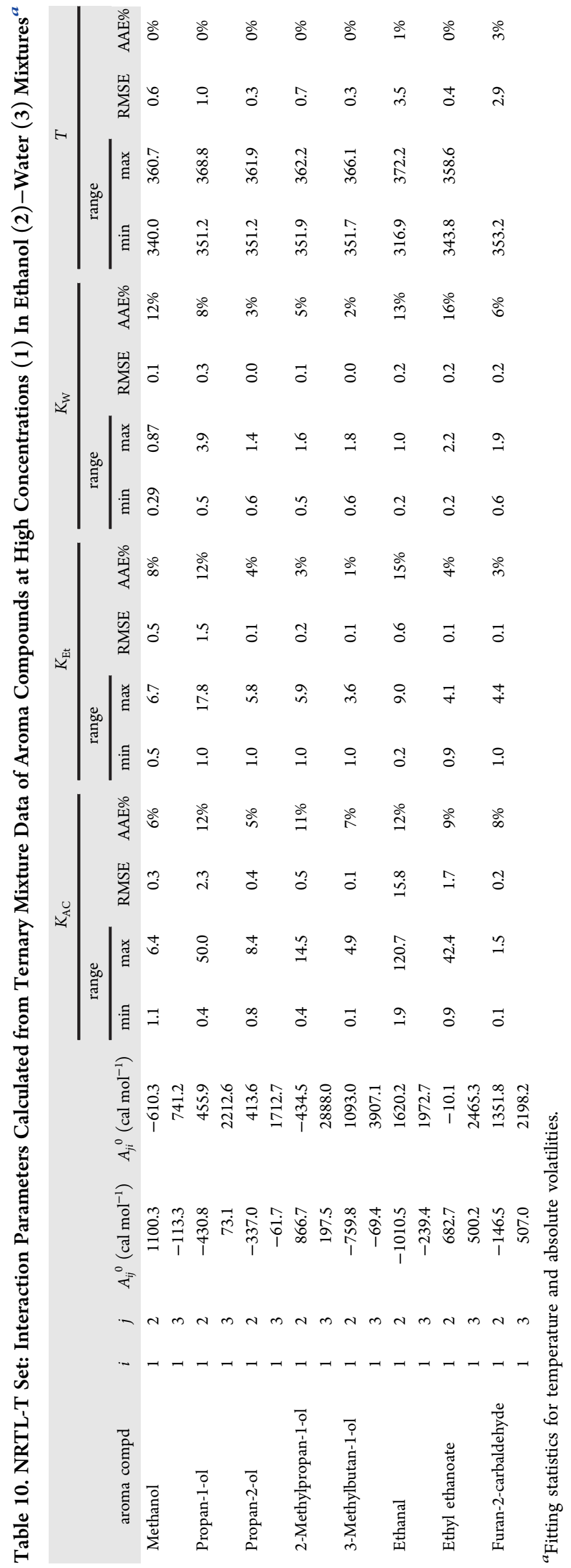


Table 11. Statistics of Fitting Quality for Absolute and Relative Volatilities of Aroma Compounds at $101.3 \mathrm{kPa}$ Using Different Three NRTL Parameters Sets: NRTL 0 (Table 5), NRTL B (Table 9), and NRTL T (Table 10)

\begin{tabular}{|c|c|c|c|c|c|c|c|}
\hline \multirow[b]{2}{*}{ aroma compound } & \multirow[b]{2}{*}{ parameters set } & \multirow{2}{*}{$\frac{K_{\text {AC }}}{\text { RMSE }}$} & \multirow[b]{2}{*}{$\mathrm{AAE} \%$} & \multirow{2}{*}{$\frac{\alpha_{\mathrm{AC} / \mathrm{Et}}}{\mathrm{RMSE}}$} & \multirow[b]{2}{*}{$\mathrm{AAE} \%$} & \multirow{2}{*}{$\frac{\alpha_{\mathrm{AC} / \mathrm{W}}}{\mathrm{RMSE}}$} & \multirow[b]{2}{*}{$\mathrm{AAE} \%$} \\
\hline & & & & & & & \\
\hline \multirow[t]{3}{*}{ Methanol } & NRTL-0 & 0.2 & $4 \%$ & 0.1 & $3 \%$ & 0.2 & $10 \%$ \\
\hline & NRTL-B & 0.4 & $6 \%$ & 0.3 & $4 \%$ & 0.2 & $12 \%$ \\
\hline & NRTL-T & 0.7 & $22 \%$ & 0.3 & $22 \%$ & 0.7 & $32 \%$ \\
\hline \multirow[t]{3}{*}{ Propan-1-ol } & NRTL-0 & 1.6 & $16 \%$ & 0.2 & $12 \%$ & 2.2 & $21 \%$ \\
\hline & NRTL-B & 1.6 & $16 \%$ & 0.2 & $13 \%$ & 2.3 & $21 \%$ \\
\hline & NRTL-T & 4.0 & $30 \%$ & 0.4 & $26 \%$ & 3.9 & $36 \%$ \\
\hline \multirow[t]{2}{*}{ Propan-2-ol } & NRTL-0 & 0.3 & $2 \%$ & 0.0 & $2 \%$ & 0.3 & $2 \%$ \\
\hline & NRTL-T & 0.7 & $7 \%$ & 0.1 & $7 \%$ & 0.8 & $7 \%$ \\
\hline \multirow[t]{2}{*}{ 2-Methylpropan-1-ol } & NRTL-0 & 0.3 & $3 \%$ & 0.0 & $3 \%$ & 0.4 & $3 \%$ \\
\hline & NRTL-T & 1.0 & $15 \%$ & 0.4 & $16 \%$ & 1.8 & $21 \%$ \\
\hline \multirow[t]{3}{*}{ 3-Methylbutan-1-ol } & NRTL-0 & 0.6 & $10 \%$ & 0.1 & $10 \%$ & 0.6 & $10 \%$ \\
\hline & NRTL-B & 3.4 & $19 \%$ & 0.3 & $19 \%$ & 3.7 & $19 \%$ \\
\hline & NRTL-T & 5.6 & $55 \%$ & 0.6 & $55 \%$ & 6.3 & $55 \%$ \\
\hline \multirow[t]{3}{*}{ Ethanal } & NRTL-0 & 6.9 & $18 \%$ & 0.8 & $12 \%$ & 8.3 & $18 \%$ \\
\hline & NRTL-B & 7.4 & $34 \%$ & 1.8 & $26 \%$ & 8.9 & $32 \%$ \\
\hline & NRTL-T & 15.7 & $35 \%$ & 2.0 & $31 \%$ & 21.4 & $37 \%$ \\
\hline \multirow[t]{2}{*}{ Ethanoic acid } & NRTL-0 & 0.0 & $1 \%$ & 0.0 & $1 \%$ & 0.0 & $1 \%$ \\
\hline & NRTL-B & 0.1 & $28 \%$ & 0.0 & $28 \%$ & 0.1 & $28 \%$ \\
\hline \multirow[t]{2}{*}{ Ethyl ethanoate } & NRTL-0 & 3.6 & $12 \%$ & 0.6 & $13 \%$ & 8.1 & $17 \%$ \\
\hline & NRTL-T & 12.4 & $19 \%$ & 0.6 & $14 \%$ & 21.1 & $26 \%$ \\
\hline \multirow[t]{3}{*}{ Furan-2-carbaldehyde } & NRTL-0 & 0.5 & $17 \%$ & 0.0 & $14 \%$ & 0.7 & $19 \%$ \\
\hline & NRTL-B & 0.5 & $55 \%$ & 0.1 & $56 \%$ & 0.8 & $55 \%$ \\
\hline & NRTL-T & 0.7 & $68 \%$ & 0.2 & $72 \%$ & 0.9 & $68 \%$ \\
\hline
\end{tabular}

the representation is only relatively good for ethyl acetate and propanol $1 \mathrm{ol}$. For ethanoic acid, the curve is systematically shifted from the experimental data, while for ethanal and furan 2 carbaldehyde, the representation with the NRTL B and NRTL $\mathrm{T}$ sets is not coherent.

The statistics indicate that the fitting quality is clearly better when using the main parameters estimated in this work (NRTL 0). Only for two aroma compounds, methanol and 1 propanol, the deviations with respect to experimental data from the NRTL B set are acceptable and comparable. When comparing the NRTL B and NRTL T sets, the deviations associated with the first one are always lower (AAE\% between $4 \%$ and $56 \%$ for NRTL B, against AAE\% between $22 \%$ and $72 \%$ for NRTL T).

Two hypothesis could be proposed to explain the reason why the extrapolation of equilibrium data at high concentration to the high dilution region is more accurate when using binary data (NRTL B) than ternary data (NRTL T). First of all, because in the latter case the composition intervals of the solvent components (ethanol and water) in the liquid phase are not strictly the same as those of the high dilution data. An analysis of the distribution of the experimental data over the whole interval of solvent-liquid composition shows that in the case of methanol, 3 methylbutan 1 ol, and furan 2 carbalde hyde, the ternary mixture data do not include experimental points at very low ethanol mole fractions $\left(x_{\mathrm{Et}}<0.1\right)$ or very high water mole fractions $\left(x_{\mathrm{W}}>0.9\right)$, region where the absolute and relative volatilities at high dilution exhibit the most pronounced variation. As a result, the extrapolation of volatility data at high concentration could be not accurate enough in this interval, in which at least one experimental point from the binary data set and at high dilution are available.

Second, the great difference among the AAE\% values could be associated with the quality of experimental data. This aspect cannot be judged precisely by lack of information, but according to Table 10, one could think that the uncertainty of the selected ternary data is more important with respect to the binary data, which could be mainly due to a greater complexity in the quantitative analysis of the coexisting phases. The uncertainty of mole compositions is amplified with the calculation of the absolute and relative volatilities (variables selected to evaluate the quality of the NRTL extrapolation) because they are both defined as composition ratios. This propagation is even more important in the case of $\alpha_{\mathrm{AC} / \mathrm{Et}}$ and $\alpha_{\mathrm{AC} / \mathrm{W}}$, whose definition contains four composition values.

In general terms, these results suggest that an accurate representation of the vapor-liquid behavior of aroma compounds in alcoholic distillation requires data at low concentration. The NRTL model could be used to extrapolate the equilibrium data at high concentration to the high dilution region but only with rough precision. If no data at high dilution are available, binary data in which the aroma compounds are present over the entire composition range could be used for the estimation of interaction parameters used for engineering purposes in the alcoholic beverages field. The reliability of this estimation must be verified with respect to experimental distillation data, by comparing the composition of the output streams (distillate and bottoms) or another equivalent variable (for instance the mass recovery from feed to distillate) predicted by simulation with the data collected during an experimental campaign. These latter data are mandatory to validate the performance of a simulation module. If the deviations are too high, the equilibrium data at high dilution will be strictly required and they should be determined either experimentally or by way of a theoretical estimation with predictive models such as UNIFAC or the quantum based COSMO models. 


\section{CONCLUSIONS}

A new set of binary interaction parameters for the NRTL model has been generated for 44 aroma compounds highly diluted in ethanol-water mixtures at $101.3 \mathrm{kPa}$. The experimental data were obtained from 10 research works published in the open literature between 1960 and 2018. They were measured through a dynamic method using two modes of recirculation: with vapor phase only and with vapor and liquid phases.

The fitting quality of the regressions is good, with respective overall RMSE and AEE\% values of 1.3 and $12 \%$ for the absolute volatility $K_{\mathrm{AO}} 0.2$ and $12 \%$ for the relative volatility with respect to ethanol, $\alpha_{\mathrm{AC} / \mathrm{Ev}}$ and 2.1 and $13 \%$ for the relative volatility with respect to water, and $\alpha_{\mathrm{AC} / \mathrm{w}}$, of the aroma compounds. Thus, the NRTL model, coupled to the ideal gas equation or to an association model by taking into account the chemical equilibrium when dealing with carboxylic acids, is recom mended for the simulation of continuous and batch distillation processes involved in the production of alcoholic beverages.

Using the proposed set of parameters, the aroma compounds can be classified in three categories according to their volatility with respect to ethanol (light key) and water (heavy key), over the whole ethanol composition range in the liquid phase $(0<$ $\left.x_{\mathrm{Et}}<1\right)$ : (I) light (10 compounds, including acetals, carbonyl compounds, and esters), (II) intermediary (32 compounds, including alcohols, carbonyl compounds, carboxylic acids, esters, furans, and terpenes), and (III) heavy (2 carboxylic acids).

Finally, the comparison with the parameters estimated from binary or ternary mixture data including an aroma compound at high concentration indicates that the equilibrium representation is roughly acceptable, as the orders of magnitude of the absolute and relative volatilities are correct, yet the values of RMSE and AAEE\% are higher than those obtained with parameter derived from data at high dilution. Accurate data at low concentration ranges are therefore necessary to correctly represent the equilibrium properties of aroma compounds and, consequently, to generate reliable simulations of distillation units. Only when this information is not available, and cannot be measured or predicted, binary data should be used for the estimation of interaction parameters for engineering applica tions.

\section{ASSOCIATED CONTENT}

Supporting Information

The Supporting Information is available free of charge on the ACS Publications website at DOI: 10.1021 /acs.iecr.7b03857.

Selection of experimental coherent data for model identification (PDF)

\section{AUTHOR INFORMATION}

\section{Corresponding Author}

*Tel.: +33 1699350 92. E mail: martine.decloux@ agroparistech.fr.

\section{ORCID}

Cristian Puentes: 0000000171261193

Martine Esteban-Decloux: 0000000280842528

\section{Notes}

The authors declare no competing financial interest.

\section{ACKNOWLEDGMENTS}

This work was supported by the ABIES Doctoral School (AgroParisTech, Université Paris Saclay; doctoral contract 20147 ) and was carried out within the framework of the RMT FIDELE (Réseau Mixte Technologique Produits Fermentés et Distillés). We thank Olivier Baudouin and Silvère Massebeuf from ProSim for their technical assistance with the Simulis Thermodynamics software.

\section{REFERENCES}

(1) Ashour, I; Aly, G. Effect of computation techniques for equation of state binary interaction parameters on the prediction of binary VLE data. Comput. Chem. Eng. 1996, 20 (1), 79-91.

(2) Cadoret, L.; Yu, C. C.; Huang, H. P.; Lee, M. J. Effects of physical properties estimation on process design: a case study using Aspen Plus. Asia Pac. J. Chem. Eng. 2009, 4, 729-734.

(3) Esteban Decloux, M.; Deterre, S.; Kadir, S.; Giampaoli, P.; Albet, J.; Joulia, X.; Baudouin, O. Two industrial examples of coupling experiments and simulations for increasing quality and yield of distilled beverages. Food Bioprod. Process. 2014, 92, 343-354.

(4) Ebeler, S. E. Analytical Chemistry: Unlocking the Secrets of Wine. Food Rev. Int. 2001, 17, 45-64.

(5) Sourisseau, J. Etude chimique de la distillation du cognac. Bulletin I'Union des Physiciens 2002, 96, 881-892.

(6) Apostolopoulou, A. A.; Flouros, A. I.; Demertzis, P. G.; Akrida Demertzi, K. Differences in concentration of principal volatile constituents in traditional Greek distillates. Food Control 2005, 16, 157-164.

(7) Valderrama, J. O.; Faúndez, C. A.; Toselli, L. A. Advances on modeling and simulation of alcoholic distillation. Part 1: Thermody namic modeling. Food Bioprod. Process. 2012, 90, 819-831.

(8) Heitz, J. E. Measurement of vapor liquid equilibria for acetaldehyde ethanol water mixtures. Am. J. Enol. Viticult. 1960, 11, 19-29.

(9) Williams, G. C. Vapor liquid equilibria of organic homologues in ethanol water solutions. Am. J. Enol. Vitic. 1962, 13, 169-180.

(10) Ortega, C.; López, R; Cacho, J.; Ferreira, V. Fast analysis of important wine volatile compounds: Development and validation of a new method based on gas chromatographic-flame ionisation detection analysis of dichloromethane microextracts. J. Chromatog. A 2001, 923, 205-214.

(11) Martí, M. P.; Mestres, M.; Sala, C.; Busto, O.; Guasch, J. Solid Phase Microextraction and gas chromatography olfactometry analysis of successively diluted samples. A new approach of the aroma extract dilution analysis applied to the characterization of wine aroma. J. Agric. Food Chem. 2003, 51, 7861-7865.

(12) Câmara, J. S.; Alves, M. A.; Marques, J. C. Multivariate analysis for the classification and differentiation of Madeira wines according to main grape varieties. Talanta 2006, 68, 1512-1521.

(13) Athès, V.; Paricaud, P.; Ellaite, M.; Souchon, I.; Fürst, W. Vapour-liquid equilibria of aroma compounds in hydroalcoholic solutions: Measurements with a recirculation method and modelling with the NRTL and COSMO SAC approaches. Fluid Phase Equilib. 2008, 265, 139-154.

(14) MacNamara, K.; Lee, M.; Robbat, A. Rapid gas chromatographic analysis of less abundant compounds in distilled spirits by direct injection with ethanol-water venting and mass spectrometric data deconvolution. J. Chromatog. A 2010, 1217, 136-142.

(15) Dahm, K D.; Visco, D. P., Jr. Fundamentals of Chemical Engineering Thermodynamics; Cencage Learning: Stamford, 2015.

(16) Coquelet, C.; Laurens, S.; Richon, D. Measurement through a gas stripping technique of Henry's law constants and infinite dilution activity coefficients of propyl mercaptan, butyl mercaptan, and dimethyl sulfide in methyldiethanolamine $(1)+$ water (2) with $\mathrm{w}_{1}=$ 0.25 and 0.35. J. Chem. Eng. Data 2008, 53, 2540-2543.

(17) Barrera Zapata, R; Villa, A.; Montes de Correa, C. Measurement of activity coefficients at infinite dilution for acetonitrile, 
water, limonene, limonene epoxide and their binary pairs. Fluid Phase Equilib. 2009, 275, 46-51.

(18) Faúndez, C. A.; Alvarez, V. H.; Valderrama, J. O. Predictive models to describe VLE in ternary mixtures water + ethanol + congener for wine distillation. Thermochim. Acta 2006, 450, 110-117. (19) Faúndez, C. A.; Valderrama, J. O. Phase equilibrium modeling in binary mixtures found in wine and must distillation. J. Food Eng. 2004, 65, 577-583.

(20) Faúndez, C. A.; Valderrama, J. O. Activity coefficient models to describe vapor liquid equilibrium in ternary hydro alcoholic solutions. Chin. J. Chem. Eng. 2009, 17, 259-267.

(21) Valderrama, J. O.; Faúndez, C. A. Modeling of vapor-liquid equilibrium in binary and ternary mixtures of interest in alcoholic distillation. Información Tecnológica 2003, 14 (1), 83-92.

(22) Wilson, G. M. Vapor liquid equilibrium. XI. A new expression for the excess free energy of mixing. J. Am. Chem. Soc. 1964, 86, 127130.

(23) Renon, H.; Prausnitz, J. M. Local compositions in thermodynamic excess functions for liquid mixtures. AIChE J. 1968, $14,135-144$.

(24) Abrams, D. S.; Prausnitz, J. M. Statistical thermodynamics of liquid mixtures: A new expression for the excess Gibbs energy of partly or completely miscible systems. AIChE J. 1975, 21, 116-128.

(25) Fredenslund, A.; Jones, R.; Prausnitz, J. Group contribution estimation of activity coefficients in nonideal liquid mixtures. AIChE J. 1975, 21 (6), 1086-1099.

(26) Holderbaum, T.; Gmehling, J. PSRK: A group contribution equation of state based on UNIFAC. Fluid Phase Equilib. 1991, 70, 251-265.

(27) Soave, G. Equilibrium constants from a modified Redlich Kwong equation of state. Chem. Eng. Sci. 1972, 27, 1197-1203.

(28) Voutsas, E. C.; Pamouktsis, C.; Argyris, D.; Pappa, G. D. Measurements and thermodynamic modeling of the ethanol-water system with emphasis to the azeotropic region. Fluid Phase Equilib. 2011, 308, 135-141.

(29) Lai, H. S.; Lin, Y. F.; Tu, C. H. Isobaric (vapor + liquid) equilibria for the ternary system of (ethanol + water $+1,3$ propanediol) and three constituent binary systems at $\mathrm{P}=101.3 \mathrm{kPa}$. J. Chem. Thermodyn. 2014, 68, 13-19.

(30) Peña Tejedor, S.; Murga, R.; Sanz, M. T.; Beltrán, S. Vaporliquid equilibria and excess volumes of the binary systems ethanol + ethyl lactate, isopropanol + isopropyl lactate and $\mathrm{n}$ butanol $+\mathrm{n}$ butyl lactate at $101.325 \mathrm{kPa}$. Fluid Phase Equilib. 2005, 230, 197-203.

(31) Vu, D. T.; Lira, C. T.; Asthana, N. S.; Kolah, A. K.; Miller, D. J. Vapor-liquid equilibria in the systems ethyl lactate + ethanol and ethyl lactate + water. J. Chem. Eng. Data 2006, 51, 1220-1225.

(32) Deterre, S.; Albet, J.; Joulia, X.; Baudouin, O.; Giampaoli, P.; Decloux, M.; Athès, V. Vapor-liquid equilibria measurements of bitter orange aroma compounds highly diluted in boiling hydro alcoholic solutions at $101.3 \mathrm{kPa}$. J. Chem. Eng. Data 2012, 57, 3344-3356.

(33) Athès, V.; Peña y Lillo, M.; Bernard, C.; Pérez Correa, R.; Souchon, I. Comparison of experimental methods for measuring infinite dilution volatilities of aroma compounds in water/ethanol mixtures. J. Agric. Food Chem. 2004, 52, 2021-2027.

(34) Ikari, A.; Kubo, R. Behaviour of simple impurities in simple distillation of aqueous solution of ethanol. J. Chem. Eng. Jpn. 1975, 8 (4), 294-299.

(35) Ikari, A.; Hatate, Y.; Sakaue, S.; Kubota, Y. Behavior of a minute amount of furfural in distillation of aqueous ethanol solution under reduced pressure. J. Chem. Eng. Jpn. 1984, 17, 486-490.

(36) Ikari, A.; Hatate, Y.; Yanagida, K.; Eta, M. Vapor liquid equilibria of a minute amount of $\mathrm{n}$ propyl, isobutyl, and isoamyl alcohols in aqueous ethanol solution under reduced pressure. Kagaku Kogaku Ronbunshu 1990, 16, 1101-1104.

(37) Ikari, A.; Hatate, Y.; Aiko, R. Vapor liquid equilibria of trace isobutyraldehyde, ethyl acetate and isoamyl acetate in aqueous ethanol solution under reduced pressure. Kagaku Kogaku Ronbunshu 1998, 24, $678-681$.
(38) Ikari, A.; Hatate, Y.; Fukumoto, T. Vapor liquid equilibria of a minute amount of methanol, isovaleraldehyde and diacetyl in aqueous ethanol solution under reduced pressure. Kagaku Kogaku Ronbunshu 1998, 24, 111-115.

(39) Martin, A.; Carrillo, F.; Trillo, L.; Rosello, A. A quick method for obtaining partition factor of congeners in spirits. Eur. Food Res. Technol. 2009, 229, 697-703.

(40) Puentes, C.; Joulia, X.; Paricaud, P.; Giampaoli, P.; Athès, V.; Esteban Decloux, M. Vapor liquid equilibrium (VLE) of ethyl lactate highly diluted in ethanol water solutions at $101.3 \mathrm{kPa}$ : experimental measurements and thermodynamic modeling with semi empirical models. J. Chem. Eng. Data 2018, 63, 365-379.

(41) Soni, M. Vapour-liquid equilibria and infinite dilution activity coefficient measurements of systems involving diketones. M.Sc. Thesis. University of Nartal: Durban, South Africa, 2003.

(42) Othmer, D. Composition of vapors from boiling binary solutions. Ind. Eng. Chem. 1943, 35 (5), 614-620.

(43) Othmer, D. Composition of vapors from boiling binary solutions. Improved Equilibrium still. Anal. Chem. 1948, 20 (8), $762-766$.

(44) Gillespie, D. T. C. Vapor liquid equilibrium still for miscible liquids. Ind. Eng. Chem., Anal. Ed. 1946, 18, 575-577.

(45) Nala, M.; Auger, E.; Gedik, I.; Ferrando, N.; Dicko, M.; Paricaud, P.; Volle, F.; Passarello, J. P.; De Hemptinne, J. C.; Tobaly, P.; Stringari, P.; Coquelet, C.; Ramjugernath, D.; Naidoo, P.; Lugo, R. Vapour-liquid equilibrium (VLE) for the systems furan $+n$ hexane and furan + toluene. Measurements, data treatment and modeling using molecular models. Fluid Phase Equilib. 2013, 337, 234-245.

(46) Dias, T. P. V. B.; Fonseca, L. A. A. P.; Ruiz, M. C.; Batista, F. R. M.; Batista, E. A. C.; Meirelles, A. J. A. Vapor-liquid equilibrium of mixtures containing the following higher alcohols: 2 propanol, 2 methyl 1 propanol, and 3 methyl 1 butanol. J. Chem. Eng. Data 2014, 59, 659-665.

(47) Christensen, S. P. Measurement of dilute mixture vapor-liquid equilibrium data for aqueous solutions of methanol and ethanol with a recirculating still. Fluid Phase Equilib. 1998, 150-151, 763-773.

(48) Rall, J. D.; Mühlbauer, A. L. Phase Equilibria: Measurement and Computation; Taylor \& Francis: WA, 1998.

(49) NIST Chemistry WebBook, SRD 69; NIST, U.S. Department of Commerce, 2017; http://webbook.nist.gov/chemistry/.

(50) Prausnitz, J. M.; Lichtenthaler, R. N.; De Azevedo, E. G. Molecular Thermodynamics of Fluid Phase Equilibria; Prentice Hall PTR: Englewood Cliffs, NJ, 1999.

(51) Rios, K. Lecture Notes on Chemical Thermodynamics; National University of Colombia: Bogota, 2009.

(52) Detcheberry, M.; Destrac, P.; Massebeuf, S.; Baudouin, O.; Gerbaud, V.; Condoret, J. S.; Meyer, X. M. Thermodynamic modeling of the condensable fraction of a gaseous effluent from lignocellulosic biomass torrefaction. Fluid Phase Equilib. 2016, 409, 242-255.

(53) Allen, G.; Caldin, E. F. The association of carboxylic acids. Q. Rev., Chem. Soc. 1953, 7, 255-278.

(54) Vawdrey, A. C.; Oscarson, J. L.; Rowley, R. L.; Wilding, W. V. Vapor phase association of $n$ aliphatic carboxylic acids. Fluid Phase Equilib. 2004, 222-223, 239-245.

(55) Miyamoto, S.; Nakamura, S.; Iwai, Y.; Arai, Y. Measurement of isothermal vapor liquid equilibria for binary and ternary systems containing monocarboxylic acid. J. Chem. Eng. Data 2001, 46, 12251230.

(56) Zhu, D.; Gao, D.; Zhang, H.; Winter, B.; Lücking, P.; Sun, H.; Guan, H.; Chen, H.; Shi, J. Geometric structures of associating component optimized toward correlation and prediction of isobaric vapor-liquid equilibria for binary and ternary mixtures of ethanal, ethanol, and ethanoic acid. J. Chem. Eng. Data 2013, 58, 7-17.

(57) Gmehling, J.; Onken, U.; Arlt, W.; Grenzheuser, P.; Weidlich, U.; Kolbe, B.; Rarey, J. Vapor-liquid Equilibrium Data Collection. Part 5: Carboxylic Acids, Anhydrides, Esters; Chemistry Data Series, Vol. 1;Dechema: Frankfurt, 2001; Vol. 1.

(58) Vidal, J. Thermodynamics. Applications in Chemical Engineering and Petroleum Industry; Editions Technip: Paris, 2003. 
(59) Vetere, A. The Riedel equation. Ind. Eng. Chem. Res. 1991, 30, 2487-2492.

(60) Rowley, R.; Wilding, W.; Oscarson, J.; Yang, Y.; Zundel, N.; Daubert, T.; Danner, R. DIPPR Data Compilation of Pure Chemical Properties; Design Institute for Physical Properties, AIChE: New York, 2003.

(61) Dreisbach, R. R.; Shrader, S. A. Vapor pressure temperature data on some organic compounds. Ind. Eng. Chem. 1949, 41 (12), 28792880.

(62) Verevkin, S. P.; Heintz, A. Determination of vaporization enthalpies of the branched esters from correlation gas chromatography and transpiration methods. J. Chem. Eng. Data 1999, 44, 1240-1244.

(63) Covarrubias Cervantes, M.; Mokbel, I.; Champion, D.; Jose, J.; Voilley, A. Saturated vapour pressure of aroma compounds at various temperatures. Food Chem. 2004, 85, 221-229.

(64) Zaitsau, D. H.; Paulechka, Y. U.; Blokhin, A. V.; Yermalayeu, A. V.; Kabo, A. G.; Ivanets, M. R. Thermodynamics of ethyl decanoate. J. Chem. Eng. Data 2009, 54, 3026-3033.

(65) Benziane, M.; Khimeche, K.; Mokbel, 1.; Sawaya, T.; Dahmani, A.; Jose, J. Experimental vapor pressures of five saturated fatty acid ethyl ester (FAEE) components of Biodiesel. J. Chem. Eng. Data 2011, 56, 4736-4740.

(66) Kozlovskiy, M.; Gobble, C.; Chickos, J. Vapor pressures and vaporization enthalpies of a series of esters used in flavors by correlation gas chromatography. J. Chem. Thermodyn. 2015, 86, 6574.

(67) Stejfa, V.; Fulem, M.; Ruzicka, K.; Matejka, P. Vapor pressures and thermophysical properties of selected hexenols and recommended vapor pressure for hexan $1 \mathrm{ol}$. Fluid Phase Equilib. 2015, 402, 18-29.

(68) GESTIS Substance Database; German Social Accident Insurance: Sankt Augusin, Germany, 2017; www.dguv.de/ifa/gestis database.

(69) Alessi, P.; Fermeglia, M.; Kikic, I. Signficance of dilute regions. Fluid Phase Equilib. 1991, 70, 239-250.

(70) Kadir, S. Optimisation du procédé de production d'Alcool surfin. Ph.D. Thesis. AgroParisTech: Paris, 2009.

(71) Arce, A.; Martinez Ageitos, J.; Soto, A. VLE for water+ethanol +1 octanol mixtures. Experimental measurements and correlations. Fluid Phase Equilib. 1996, 122, 117-129.

(72) Yang, B.; Wang, H. Vapor liquid equilibrium for mixtures of water, alcohols, and ethers. J. Chem. Eng. Data 2002, 47, 1324-1329.

(73) Kamihama, N.; Matsuda, H.; Kurihara, K.; Tochigi, K.; Oba, S. Isobaric Vapor-liquid equilibria for ethanol + water + ethylene glycol and its constituent three binary systems. J. Chem. Eng. Data 2012, 57, 339-344.

(74) Integrated Analytic Solver; Frontline Systems, Inc.: Incline Village NV, 2018; http://www.solver.com.

(75) Tan, T. C.; Chai, C. M.; Tok, A. T.; Ho, K. W. Prediction and experimental verification of the salt effect on the vapour-liquid equilibrium of water-ethanol-2 propanol mixture. Fluid Phase Equilib. 2004, 218, 113-121.

(76) Tan, T. C.; Tan, R.; Soon, L. H.; Ong, S. H. P. Prediction and experimental verification of the effect of salt on the vapour-liquid equilibrium of ethanol/1 propanol/water mixture. Fluid Phase Equilib. 2005, 234, 84-93.

(77) Amer, H. H.; Paxton, R. R.; Van Winkle, M. MethanolEthanol-Acetone. Ind. Eng. Chem. 1956, 48 (1), 142-146. Cited in Ohe, S. Vapor-liquid Equilibrium Data; Kodansha: Tokyo, 1989.

(78) Delzenne, A. Vapor Liquid equilibrium data for ternary system methanol ethanol water. Chem. Eng. Data Ser. 1958, 3 (2), 224-230. Cited in Gmehling, J.; Onken, U. Vapor Liquid Equilibrium Data Collection. Organic Hydroxy compounds: Alcohols; Dechema: Frankfurt, 1977.

(79) Slobodyanik, I. P.; Babushkina, E. M. Zh. Prikl. Khim. 1966, 39, 1555. Cited in Gmehling, J.; Onken, U. Vapor-Liquid Equilibrium Data Collection. Organic Hydroxy compounds: Alcohols; Dechema: Frankfurt, 1977.

(80) Dunlop, J. G. M.Sc. Thesis. Brooklyn Polytechnic Institute: New York, 1948. Cited in Gmehling, J.; Onken, U. Vapor-Liquid
Equilibrium Data Collection. Aqueous-Organic Systems; Dechema: Frankfurt, 1977.

(81) Ocon, J.; Rebolleda, F. Vapor-liquid equilibrium. VI. Binary system methanol-water. An. Real. Soc. Espan. Fis. Quim. 1958, 54B (7-8), 525. Cited in Gmehling, J.; Onken, U. Vapor-Liquid Equilibrium Data Collection. Aqueous-Organic Systems; Dechema: Frankfurt, 1977.

(82) Kohoutova, J.; Suska, J.; Novak, J. P.; Pick, J. Liquid Vapor Equilibrium XLV. System methanol 2 propanol water. Collect. Czech. Chem. Commun. 1970, 35, 3210-3222. Cited in Gmehling, J.; Onken, U. Vapor-Liquid Equilibrium Data Collection. Aqueous-Organic Systems; Dechema: Frankfurt, 1977.

(83) Gay, L. Deuxième mémoire (Second Submission). Chim. Ind. Genie Chim. 1927, 18, 187. Cited in Ohe, S. Vapor Liquid Equilibrium Data; Kodansha: Tokyo, 1989.

(84) Ochi, K.; Kojima, K. Kagaku Kogaku 1969, 33, 352-357. Cited in Gmehling, J.; Onken, U. Vapor-Liquid Equilibrium Data Collection. Organic Hydroxy compounds: Alcohols; Dechema: Frankfurt, 1977.

(85) Chu, J. C.; Getty, R. J.; Brennecke, L. F.; Paul, R. Distillation Equilibrium Data; Reinhold Publishing Corporation: New York, 1950.

(86) Smirnova, N. A. Vestn. Leningr. Univ. Fiz. Khim. 1959, 81. Cited in Gmehling, J.; Onken, U. Vapor-Liquid Equilibrium Data Collection. Aqueous-Organic Systems; Dechema: Frankfurt, 1977.

(87) Dobroserdov, L. L.; Ilina, V. P. Zh. Prikl. Khim. 1961, 34, 386. Cited in Gmehling, J.; Onken, U. Vapor-Liquid Equilibrium Data Collection. Aqueous-Organic Systems; Dechema: Frankfurt, 1977.

(88) Andiappan, A. N.; McLean, A. Y. Prediction of isobaric vaporliquid equilibrium data for mixtures of water and simple alcohols. Adv. Chem. Ser. 1974, 115, 93. Cited in ThermoData (TDE) Version 3.0; NIST Standard Reference Database, 2008.

(89) Suska, J. Collect. Czech. Chem. Commun. 1979, 44, 1852. Cited in Ohe, S. Vapor-liquid Equilibrium Data; Kodansha: Tokyo, 1989.

(90) Perry, J. H. Chemical Engineers Handbook; McGraw Hill Book Co: New York, 1950.

(91) Rius, A.; Otero, J. L.; Macarron, A. Chem. Eng. Sci. 1959, 10, 105. Cited in Gmehling, J.; Onken, U. Vapor-Liquid Equilibrium Data Collection. Organic Hydroxy compounds: Alcohols; Dechema: Frankfurt, 1977.

(92) Brown, I.; Ewald, A. H. Liquid vapour equilibria. I. The systems carbon tetrachloride cyclohexane and water acetic acid. Austral. J. Sci. Res. A 1950, 3, 306. Cited in Gmehling, J.; Onken, U. Vapor-Liquid Equilibrium Data Collection. Aqueous-Organic Systems; Dechema: Frankfurt, 1977.

(93) Conti, J. J.; Othmer, D. F.; Gilmont, R. Composition of vapors from boiling binary solutions. Systems Containing formic acid, acetic acid, water, and chloroform. J. Chem. Eng. Data 1960, 5 (3), 301-307. Cited in Gmehling, J.; Onken, U. Vapor-Liquid Equilibrium Data Collection. Aqueous-Organic Systems; Dechema: Frankfurt, 1977.

(94) Sebastiani, E.; Lacquaniti, L. Acetic acid-water system thermodynamic correlation of vapor-liquid equilibrium data. Chem. Eng. Sci. 1967, 22 (9), 1155-1162. Cited in Gmehling, J.; Onken, U. Vapor-Liquid Equilibrium Data Collection. Aqueous-Organic Systems; Dechema: Frankfurt, 1977.

(95) Kharin, S.E.; Perelygin, V. M.; Polyansky, K. K. Gidroliz. Lesokhim. Prom. 1970, 23, 15. Cited in Gmehling, J.; Onken, U. Vapor-Liquid Equilibrium Data Collection. Organic Hydroxy com pounds: Alcohols; Dechema: Frankfurt, 1977.

(96) Mains, G. H. Chem. Met. Eng. 1922, 26, 779. Cited in Gmehling, J.; Onken, U. Vapor-Liquid Equilibrium Data Collection. Aqueous Organic Systems; Dechema: Frankfurt, 1977.

(97) Griswold, J.; Dinwiddie, J. A. Vapor liquid equilibrium of methanol ethanol water. Mechanism of Ethanol Dehydration. Ind. Eng. Chem. 1942, 34 (10), 1188-1191.

(98) Hughes, H. E.; Maloney, J. O. Binary and Ternary Equilibrium Data. Chem. Eng. Prog. 1952, 48, 192-200. Cited in Gmehling, J.; Onken, U. Vapor-Liquid Equilibrium Data Collection. Aqueous Organic Systems; Dechema: Frankfurt, 1977.

(99) Kharin, S. E.; Perelygin, V. M.; Remizov, G. P. J. Appl. Chem. 1970, 43, 2036. Cited in Gmehling, J.; Onken, U. Vapor-Liquid 
Equilibrium Data Collection. Aqueous-Organic Systems; Dechema: Frankfurt, 1977.

(100) Kojima, K.; Ochi, K.; Nakazawa, Y. Relationship between liquid activity coefficient and composition for ternary systems. Int. Chem. Eng. 1969, 9, 342. Cited in Gmehling, J.; Onken, U. Vapor-Liquid Equilibrium Data Collection. Aqueous-Organic Systems; Dechema: Frankfurt, 1977.

(101) Kharin, S. E.; Perelygin, V. M.; Smirnov, V. S. Khim. Prom. 1971, 47, 510. Cited in Gmehling, J.; Onken, U. Vapor-Liquid Equilibrium Data Collection. Aqueous Organic Systems; Dechema: Frankfurt, 1977.

(102) Suska, J.; Holub, R.; Vonka, P.; Pick, J. Collect. Czech. Chem. Commun. 1970, 35, 385. Cited in Gmehling, J.; Onken, U. VaporLiquid Equilibrium Data Collection. Aqueous-Organic Systems; Dechema: Frankfurt, 1977.

(103) Kharin, S. E.; Perelygin, V. M.; Remizov, G. P. J. Appl. Chem. 1971, 44, 127. Cited in Gmehling, J.; Onken, U. Vapor-Liquid Equilibrium Data Collection. Aqueous-Organic Systems; Dechema: Frankfurt, 1977.

(104) Kharin, S. E.; Perelygin, V. M.; Pisarevsky, V. G. Zh. Prikl. Khim. 1972, 45, 466. Cited in Gmehling, J.; Onken, U. Vapor-Liquid Equilibrium Data Collection. Aqueous-Organic Systems; Dechema: Frankfurt, 1977.

(105) Griswold, J.; Chu, P. L.; Winsauer, W. O. Phase equilibria in ethyl alcohol-ethyl acetate-water system. Ind. Eng. Chem. 1949, 41 (10), 2352-2358.

(106) Van Zandijcke, F.; Verhoeye, L. J. Appl. Chem. Biotechnol. 1974, 24, 709. Cited in Gmehling, J.; Onken, U. Vapor-Liquid Equilibrium Data Collection. Aqueous Organic Systems; Dechema: Frankfurt, 1977.

(107) Kharin, S. E.; Perelygin, V. M.; Polyansky, K. K. Gidroliz. Lesokhim. Prom. 1971, 24, 10. Cited in Gmehling, J.; Onken, U. Vapor-Liquid Equilibrium Data Collection. Aqueous-Organic Systems; Dechema: Frankfurt, 1977. 


\section{SUPPORTING INFORMATION}

\section{Review and thermodynamic modeling with NRTL model of vapor-liquid equilibria (VLE) of aroma compounds highly diluted in ethanol-water mixtures at $101.3 \mathrm{kPa}$}

Cristian Puentesa, Xavier Jouliab, Violaine Athèsc, Martine Esteban-Decloux ${ }^{a *}$

\footnotetext{
a Unité Mixte de Recherche Ingénierie Procédés Aliments, AgroParisTech, INRA, Université ParisSaclay, F-91300 Massy, France.

b Laboratoire de Génie Chimique, Université de Toulouse INPT-ENSIACET, CNRS, F-31030 Toulouse, France.

d Unité Mixte de Recherche Génie et Microbiologie des Procédés Alimentaires, AgroParisTech, INRA, Université Paris-Saclay, F-78850 Thiverval-Grignon, France.

\section{Corresponding author}

* Tel: + 331699350 92. E-mail: martine.decloux@agroparistech.fr.
} 


\section{Selection of experimental coherent data for model identification}

One of the critical points for identifying the NRTL interaction parameters was the selection of coherent experimental data. Two criteria were successively applied to accept or reject an experimental value:

- Observation of the overall trend: the evolution of absolute $\left(K_{A C}\right)$ and relative volatility $\left(\alpha_{A C / E t}\right)$ is expected to be monotonous with respect to ethanol mole fraction in the liquid phase $\left(x_{E t}\right)$. Experimental points that do not follow this trend were rejected.

- Point-to-point comparison: this criterion was applied when two experimental points from different sources were available at a given $x_{E t}$ (with a maximal difference of \pm 0.001 ). The pair of data pass this test if the relative deviation (AE\%) between the volatility values $\left(K_{A C}\right.$ and $\left.\alpha_{A C / E t}\right)$ is lower than a tolerance, here defined as $20 \%$. Otherwise, one of the points is rejected by considering again the general trend with respect to $x_{E t}$

The relative deviation (AE\%) between two experimental points $U_{i}$ and $U j$ is defined as follows:

$$
\mathrm{AE} \%=\left|\frac{U_{i}-U^{j}}{\min \left(U_{i} U^{j}\right)}\right| 100 \%
$$

The tolerance value corresponds to the order of magnitude of the overall relative deviation (AAE\%) from NRTL correlation, reported for multicompound systems aroma compoundethanol-water by Athès et al.,13 Faúndez et al., ${ }^{18}$ and Faúndez and Valderrama. ${ }^{20}$

The results of the point-to-point comparison are summarized in Table S1 for the 10 aroma compounds with several data sources. A synthesis of the experimental points rejected for this group of aroma compounds is presented in Table S2. The experimental values of $K_{A C}$ and $\alpha_{A C / E t}$ as a function of $x_{E t}$, together with the rejected points (not considered in model identification) are depicted by chemical family in Figures $\mathbf{S 1}$ to $\mathbf{S 2}$.

Given the relatively limited number of sources, this methodology was not intended to validate or reject a whole data set, but to choose all the coherent experimental points according to the criteria proposed. In this context, correlation results based on the selected data can be considered as reliable for engineering calculations. Nevertheless, it is important to point out that the uncertainty of equilibrium data used in this work is not negligible, due to the complexity and limited accuracy on the quantification of volatile aroma compounds at high dilution. For simulation purposes in spirits distillation, the interaction parameters here identified must be validated by comparing the simulation results against experimental data, ideally from different distillation units. The aim is not to reproduce perfectly the experimental values but to represent the separation patterns, tendencies and sensitivities, in order to elucidate the influence of design and operating parameters on distillate composition and then on the quality of products 
Table S1. Point-to-point comparison of experimental volatility data from different sources for aroma compounds highly diluted in ethanol-water mixtures.

\begin{tabular}{|c|c|c|c|c|c|c|c|c|c|c|}
\hline \multirow{2}{*}{$\begin{array}{l}\text { Chemical } \\
\text { family }\end{array}$} & \multicolumn{3}{|c|}{ Aroma compound } & \multirow{2}{*}{$x_{E t}$} & \multicolumn{2}{|c|}{$K_{A C}$} & \multicolumn{2}{|c|}{$\alpha_{A C / E t}$} & \multirow{2}{*}{ Validation } & \multirow{2}{*}{ Rejection } \\
\hline & Common name & IUPAC name & No. CAS & & Average & $\% A E$ & Average & $\% A E$ & & \\
\hline \multirow{24}{*}{ Alcohols } & \multirow{12}{*}{ 1-Propanol } & \multirow{12}{*}{ Propan-1-ol } & \multirow{12}{*}{$71-23-8$} & $0.000 \pm 0.000$ & 29.73 & $57.34 \%$ & 2.45 & $57.34 \%$ & & $x$ \\
\hline & & & & $0.100 \pm 0.000$ & 4.38 & $18.51 \%$ & 0.99 & $18.51 \%$ & $x$ & \\
\hline & & & & $0.200 \pm 0.000$ & 3.62 & $5.65 \%$ & 0.88 & $5.65 \%$ & $x$ & \\
\hline & & & & $0.300 \pm 0.000$ & 1.47 & $1.20 \%$ & 0.76 & $1.20 \%$ & $x$ & \\
\hline & & & & $0.400 \pm 0.000$ & 1.08 & $0.39 \%$ & 0.70 & $0.39 \%$ & $x$ & \\
\hline & & & & $0.500 \pm 0.000$ & 0.86 & $1.97 \%$ & 0.65 & $1.97 \%$ & $x$ & \\
\hline & & & & $0.600 \pm 0.000$ & 0.71 & $3.37 \%$ & 0.61 & $3.37 \%$ & $x$ & \\
\hline & & & & $0.700 \pm 0.000$ & 0.63 & $3.42 \%$ & 0.58 & $3.42 \%$ & $x$ & \\
\hline & & & & $0.800 \pm 0.000$ & 0.57 & $1.64 \%$ & 0.56 & $1.64 \%$ & $x$ & \\
\hline & & & & $0.875 \pm 0.001$ & 0.55 & $1.64 \%$ & 0.55 & $2.05 \%$ & $x$ & \\
\hline & & & & $0.900 \pm 0.000$ & 0.54 & $0.77 \%$ & 0.54 & $0.77 \%$ & $x$ & \\
\hline & & & & $1.000 \pm 0.000$ & 0.52 & $0.58 \%$ & 0.52 & $0.58 \%$ & $x$ & \\
\hline & \multirow{12}{*}{ Isobutanol } & \multirow{12}{*}{ 2-Methylpropan-1-ol } & \multirow{12}{*}{$78-83-1$} & $0.000 \pm 0.000$ & 54.28 & $60.14 \%$ & 4.48 & $60.14 \%$ & & $x$ \\
\hline & & & & $0.100 \pm 0.000$ & 6.22 & $28.81 \%$ & 1.41 & $28.81 \%$ & & $x$ \\
\hline & & & & $0.200 \pm 0.000$ & 2.65 & $8.89 \%$ & 0.99 & $8.89 \%$ & $x$ & \\
\hline & & & & $0.300 \pm 0.000$ & 1.50 & $2.33 \%$ & 0.78 & $2.33 \%$ & $x$ & \\
\hline & & & & $0.400 \pm 0.000$ & 1.00 & $5.98 \%$ & 0.65 & $5.98 \%$ & $x$ & \\
\hline & & & & $0.474 \pm 0.001$ & 0.63 & $47.40 \%$ & 0.47 & $44.64 \%$ & & $x$ \\
\hline & & & & $0.500 \pm 0.000$ & 0.74 & $7.71 \%$ & 0.57 & $7.71 \%$ & $x$ & \\
\hline & & & & $0.600 \pm 0.000$ & 0.59 & $10.21 \%$ & 0.50 & $10.21 \%$ & $x$ & \\
\hline & & & & $0.700 \pm 0.000$ & 0.49 & $13.12 \%$ & 0.46 & $13.12 \%$ & $x$ & \\
\hline & & & & $0.800 \pm 0.000$ & 0.44 & $14.73 \%$ & 0.43 & $14.73 \%$ & $x$ & \\
\hline & & & & $0.900 \pm 0.000$ & 0.41 & $14.73 \%$ & 0.41 & $14.73 \%$ & $x$ & \\
\hline & & & & $1.000 \pm 0.000$ & 0.39 & $17.67 \%$ & 0.39 & $17.67 \%$ & $x$ & \\
\hline
\end{tabular}


Table S1. Continuation. Point-to-point comparison of experimental volatility data from different sources for aroma compounds highly diluted in ethanol-water mixtures.

\begin{tabular}{|c|c|c|c|c|c|c|c|c|c|c|}
\hline \multirow{2}{*}{$\begin{array}{l}\text { Chemical } \\
\text { family }\end{array}$} & \multicolumn{3}{|c|}{ Aroma compound } & \multirow{2}{*}{$x_{E t}$} & \multicolumn{2}{|c|}{$K_{A C}$} & \multicolumn{2}{|c|}{$\alpha_{A C / E t}$} & \multirow{2}{*}{ Validation } & \multirow{2}{*}{ Rejection } \\
\hline & Common name & IUPAC name & No. CAS & & Average & $\% A E$ & Average & $\% A E$ & & \\
\hline \multirow{14}{*}{ Alcohols } & \multirow{14}{*}{ Isopentanol } & \multirow{14}{*}{ 3-Methylbutan-1-ol } & \multirow{14}{*}{$123-51-3$} & $0.000 \pm 0.000$ & 48.704 & $43.99 \%$ & 4.016 & $43.99 \%$ & & $x$ \\
\hline & & & & $0.021 \pm 0.000$ & 24.325 & $17.63 \%$ & 2.241 & $19.99 \%$ & $x$ & \\
\hline & & & & $0.075 \pm 0.000$ & 7.066 & $38.90 \%$ & 1.345 & $38.91 \%$ & & $x$ \\
\hline & & & & $0.100 \pm 0.000$ & 5.056 & $34.78 \%$ & 1.148 & $34.78 \%$ & & $x$ \\
\hline & & & & $0.195 \pm 0.001$ & 1.707 & $0.88 \%$ & 0.615 & $1.47 \%$ & $x$ & \\
\hline & & & & $0.200 \pm 0.000$ & 1.731 & $9.41 \%$ & 0.648 & $9.41 \%$ & $x$ & \\
\hline & & & & $0.300 \pm 0.000$ & 0.845 & $4.97 \%$ & 0.437 & $4.97 \%$ & $x$ & \\
\hline & & & & $0.400 \pm 0.000$ & 0.518 & $8.22 \%$ & 0.335 & $8.22 \%$ & $x$ & \\
\hline & & & & $0.500 \pm 0.000$ & 0.366 & $9.04 \%$ & 0.279 & $9.04 \%$ & $x$ & \\
\hline & & & & $0.600 \pm 0.000$ & 0.284 & $12.16 \%$ & 0.243 & $12.16 \%$ & $x$ & \\
\hline & & & & $0.700 \pm 0.000$ & 0.236 & $17.60 \%$ & 0.218 & $17.60 \%$ & $x$ & \\
\hline & & & & $0.800 \pm 0.000$ & 0.208 & $17.64 \%$ & 0.202 & $17.64 \%$ & $x$ & \\
\hline & & & & $0.900 \pm 0.000$ & 0.194 & $19.46 \%$ & 0.193 & $19.46 \%$ & $x$ & \\
\hline & & & & $1.000 \pm 0.000$ & 0.186 & $20.04 \%$ & 0.186 & $20.04 \%$ & $\times$ & \\
\hline Furans & Furfural & Furan-2-carbaldehyde & $98-01-1$ & $0.401 \pm 0.001$ & 0.32 & $13.29 \%$ & 0.45 & $0.22 \%$ & $x$ & \\
\hline Terpenes & Linalool & 3,7-dimethylocta-1,6-dien-3-ol & $78-70-6$ & $0.062 \pm 0.000$ & 18.12 & $30.82 \%$ & 2.82 & $21.17 \%$ & & \\
\hline
\end{tabular}


Table S2. Synthesis of rejected experimental points, before model identification, for aroma compounds highly diluted in ethanol-water mixtures with several data sources available.

\begin{tabular}{|c|c|c|c|c|c|c|c|c|c|c|c|}
\hline \multirow[b]{2}{*}{$\begin{array}{l}\text { Chemical } \\
\text { family }\end{array}$} & \multicolumn{3}{|c|}{ Aroma compound } & \multirow[b]{2}{*}{ Reference } & \multirow[b]{2}{*}{$\begin{array}{l}\text { Number of } \\
\text { accepted data }\end{array}$} & \multirow[b]{2}{*}{$\begin{array}{l}\text { Number of } \\
\text { rejected } \\
\text { data }\end{array}$} & \multicolumn{3}{|c|}{ Rejected data } & \multicolumn{2}{|c|}{ Criterion } \\
\hline & Common name & IUPAC name & No. CAS & & & & $\boldsymbol{X}_{E t}$ & $K_{A C}$ & $\alpha_{A C / E t}$ & Overall trend & $\begin{array}{c}\text { Point-to- } \\
\text { point } \\
\text { comparison }\end{array}$ \\
\hline \multirow{16}{*}{ Alcohols } & \multirow{4}{*}{ 1-Propanol } & \multirow{4}{*}{ Propan-1-ol } & \multirow{4}{*}{$71-23-8$} & \multirow{2}{*}{ Williams, $1962^{9}$} & \multirow{2}{*}{9} & \multirow{2}{*}{2} & 0.000 & 10.03 & 1.48 & $x$ & \\
\hline & & & & & & & 0.000 & 10.04 & 1.48 & $x$ & \\
\hline & & & & Ikari et al., $1990^{36}$ & 11 & 0 & - & - & - & & \\
\hline & & & & Martin et al., $2009^{39}$ & - & - & \multicolumn{3}{|c|}{$x_{E t}<0.03$} & $\times$ & $\times$ \\
\hline & \multirow{5}{*}{ Isobutanol } & \multirow{5}{*}{ 2-Methylpropan-1-ol } & \multirow{5}{*}{$78-83-1$} & \multirow{2}{*}{ Williams, $1962^{9}$} & \multirow{2}{*}{10} & \multirow{2}{*}{2} & 0.000 & 17.11 & 2.53 & $x$ & \\
\hline & & & & & & & 0.000 & 16.65 & 2.47 & $x$ & \\
\hline & & & & Ikari et al., $1990^{36}$ & 10 & 1 & 0.100 & 7.26 & 1.65 & & $x$ \\
\hline & & & & Athès et al., $2008^{13}$ & 8 & 1 & 0.474 & 0.43 & 0.34 & & $x$ \\
\hline & & & & Martin et al., $2009^{39}$ & - & - & \multicolumn{3}{|c|}{$x_{E t}<0.03$} & $\times$ & $\times$ \\
\hline & \multirow{7}{*}{ Isopentanol } & \multirow{7}{*}{ 3-Methylbutan-1-ol } & \multirow{7}{*}{$123-51-3$} & \multirow{4}{*}{ Williams, $1962^{9}$} & \multirow{4}{*}{11} & \multirow{4}{*}{4} & 0.001 & 18.50 & 2.85 & $x$ & \\
\hline & & & & & & & 0.001 & 16.37 & 2.42 & $x$ & \\
\hline & & & & & & & 0.001 & 18.93 & 2.44 & $x$ & \\
\hline & & & & & & & 0.075 & 8.77 & 1.67 & & $x$ \\
\hline & & & & Ikari et al., $1990^{36}$ & 10 & 1 & 0.100 & 6.12 & 1.39 & & $x$ \\
\hline & & & & Athès et al., $2008^{13}$ & 8 & 1 & 0.062 & 15.11 & 2.23 & $x$ & \\
\hline & & & & Martin et al., $2009^{39}$ & - & - & & $X_{E t}<0.03$ & & $x$ & $\times$ \\
\hline \multirow{7}{*}{$\begin{array}{l}\text { Carbonyl } \\
\text { compounds }\end{array}$} & \multirow{7}{*}{ Acetaldehyde } & \multirow{7}{*}{ Ethanal } & & & & & 0.020 & 52.67 & 5.88 & $x$ & \\
\hline & & & & & & & 0.079 & 43.77 & 8.75 & $x$ & \\
\hline & & & & Heitz 19608 & 22 & 6 & 0.080 & 52.35 & 10.81 & $x$ & \\
\hline & & & $75-07-0$ & Heltz, $1900^{\circ}$ & 22 & 0 & 0.159 & 62.33 & 55.08 & $x$ & \\
\hline & & & & & & & 0.162 & 120.67 & 109.14 & $x$ & \\
\hline & & & & & & & 0.259 & 6.26 & 5.87 & $x$ & \\
\hline & & & & Williams, $1962^{9}$ & 14 & 0 & - & - & - & & \\
\hline
\end{tabular}


Table S2. Continuation. Synthesis of rejected experimental points, before model identification, for aroma compounds highly diluted in ethanol-water mixtures with

\begin{tabular}{|c|c|c|c|c|c|c|c|c|c|c|c|}
\hline \multirow{2}{*}{$\begin{array}{l}\text { Chemical } \\
\text { family }\end{array}$} & \multicolumn{3}{|c|}{ Aroma compound } & \multirow[b]{2}{*}{ Reference } & \multirow{2}{*}{$\begin{array}{l}\text { Number of } \\
\text { accepted data }\end{array}$} & \multirow{2}{*}{$\begin{array}{l}\text { Number of } \\
\text { rejected } \\
\text { data }\end{array}$} & \multicolumn{3}{|c|}{ Rejected data } & \multicolumn{2}{|c|}{ Criterion } \\
\hline & Common name & IUPAC name & No. CAS & & & & $\boldsymbol{X}_{E t}$ & $K_{A C}$ & $\alpha_{A C / E t}$ & Overall trend & $\begin{array}{l}\text { Point-to-point } \\
\text { comparison }\end{array}$ \\
\hline \multirow{11}{*}{$\begin{array}{l}\text { Carbonyl } \\
\text { compounds }\end{array}$} & \multirow{11}{*}{ Isobutyraldehyde } & \multirow{11}{*}{ 2-Methylpropanal } & \multirow{11}{*}{$78-84-2$} & \multirow{7}{*}{ Williams, $1962^{9}$} & \multirow{7}{*}{11} & \multirow{7}{*}{7} & 0.006 & 45.44 & 4.78 & $x$ & \\
\hline & & & & & & & 0.006 & 45.15 & 5.45 & $x$ & \\
\hline & & & & & & & 0.016 & 83.93 & 6.74 & $x$ & \\
\hline & & & & & & & 0.017 & 60.23 & 6.29 & $x$ & \\
\hline & & & & & & & 0.021 & 64.02 & 6.33 & $x$ & \\
\hline & & & & & & & 0.035 & 63.45 & 6.56 & $x$ & \\
\hline & & & & & & & 0.043 & 47.72 & 6.57 & $x$ & \\
\hline & & & & Ikari et al., 1998a ${ }^{37}$ & 14 & 0 & - & - & - & & \\
\hline & & & & & & & 0.021 & 76.94 & 5.75 & $x$ & \\
\hline & & & & Athès et al., $2008^{13}$ & 6 & 3 & 0.144 & 19.41 & 5.21 & $x$ & \\
\hline & & & & & & & 0.474 & 3.20 & 2.48 & $x$ & \\
\hline \multirow{8}{*}{ Esters } & \multirow{2}{*}{ Ethyl acetate } & \multirow{2}{*}{ Ethyl ethanoate } & \multirow{2}{*}{$141-78-6$} & Ikari et al., $1998 a^{37}$ & 14 & 0 & - & - & - & & \\
\hline & & & & Athès et al., $2008^{13}$ & 8 & 1 & 0.062 & 83.90 & 12.37 & $\times$ & \\
\hline & \multirow{2}{*}{ Isopentyl acetate } & \multirow{2}{*}{ 3-Methylbutyl ethanoate } & \multirow{2}{*}{$123-92-2$} & Ikari et al., $1998 a^{37}$ & 14 & 0 & - & - & - & & \\
\hline & & & & Athès et al., $2008^{13}$ & 8 & 1 & 0.062 & 130.45 & 19.23 & $x$ & \\
\hline & \multirow{4}{*}{ Ethyl caproate } & \multirow{4}{*}{ Ethyl hexanoate } & \multirow{4}{*}{$123-66-0$} & & & & 0.021 & 379.05 & 28.31 & $x$ & \\
\hline & & & & Athès et al., $2008^{13}$ & 6 & 3 & 0.062 & 14.59 & 2.15 & $x$ & \\
\hline & & & & & & & 0.474 & 37.90 & 29.34 & $x$ & \\
\hline & & & & Martin et al., $2009^{39}$ & - & - & - & - & - & & \\
\hline \multirow{3}{*}{ Furans } & \multirow{3}{*}{ Furfural } & \multirow{3}{*}{ Furan-2-carbaldehyde } & \multirow{3}{*}{$98-01-1$} & Williams, $1962^{9}$ & 9 & 0 & - & - & - & & \\
\hline & & & & Ikari et al., $1984^{35}$ & 13 & 0 & - & - & - & & \\
\hline & & & & Athès et al., $2008^{13}$ & 9 & 0 & - & - & - & & \\
\hline & & & & Athès et al., $2008^{13}$ & 8 & 1 & 0.062 & 21.42 & 3.16 & & $x$ \\
\hline & & & & & & & 0.012 & 111.47 & 15.01 & $x$ & \\
\hline Ternenes & Linalool & 3.7-dimethylocta-16-dien-3-ol & $78-70-6$ & & & & 0.096 & 2.40 & 0.47 & $x$ & \\
\hline & & & & $2012^{32}$ & 19 & 5 & 0.207 & 0.23 & 0.09 & $x$ & \\
\hline & & & & & & & 0.208 & 0.03 & 0.01 & $x$ & \\
\hline & & & & & & & 0.294 & 0.67 & 0.36 & $x$ & \\
\hline
\end{tabular}




\section{Alcohols}
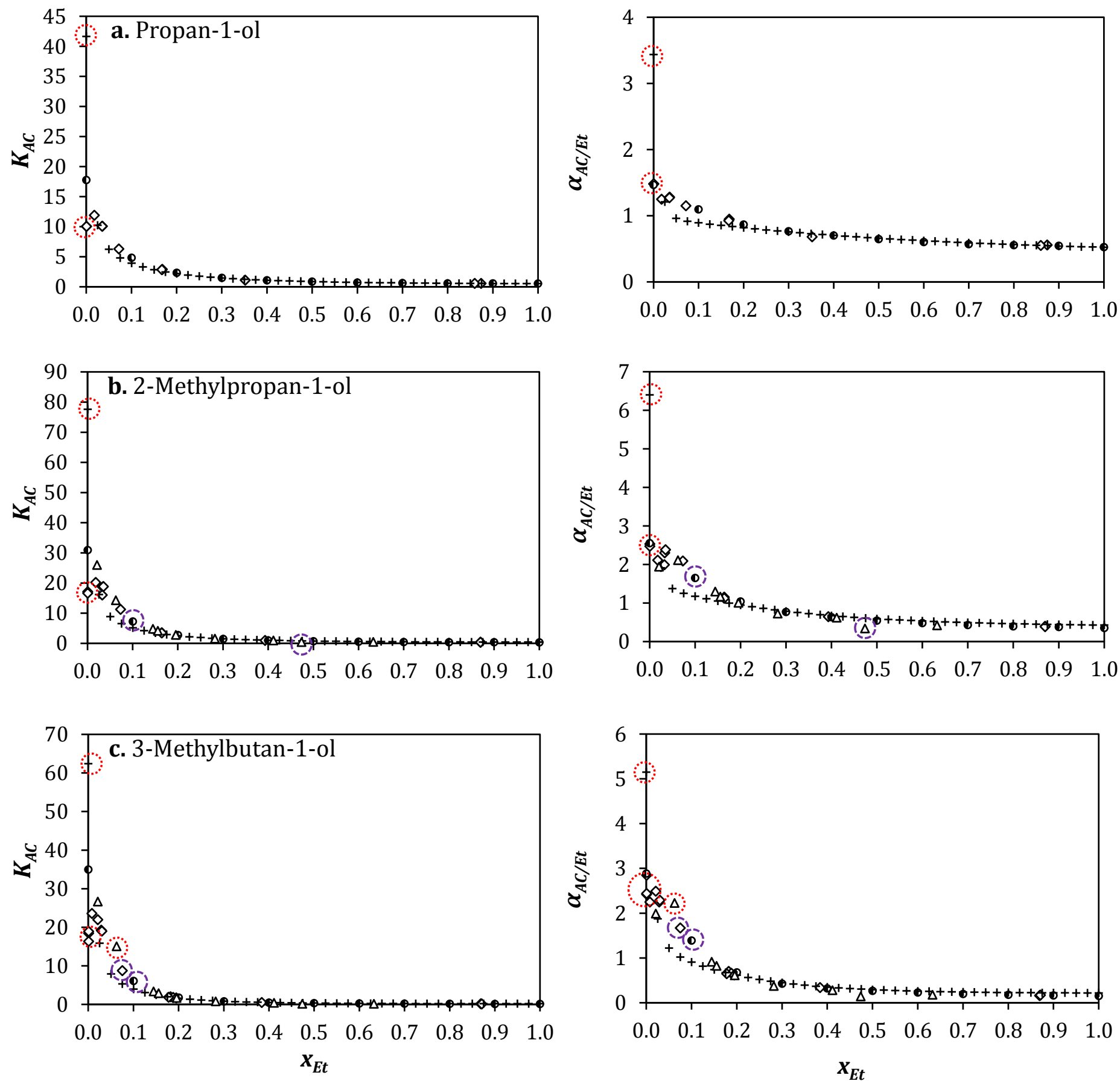

Figure S1. Evolution of the absolute $\left(K_{A C}\right)$ and relative $\left(\alpha_{A C / E t}\right)$ volatilities with ethanol composition in the liquid phase $\left(x_{E t}\right)$ at $101.3 \mathrm{kPa}$ for alcohols: a. Propan-1-ol, b. 2-Methylpropan-1-ol, c. 3-Methylbutan-1-ol.

Experimental data at high dilution from: $(\boldsymbol{\nabla}) \cdot{ }^{9}(\mathbf{D}) \cdot{ }^{36}(\boldsymbol{\Delta}) \cdot{ }^{13}(\boldsymbol{+}) \cdot{ }^{39}$ The data rejected from the observation of the overall trend are pointed out in, and those rejected by the point-to-point comparison are highlighted in 0 . 


\section{Carbonyl compounds}
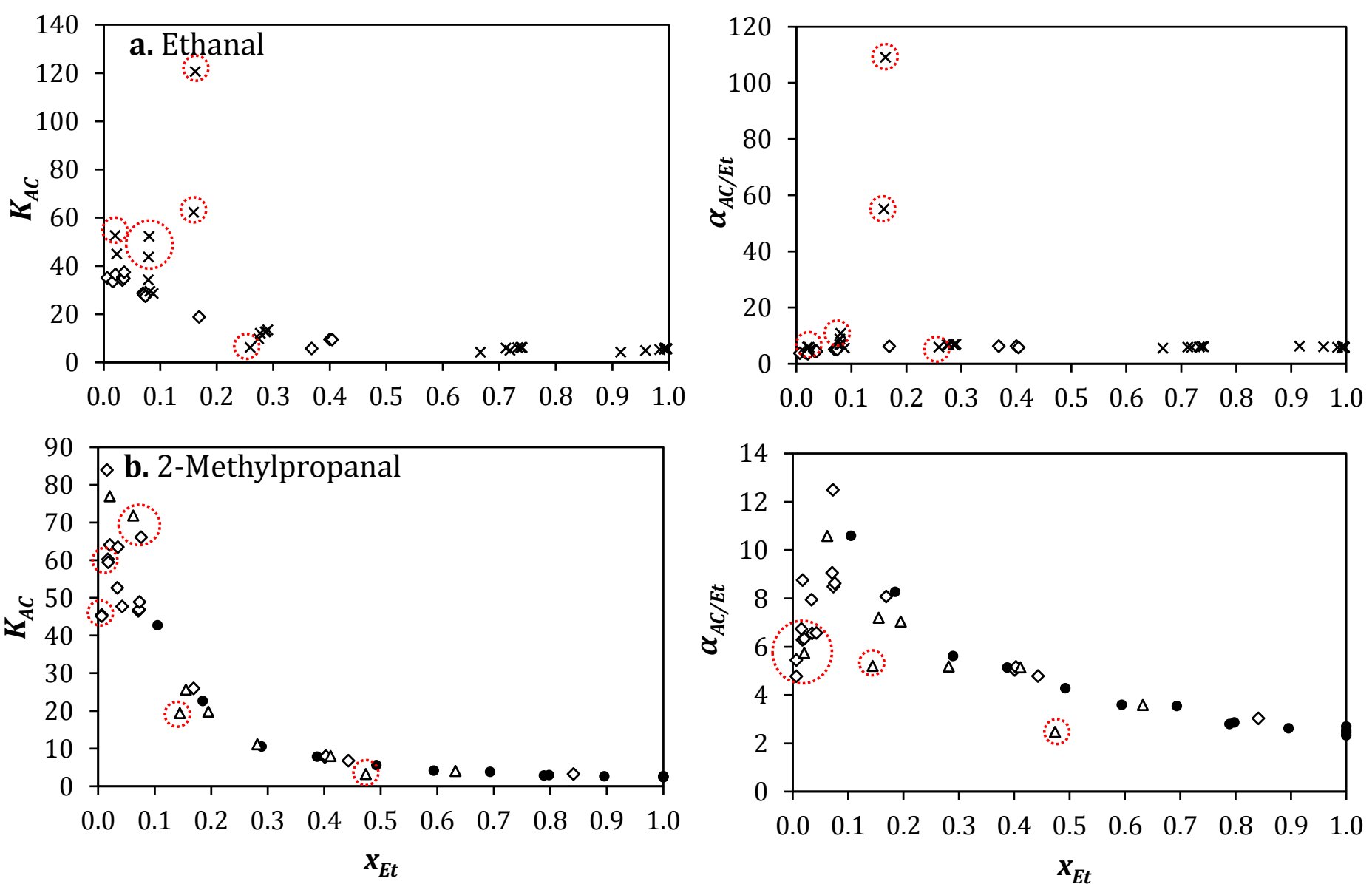

Figure S2. Evolution of the absolute $\left(K_{A C}\right)$ and relative $\left(\alpha_{A C / E t}\right)$ volatilities with ethanol composition in the liquid phase $\left(X_{E t}\right)$ at $101.3 \mathrm{kPa}$ for carbonyl compounds: a. Ethanal, b. 2-Methylpropanal.

Experimental data at high dilution from: $(\mathbf{X}) \cdot{ }^{8}(\boldsymbol{\Delta}) \cdot{ }^{9}(\boldsymbol{\Delta}) \cdot{ }^{13}(\boldsymbol{O}) \cdot{ }^{37}$ The data rejected from the observation of the overall trend are pointed out in 


\section{Esters}
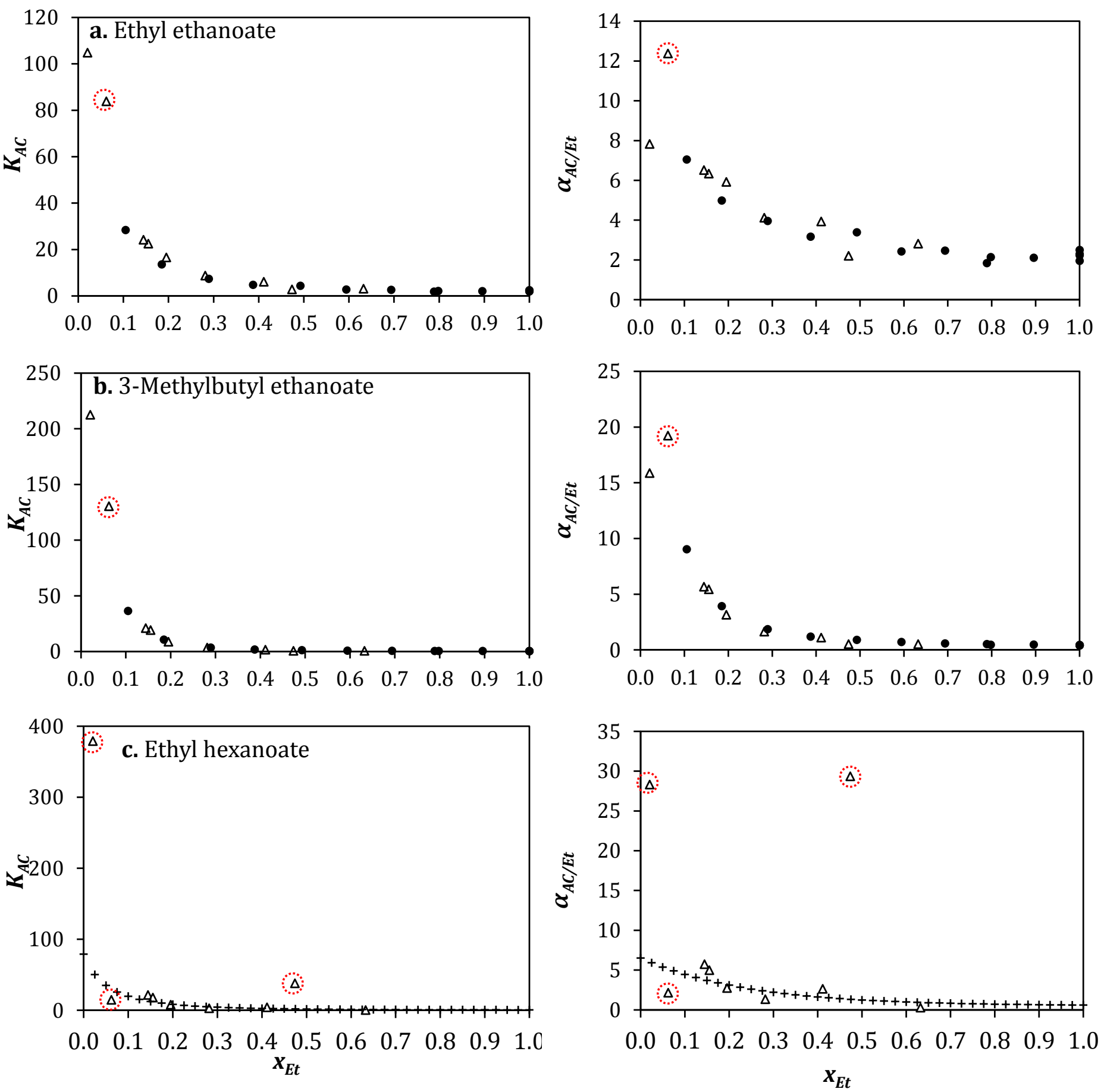

Figure S3. Evolution of the absolute $\left(K_{A C}\right)$ and relative $\left(\alpha_{A C / E t}\right)$ volatilities with ethanol composition in the liquid phase $\left(X_{E t}\right)$ at $101.3 \mathrm{kPa}$ for esters: a. Ethyl ethanoate, b. 3-methylbutyl ethanoate, c. Ethyl hexanoate.

Experimental data at high dilution from: $(\boldsymbol{\Delta}) \cdot{ }^{13}(\mathbf{O}) \cdot{ }^{37}(\boldsymbol{+}) \cdot{ }^{39}$ The data rejected from the observation of the overall trend are pointed out in 


\section{Furans}
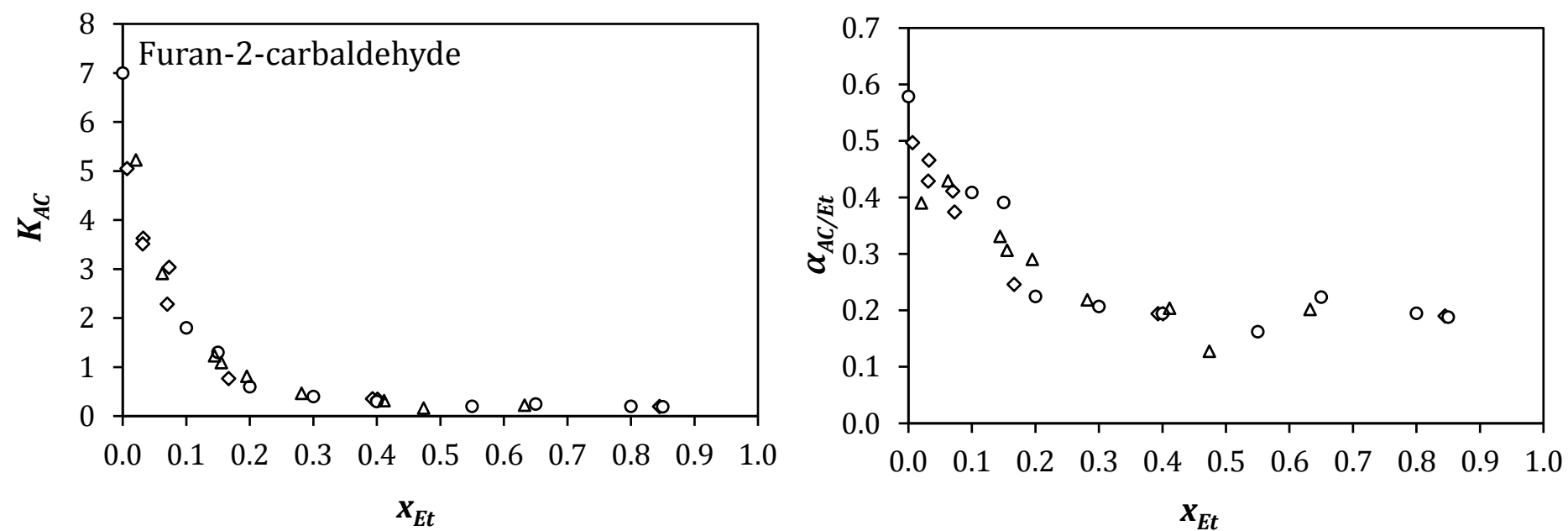

Figure S4. Evolution of the absolute $\left(K_{A C}\right)$ and relative $\left(\alpha_{A C / E t}\right)$ volatilities with ethanol composition in the liquid phase $\left(x_{E t}\right)$ at $101.3 \mathrm{kPa}$ for furan-2-carbaldehyde.

Experimental data at high dilution from: $\left(\diamond \cdot{ }^{9}(\boldsymbol{\Delta}) \cdot{ }^{13}(\mathbf{O}) \cdot{ }^{35}\right.$ All data were accepted for model identification.

Terpenes
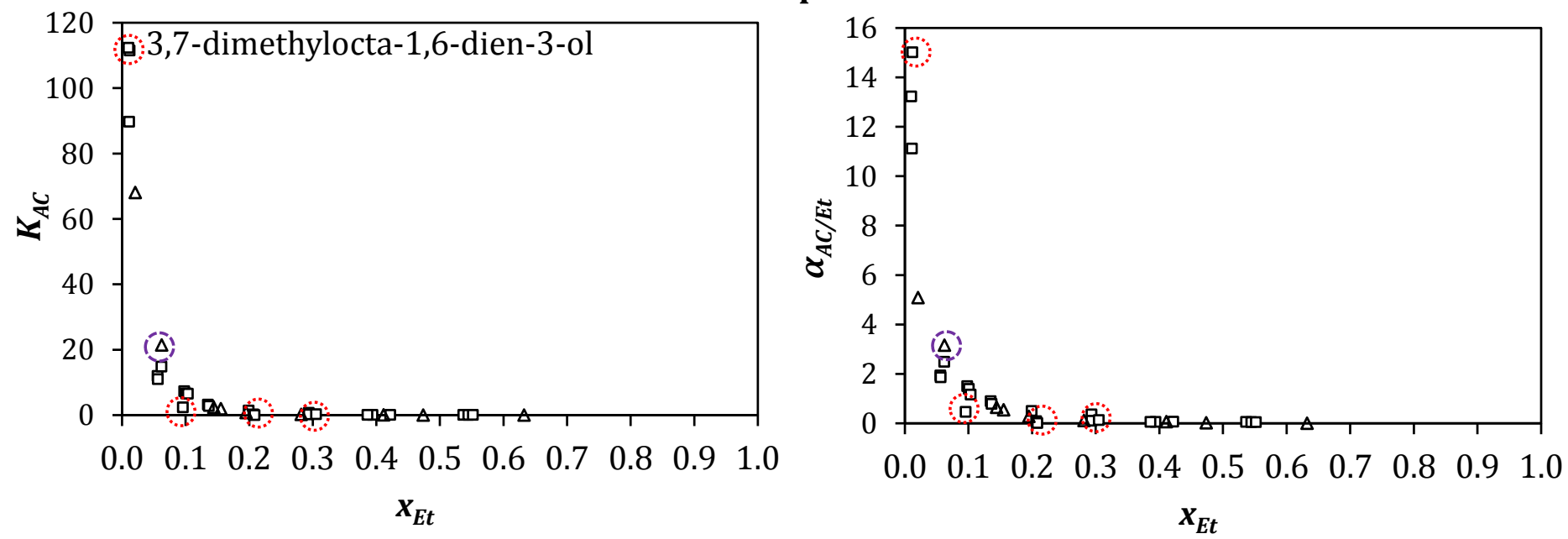

Figure S5. Evolution of the absolute $\left(K_{A C}\right)$ and relative $\left(\alpha_{A C / E t}\right)$ volatilities with ethanol composition in the liquid phase $\left(x_{E t}\right)$ at $101.3 \mathrm{kPa}$ for terpene 3,7-dimethylocta-1,6-dien-3-ol.

Experimental data at high dilution from: $(\boldsymbol{\Delta}) \cdot{ }^{13}(\boldsymbol{\square}) .{ }^{32}$ The data rejected from the observation of the overall trend are pointed out in $\mathrm{e}$, and those rejected by the point-to-point comparison are highlighted in 0 . 